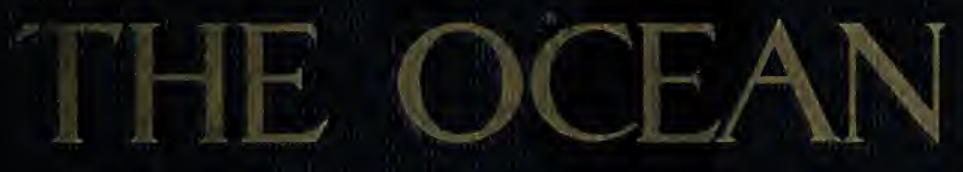
And its Mysteries
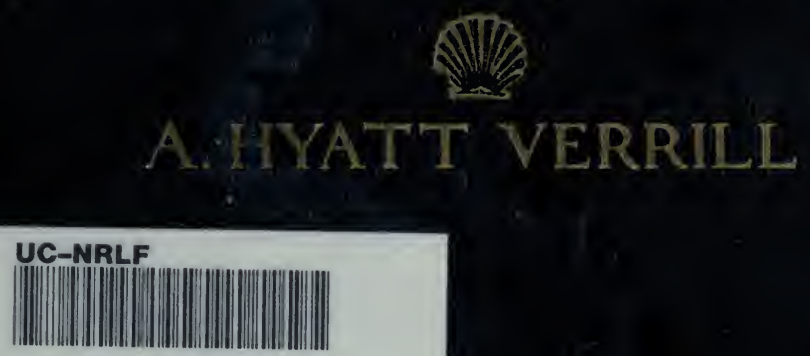


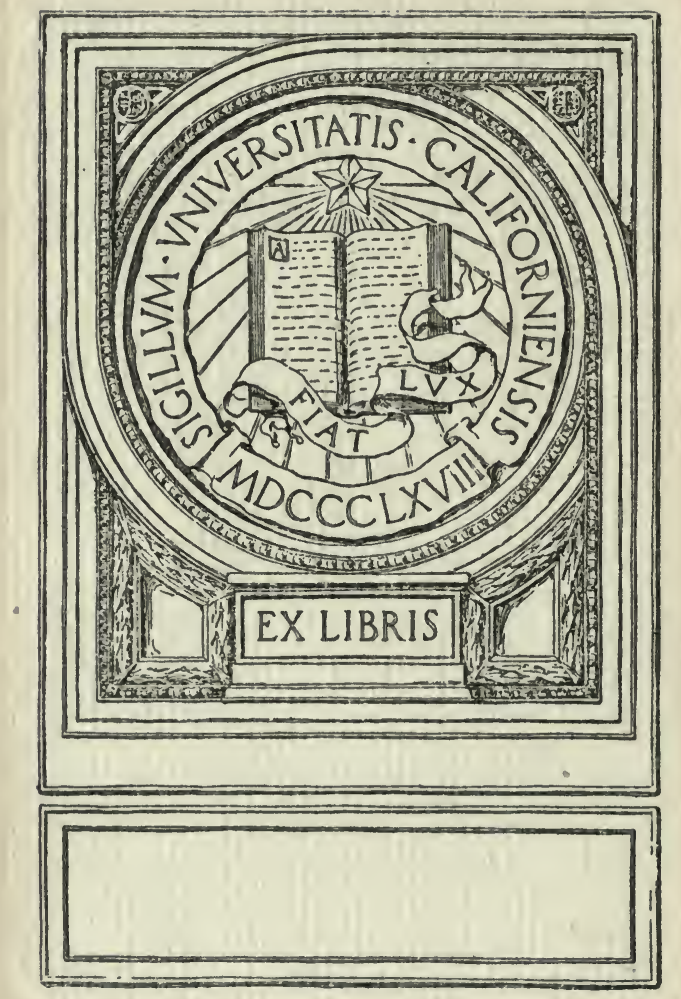



Digitized by the Internet Archive in 2008 with funding from Microsoft Corporation 
THE OCEAN AND ITS MYSTERIES 

H

3., 


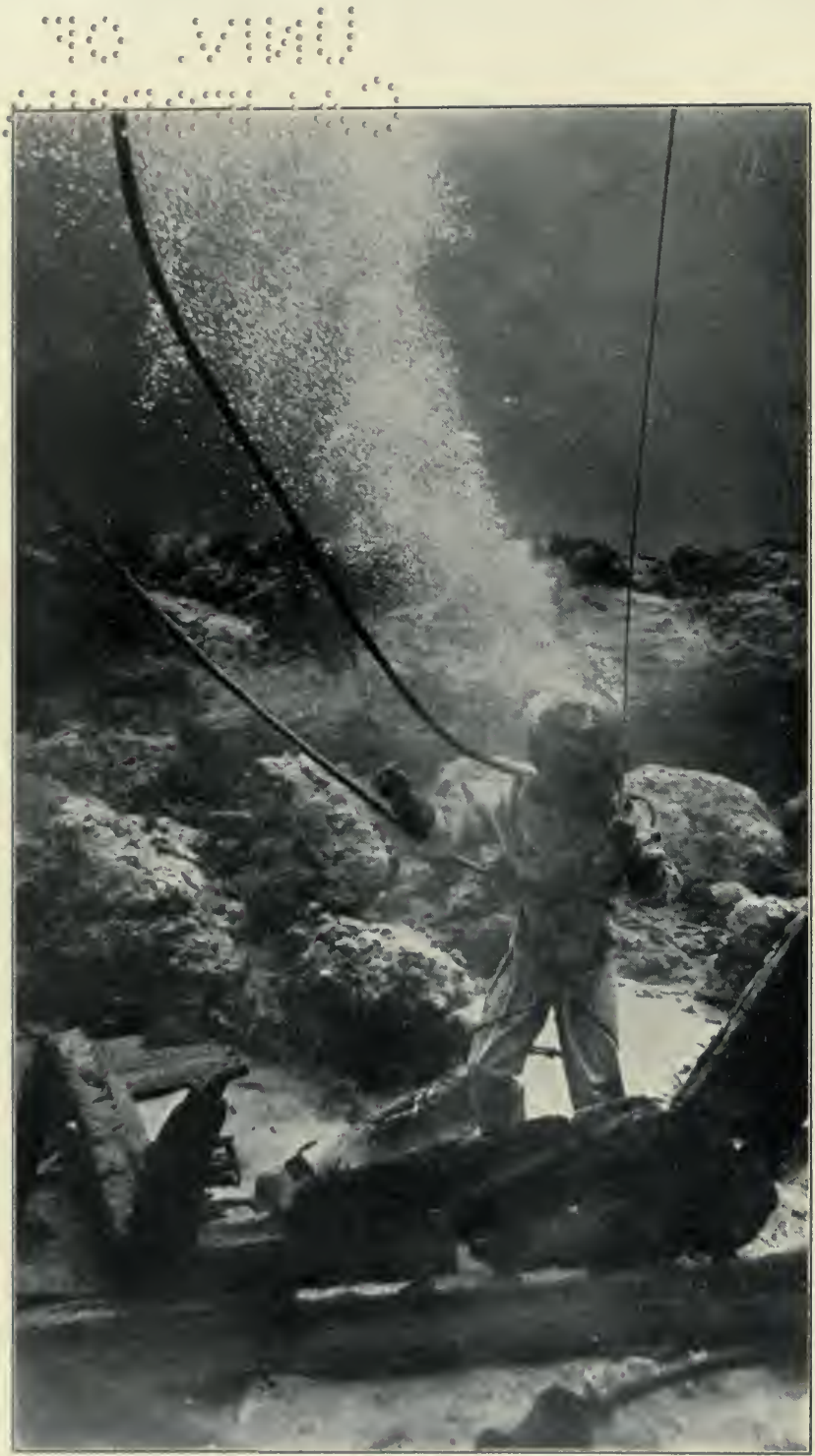

(Courtesy Universal Motion Pictures)

THE DEPTHS OF THE SEA

A diver exploring an old wreck 


\title{
The Ocean
}

\section{and Its Mysteries}

\author{
BY \\ A. HYATT VERRILL
}

\author{
ILLUSTRATED
}
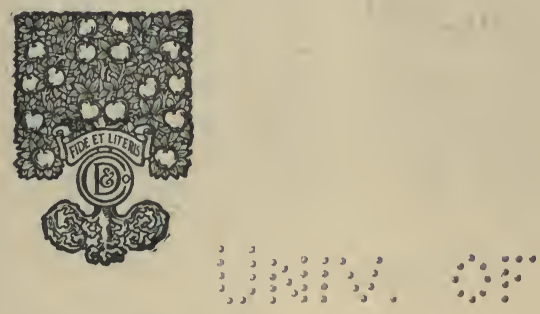

0.

NEW YORK

DUFFIELD \& CO.

I 9 I 7 


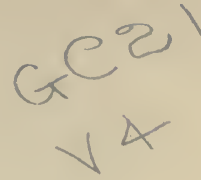

Copyright, rgr6,

By Duffield \& Co.

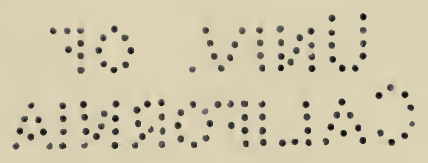




\section{CONTENTS}

CHAPTER

INTRODUCTION . • • • • $\quad$ PAGE

I. The Depths of The Sea . . . . I

II. Currents and Streams • • • 16

+ III. Derelicts ANd Icebergs . • • . 36

IV. Tides AND Waves . • . . 60

V. Safeguards of The Sea .. . . . 80

VI. Life in the Great Depths • • - 99

VII. Life at and Near the Surface • • I2I

VIII. The Story the Sea has Told • 148

IX. The Battle Between Sea and Land - 165

X. Human Life Under the Sea • • I76 



\section{ILLUSTRATIONS}

The Depths of the Sea . . . Frontispiece

Relief Map of the Sea and Land . . 4 The Gulf Stream . . . . . . 20

A Derelict. . . . . . . . . 36

A Chart Showing the Wonderful Drift of the Derelict Schooner Fannie E. Wolston . . . .. . . . . . . . 46

A Waterspout at Sea . . . . . 74 The Death . . . . . . . 90 Weird Fish from the Ocean Depths . . 106 Forms of Surface Life . . . . . . I24 Serpuline Atolls at Bermuda . . . . 140 Pages from the Sea's Story . . . ${ }_{15} 8$ The Beginning of a Coral Island Showing Corals Growing on a Reef Exposed at Low Water. . . . . . . I72 



\section{INTRODUCTION}

THE ocean, that vast, restless expanse of water which covers three-fourths of our earth's surface, has ever been an interesting theme; a thing of wonder, romance and mystery.

Even to-day, when science has solved many of the mysteries of the sea and when great iron steamships have made the ocean-lanes almost as well travelled and as definite as city boulevards, we still experience a sort of awe, a tingling of suppressed excitement and a feeling that we are approaching the mysterious and unknown when we set forth on an ocean voyage.

To the younger generation the sea appeals particularly and few indeed are the healthyminded boys who do not love tales of pirates or buccaneers or yarns of wrecks, castaways and other stories of the sea.

Fascinating as are the romances and mysteries of the sea, scarcely less interesting are the actual facts about the ocean, for, when it ix 
relates to the sea, the "truth is stranger than fiction."

It is to tell the real truths about the sea in a simple, concise and entertaining way that this book has been written. Although many volumes have been published in regard to the explorations, discoveries and investigations of the ocean and its life and countless reports have been issued filled with wonderful and interesting facts relating to the sea, its bed and its wonders, yet most of these books are so technical in character, so dry and so filled with statistics, figures and scientific terms that they prove far from entertaining.

In the present work I have endeavoured to bring out all the most noteworthy and important facts about the ocean and its life, its depths and surface, its currents and tides, its bottom and its waves without burying them beneath a mass of formidable terms and figures. In addition much has been included in regard to wrecks, derelicts and icebergs and other menaces of "those who go down to the sea in ships," as well as to the various safeguards of the sea which protect the mariner from the in- 
numerable dangers besetting him on every side.

With all our knowledge of the sea and its life, with all the progress and advancement we have made through modern science and investigation, many unsolved mysteries remain and no one realises this more than the scientist himself. It is not necessary to look to fiction for entertaining stories of the sea, for the annals of the shipping and the navies of the world, the records of scientific expeditions and the government reports are filled with unimpeachable, truthful accounts of incidents and happenings which are as mysterious as any the wildest imagination could conjure up.

For many years I spent my summers at various stations of the United States Fish Commission or on the ships which were engaged in deep sea exploration and research work in the North Atlantic. There, in the impressionable days of my youth, I was surrounded by the greatest scientists engaged in the study of marine life and ocean exploration. Such men as Baird, Goode, Bean, Verrill, Smith, Jordan, Morse, Hyatt, Rathbun, directed the work and carried on their investigations and 


\section{xii}

INTRODUCTION

researches in the laboratories and there, boylike, I made my childish collections. At a laboratory table I assorted and labelled my specimens, used my microscope and absorbed a vast deal of useful information while aided and encouraged by the scientists who have been foremost in giving the world our knowledge of the ocean's depth and its wonderful life.

Many hours were thus employed in the shore laboratories and many days were spent at sea upon the Bluelight, Speedwell, Fishhawk and Albatross as they cruised back and forth in the Gulf Stream or the Arctic Current, sounding, dredging and trawling far from land.

At each haul of the dredge or trawl new and remarkable forms of life were drawn up from the ocean's depths, for in those days little was known of deep-sea life and staid, dignified scientists became as excited and enthusiastic as schoolboys when some strange creature, new to science, was dumped upon the deck after being lifted for hundreds of fathoms from the wonderland at the bottom of the sea. 
Like every youngster I always wanted to know how and why "the wheels went round" and my insatiable appetite for information was freely and fully satisfied by the goodnatured officers and crew, who took the greatest pleasure-and no doubt obtained plenty of amusement as well-in explaining the meaning of charts, signals and buoys, the operation of the compass and sextant, the mechanism of engines and machinery and in pointing out the importance of waves, winds, tides and currents.

Oftentimes, when the dredging and trawling was over and the ship headed for port with her load of natural history prizes, the crew would foregather on the "fo'c's'le" and the grizzled old men-o'-warsmen would vie with one another in entertaining the "Professor's Kid" with deep-sea yarns.

One memorable summer was passed at a lighthouse-service station and there $I$ found never-ending sources of entertainment and amusement in company with a boy companion whose father commanded the lighthouse tender Anemone. To watch the great buoys be- 
xiv INTRODUCTION

ing prepared and placed, to visit the lightships and lighthouses on the tender and to become intimately familiar with the thousandand-one details of safeguarding lives and ships was fascinating in the extreme.

But all this paled into insignificance when the stern-faced commander stretched himself in a steamer-chair beneath his ship's awnings and with the two boys seated at his side, told true stories of adventure on the seven seas. No book of fiction, no Clark Russell sea-tale, was ever half so thrilling as those stories of shipwreck, of naval battles, of Malay pirates and of hair-breadth escapes in which the narrator had actually taken part. Little did his hearers dream that in later years a figure in America's next war would be this story teller -Admiral Schley.

Knowing the interest which the sea and its life held for me when a boy, I believe that it will still prove interesting to the boys of today, and I have endeavoured to write a book such as I would have appreciated in my own youth. I have tried to explain the matters which once puzzled me, to tell the most in- 


\section{INTRODUCTION}

teresting facts in a simple way, to touch on the mysteries and unknown things of the sea and in short to produce a volume which will give my readers a true and correct knowledge of the ocean and its life, from its restless surface and wave-washed shores to its vast depths and submerged mountain-chains. 



\section{THE OCEAN AND ITS MYSTERIES}

\section{CHAPTER I \\ THE DEPTHS OF THE SEA}

DID you ever think what a strange sight would be presented if the ocean should be drained away and we could gaze upon its dry bed? It would indeed be a wonderful scene and yet probably not one person in thousands would find the appearance of the vast ocean-bed in the least as he had pictured it in his imagination.

It is impossible to imagine anything totally different from anything we have ever seen, heard or known. We cannot imagine an absolutely new form, a new colour or a new sound, for even in our wildest flights of fancy or our weirdest dreams everything bears some resemblance to some well-known or familiar object. But if we were able to look forth 
upon the great area now occupied by the waters of the ocean and could wander over the vast bed of the sea we would surely see many things which would be totally different from anything we had ever seen, or imagined.

In the depths of the sea lie the greatest of the ocean's mysteries, and while for many years vast sums of money and an immense amount of time have been expended in exploring the ocean depths, yet we really know very little about them.

To be sure we have made countless soundings throughout the seven seas, we have dredged and trawled in stupendous depths, we have recorded pressures and temperatures at the bottom of the ocean; from the mysterious depths we have drawn weird, strange forms of life and we have made charts, maps and models of the ocean's bed; but after all, what does it amount to? We know that certain places have certain depths, that there are elevated and depressed regions, that in some spots there are certain kinds of material at the bottom and that some of the denizens of the sea are of certain forms, but all this gives us 


\section{THE DEPTHS OF THE SEA}

no real idea of the bottom of the sea. Suppose we imagine an aeroplane, or an airship, from some distant planet soaring miles above our earth and hidden from view by impenetrable clouds. Imagine such an airship dropping weighted lines downward to our earth's surface, dragging nets across our plains and mountains, gathering samples of our soils and plant life by tiny grapples and grease-coated weights. Would such methods give the beings in the aircraft a true idea of the appearance of the earth, of its flora, its animal life and its details; would maps prepared from data thus obtained be accurate charts of the earth's topography; would learned volumes written by the crew of the airship and based on the material they gathered throw any great light upon the appearance, life or formation of our land? Of course it would not, and yet by such methods alone do we know anything of the ocean depths which cover three-fourths of the entire surface of the globe.

It is marvellous that we have accomplished so much; that we should have learned even the little we do know of the vast areas deep 
beneath the waves and not one-tenth enough credit has been given, not a tithe of the deserved honours bestowed upon the scientists who have devoted their lives to this work. Patiently, quietly, painstakingly these men have laboured year in and year out to solve in some measure the mysteries of the ocean depths and without remuneration, without recompense and with no hope of reward they have given their knowledge and their discoveries to an unappreciative world. To such men as Darwin, Agassiz, Verrill, Dana, the Prince of Monaco and many lesser authorities we owe a debt which can never be repaid, for through their labours and researches we have learned all we know of the mysterious world beneath the sea and of its more mysterious life.

From the work carried on by scientists and oceanographers we know much of the character and formation of the ocean's bed. We know that beneath the level surface of the great ocean the face of our planet is as irregular, as rough and as diversified as upon the continents and islands that rise above it. There are submerged plains and valleys, great table- 


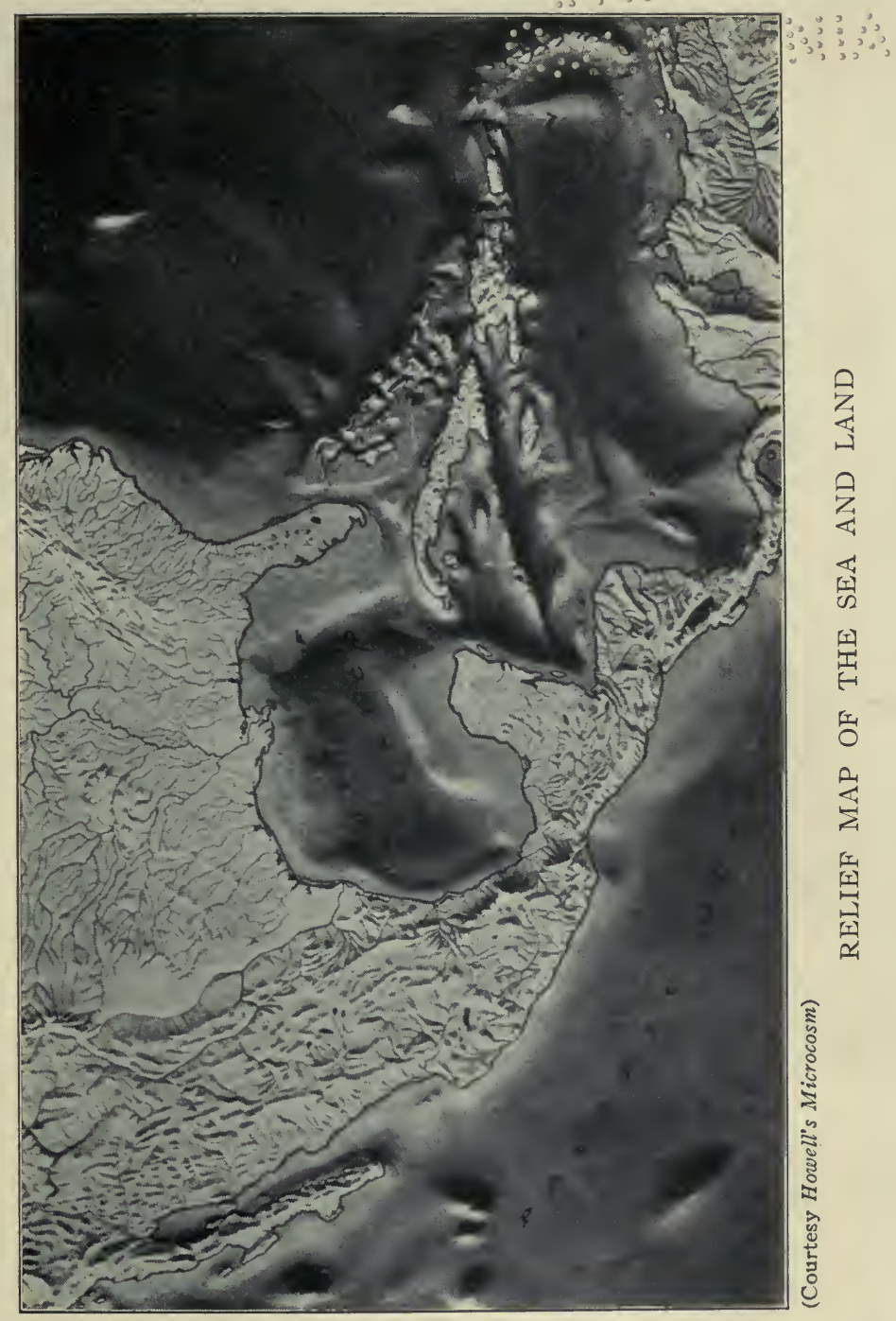




\section{THE DEPTHS OF THE SEA}

lands and plateaus hidden by hundreds of fathoms of water; vast mountain chains with their topmost peaks far beneath the restless waves and enormous depressions and mighty cañons so deep that the loftiest of our mountains-the towering Alps, the cloud-piercing Andes or even Mount Everest itself-might be dropped into the deep and their summits would disappear beneath many fathoms of water. This may sound like an exaggeration, but off Porto Rico dredging has been done in over four thousand fathoms (24,000 feet), and spots have been sounded which were over nine miles in depth in the South Atlantic. It is indeed a difficult matter to imagine the vastness of these great submarine plains, the terrific abysses and fathomless cañons, the precipices and abrupt slopes which exist beneath the sea.

One cannot conceive of the grandeur such scenes would present if bared to human eyes. For example, the low-lying Bahama Islands give us no impression of the tremendous heights and marvellous immensity of the ocean-bed about them. Should this portion 
of the sea be exposed to view we would see a stupendous slope twelve thousand feet in height stretching for seven hundred miles and forming the precipitous edge of an immense triangular plateau five hundred miles in length and two hundred miles in width, cut by deep cañons and with its southern edge crowned with the Sierra Maestra of Cuba which would rise twenty-eight thousand feet above the ocean floor.

As a rule the ocean near the coast of the continents is comparatively shallow and the depth increases very gradually for some distance from land. This broad, shallow area is known as the "Continental Shelf" and with the shore islands, which are portions of the shelf that rise above sea level, it forms a part of the continent it borders. The continental shelf varies in width and depth in different parts of the ocean, but as a rule it corresponds more or less with the character of the shore above the sea. Thus, on the Atlantic coast of America, the shelf is broad and level like the slope of the continent itself, whereas on the Pacific side it is narrow and steep like the 


\section{THE DEPTHS OF THE SEA}

short, abrupt slope of the western coast. Beyond the limits of these continental shelves the bottom usually drops very rapidly to great depths, often to two thousand fathoms or more in a short distance.

Along our Atlantic coast from Cape Hatteras to George's Banks the width of the continental shelf varies from fifteen miles at Cape Hatteras to nearly one hundred miles off southern New England, while on the Grand Banks off Maine the shelf extends out for nearly two hundred miles. Here and there wide tongues or inlets extend towards the coast through this gently-sloping plateau, and off Cape Cod, Maine, and Cape Sable the true ocean depths extend to within fifteen or twenty miles of the shores. Between Cape Hatteras and the Bahamas there is a vast triangular plateau sloping gradually from the shore to a depth of six hundred fathoms and then dipping sharply to the floor of the Atlantic. Along the coasts the one hundred fathom line runs almost parallel to the shore from George's Banks to Hatteras, and almost parallel with this line and at no place over fifteen 
miles from it the one thousand fathom line extends. From this latter contour line to the two thousand fathom limit the slope is less abrupt. It varies from forty miles off George's Banks to one hundred miles off New Jersey and is narrowest off Hatteras, where it sweeps in to within about fifteen miles of the coast.

Off the southern coast of New England the continental shelf slopes very gradually to the one hundred fathom line, but here it falls off abruptly, forming a steep bank known as the Gulf Stream Slope, from the fact that it forms the western edge or boundary of the Gulf Stream.

Although a great many islands are merely elevations of these plateaus which rise above the shallow water, yet other islands rise very abruptly from great depths. Many of these are merely the tips of volcanic mountain peaks whose greatest masses lie hidden far beneath the sea and which, if raised to sea level, would make our mightiest mountairs appear like mere hills. In many of these islands the slopes are so abrupt that there is practically 


\section{THE DEPTHS OF THE SEA}

no shallow water and in some places a person may stand on the shores and drop a line into a thousand fathoms or more of water. Where these islands are of volcanic formation they often contain active volcanic craters and are liable at any time to be partially submerged or to be suddenly raised many feet above their present level. Indeed, a great many of them are constantly rising or falling, although the motion may be so slow and gradual as to pass unnoticed. Wherever there is an active volcano sudden and violent changes are liable to occur and we have ample proof that numerous volcanic islands have been repeatedly submegrged and then raised again for hundreds of feet during past ages.

On some of the West Indian islands, for example, one may find fossil coral-reefs, shells and other forms of marine life, similar to those which exist to-day, far up on the forest-covered mountain-sides, proving that at some period the land has been raised far above the level that it occupied when the reefs were formed. Moreover, in many cases these fossil corals alternate with layers of lava and volcanic ash, 
affording ample proof that not only once but many times the islands have been raised and sunk; each growth of coral indicating a period of submergence and each layer of ash and lava telling of a time when the blazing, molten matter from the crater poured down and covered the marine growths which had been raised from their ocean bed.

Such sudden and immense alterations in the islands of the world are not all happenings of the dim and distant past. Even within a few years large islands have been suddenly lifted above the sea in the Pacific by some subterranean upheaval; in some cases to remain permanently, in others to disappear almost as suddenly as they appeared.

Knowing that such things take place above the sea there is no reason to think that similar great changes do not occur beneath the ocean, and no doubt mountain-chains are formed, vast chasms opened, peaks levelled and other great alterations made in the ocean bed of which we know absolutely nothing. Perhaps the violent distant earthquakes which are frequently recorded by our instruments may 
indicate the great convulsions of nature which are taking place in the depths of the seas.

Still another class of islands are known as "coral islands," but in a way this is a misnomer and is confusing, for most of the socalled coral islands are the summits of solid, rock-formed mountains which are merely coated with coral. Corals of the kinds which form these islands cannot live at depths greater than one hundred and fifty feet and hence it is impossible for corals to rear an island from great depths to the surface of the sea. But where there is a submerged mountain-top or an elevation rising to within thirty fathoms of the surface the corals grow upon it and gradually accumulate until the summit is awash. Then the action of winds and waves pulverises the coral, piles it in rows and dunes and gradually forms an island whose sands, through countless ages, become solidified into coral-limestone. Such an island may be raised still further by subterranean forces and in time a mass of solid coral-rock may be formed which is several hundred feet above the sea. 
The Bermudas and the Bahamas are of this character.

We must not think of the submarine landscape as hard, firm land or rocks, for in most places it is covered by a deposit of ooze many feet in depth. This ooze is soft, impalpably fine and slimy and is composed of the minute skeletons of countless billions of tiny marine animals. In places where the slopes are steep or the currents run swiftly, the bottom may be hard, bare rock; at other places of less depth it may be sand or gravel, while large portions of the ocean bed are covered with a deposit of broken shells, coral, sand, or mud.

Near the shores and in shallow water the bottom may be fairly well lighted by the sun's rays that penetrate the water, but in the great depths no light ever reaches the bottom and thousands of fathoms beneath the surface lies a world of eternal night; of stygian, inky blackness.

Few people realise the conditions which obtain in this strange submarine world or conceive of the stupendous pressure which the immense depth of water produces. 


\section{THE DEPTHS OF THE SEA}

As the weight or pressure of sea water is well known we can readily compute the pressures at the greatest depths and we know that at a depth of one thousand fathoms the pressure must amount to about one ton to the square inch, while at three thousand fathoms it is over three times as great. Such pressures are almost beyond our imagination and are so tremendous that thick, solid wood, when lowered to the depths of the sea is pressed full of water and will not float, while thick glass or metal globes with a small internal empty space, after being lowered to these depths, are, when again raised to the surface, found filled with water, the liquid actually having been forced through the surrounding material by the pressure on every side. We can scarcely conceive of animals existing under such conditions, but in reality they are no more inconvenienced by the pressure of the water than are creatures on land troubled by the pressure of the air.

Moreover, here, far below the reach of daylight, the temperature of the water never changes and remains forever almost at the 
freezing point. Even in comparatively shallow water the temperature varies but slightly and under the equator the water in the deep sea is scarcely warmer than at the Arctic and Antarctic Circles.

All these facts we know from actual investigation, for by means of weights attached to strong piano-wire, self-registering thermometers, pressuré-recorders and other speciallydesigned instruments we have learned a great deal about the conditions at the bottom of the sea.

Even the simple matter of sounding and securing samples of the bottom at great depths was a most difficult problem to solve. If a large rope or line was used it required enormously heavy weights to carry it straight to the bottom, and if weights of sufficient size to sink the line were used they would be too heavy to draw up without the cable giving way under the strain. At last means were devised for lowering an iron tube to the bottom by means of a cannon-ball or other heavy weight which was provided with a trip or catch which released the weight when it 


\section{THE DEPTHS OF THE SEA I5}

touched bottom and thus left only the tube and the sample of the bottom it caught to be drawn up.

At first thought one would not consider it such a difficult matter to drop the various instruments and apparatus over a ship's side, draw them along the bottom and haul them in, but when we consider the miles of cable required and its weight we can appreciate the difficulties encountered by the earlier investigators and we can understand why special machinery and appliances were necessary before any great results could be accomplished in deep-sea work.

We would imagine that this world of ooze, darkness and cold would be a dead, uninhabited waste and for many years the foremost scientists believed this to be the case. But we now know that this is not true and that while the very deepest abysses of the ocean are scarcely inhabited, at least by any forms of life that we can capture, yet in most places the ocean's bed fairly teems with myriads of strange creatures, the majority of which the eye of man has never seen. 


\section{CHAPTER II}

\section{CURRENTS AND STREAMS}

EVER since man first ventured to embark upon the sea in crude skin boats or hollowed-out logs the ocean has been a thing of mystery. Its vast expanse, its loneliness, its irresistible power and its uncertain, ever-changing moods have always impressed mankind with wonder and a vague fear of the unknown.

In olden days sailors peopled the sea with mermaids, mermen and strange and impossible sea-monsters and related stories of weird and remarkable adventures. Even to-day, when great steamships plow the oceans in every direction and every nook and corner of the seas is known, deep-sea sailors spin wonderful yarns and almost yearly some one tells in all seriousness of having seen a sea-serpent.

We know that many of the stories of the sea are purely imaginary and that mermaids and many other sea-monsters are mere myths, but 
the fact remains that we really know very little of the sea or its inhabitants and that many of the ocean's greatest mysteries still remain unsolved.

Standing upon the shore or on the deck of a ship, and gazing upon the great expanse of water that stretches to the horizon, it is very hard for us to realise that the ever-restless surface before us is composed of countless great rivers, some flowing in one direction and some in another.

These ocean rivers, many of which are thousands and thousands of times as large as the Amazon, are known as "Ocean Currents," and many of them flow in courses almost as definite and as regular as the rivers on land, although their banks are only water which cannot be distinguished from the rivers themselves.

If you sail east or southeast in a steamer from New York or Boston you will notice that a day or two after leaving port the dull, greenish water changes to a clear and sparkling indigo-blue, and if you have set sail during cold weather you will find that as soon as your 
ship enters this wonderfully blue water the air becomes a great deal warmer.

This change in the colour of the sea and in the temperature of the air proves that you are in the Gulf Stream, one of the largest and most wonderful of all the great ocean rivers. The

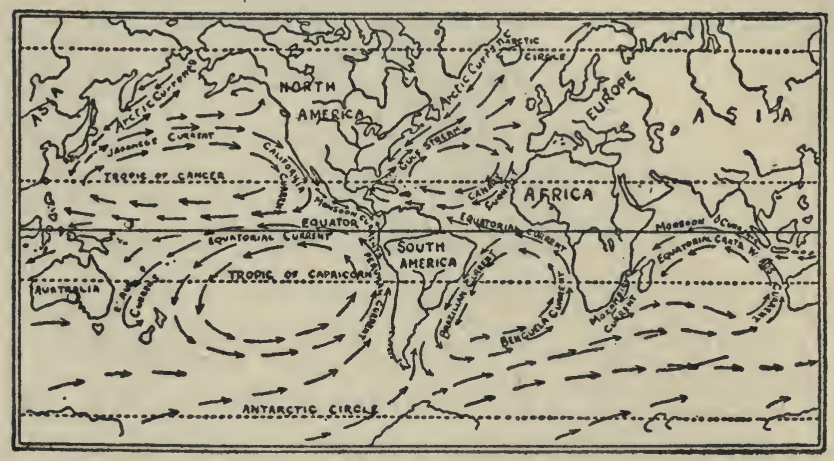

THE GREAT OCEAN CURRENTS

Gulf Stream is so called because it starts or "rises," so to speak, in the Gulf of Mexico, and although we cannot see it move yet it flows steadily northward so rapidly and with such a strong current that you would find it very difficult to row a boat against it. Even the speed of great steamships is so affected by this stream that when travelling south the captains 
always avoid it and when coming north they keep in it, for the great river travels silently along through its ocean channel at from three to eight miles an hour and ships sailing in it lose or gain that much speed, according to the direction in which they are moving.

For mile after mile and league after league this mighty stream flows northward towards the Arctic Ocean, swinging towards the east and finally losing itself and mingling with the waters of the surrounding ocean off the coast of northern Europe.

Although you would scarcely call it warm, were you to dip your hands in it, yet this enormous ocean river is so much warmer than the surrounding water that it has a wonderful effect upon the atmosphere and the climate of the countries near which it passes. Indeed, so tremendous is the volume of warm water in the Gulf Stream that it has been estimated that it carries enough heat to melt down a solid mass of iron the size of Mount Washington every twenty-four hours.

This is more readily understood when we realise that the average surface temperature 
of the Gulf Stream is $83^{\circ} \mathrm{F}$. with a bottom temperature of $45^{\circ}$ and that through the Florida Straits alone over four hundred and thirtysix trillion tons of this heated water flow northward daily. Even a larger amount finds its way out through the Windward Passage, the Bahama Channel and other passages into the Atlantic, and year after year and century after century, this huge warm river flows through the ocean.

At times strong winds or storms may churn the surface of the ocean and cause the waters of the stream and the surrounding sea to mingle, but this happens only near the surface, and a few fathoms beneath the current flows along in an almost unvarying course.

Sometimes, when sailing across the Gulf Stream, one may note its presence by steam or vapour above its surface which is caused by the warm air rising from the stream meeting the cold wind blowing across it,-exactly as our warm breath looks like steam in the frosty air on a cold winter's day. At intervals, and after long periods of calm weather, the edge of the Gulf Stream may some- 


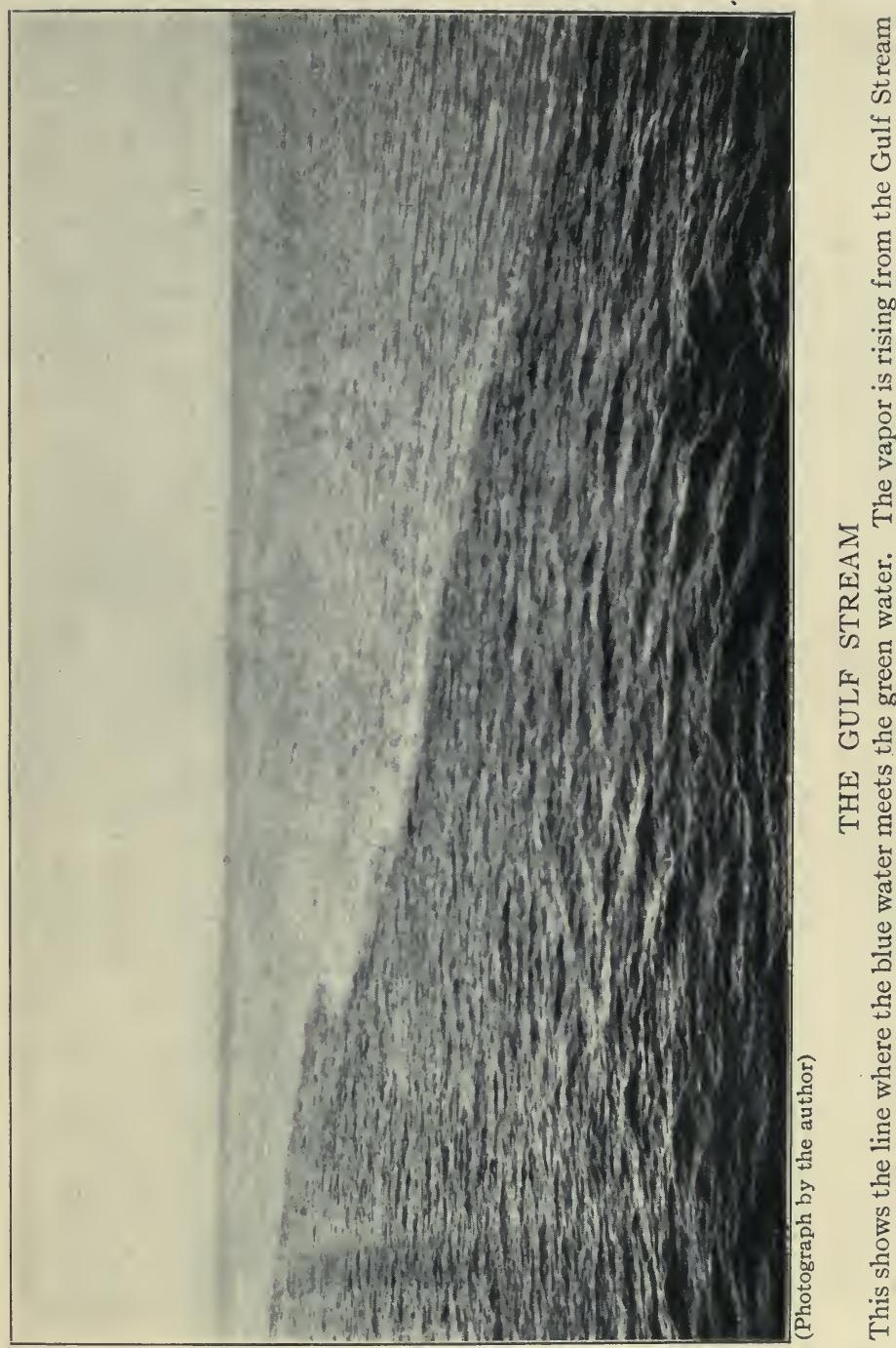



times be seen, sharply outlined against the duller waters of the surrounding ocean. When such conditions occur the curved and irregular course of the stream appears like a ribbon of brightest blue winding through the sea, and, looking downwards from a steamer's deck, passengers actually may watch the ship enter the great river and even may see half of the vessel in the blue water of the Gulf Stream and the other half still in the dark, dull ocean water which forms its banks. Usually, however, the transition from the ordinary water to that of the stream is very gradual, for at the surface the waves and winds cause the warm and cold waters to mingle and it is hard to say at just what point the ship enters the stream.

Every hour that the ship travels further into the Gulf Stream the air becomes warmer and soon the passengers find themselves in a mild and balmy climate, even though wintry winds may whistle about the buildings in the cities from which they sailed and the land, a couple of hundred miles distant, may be covered with snow. To have a home in or beyond the Gulf Stream would be to live in a 
climate of perpetual June and this is what actually occurs in Bermuda. Although no farther south than our Central Atlantic states, yet frost is unknown in Bermuda and all sorts of tropical flowers and fruits thrive out of doors throughout the winter.

As the ship sails southward in the Gulf Stream many bits of yellowish-brown seaweed may be noticed floating on the surface and the farther south one travels the more of this weed will be seen. Sometimes it will appear in great masses stretching for acres over the water, now and then visible on every hand as far as the eye can reach, and in places so thick and matted and in such wide areas that the ocean's surface looks like a great, yellow meadow: If some of the weed is fished up it proves to be a rather pretty plant with golden-brownish leaves and little round berries or fruits and quite different from any ordinary sea weed. This plant is known as Sargassum and it grows upon the surface of the sea instead of being attached to the rocks, shores or bottom of the ocean like other marine plants. 
Between the West Indies and Africa there is a large area of the ocean where there is little current,-a sort of ocean back-water,-and here the sargassum grows upon the surface in immense masses, but never thick enough to stop any ship, and steamers sail regularly across the very centre of this "Sargasso Sea," as sailors in olden times called the spot. Sailors were greatly afraid of it and believed ships could not sail through it and told marvellous tales of vessels that had become entangled in the weed and drifted about forever. They pictured this mythical place as filled with wrecks, - a regular ocean graveyard,-and thought the weed was so strong that men could walk about on it.

Sailing vessels do avoid the Sargasso Sea, but it is not on account of the yellow weed but because the portion of the ocean where it is thickest is an area of calms and light winds. In the days of sailing ships the question of winds was of the greatest importance and the early navigator soon learned that in various parts of the ocean the winds blew from certain directions, during part of the year at least, and 


\section{THE OCEAN}

that by sailing in such places they could be sure of a fair strong wind. In other places they learned that the winds were usually very light and baffling or that calms prevailed most of the time and consequently they tried to avoid such places as much as possible.

The winds which blew steadily in one direction were called Trade Winds because they helped the trade of ships with foreign countries, while the calm spots were called Doldrums. When a few days out from New York, on a southern trip, odd, fleecy little clouds may be noticed hanging in long rows about the horizon and if the Captain is asked about them he will say they are Trade Clouds, and that the ship is getting into the Northeast Trades. By this he means that the vessel is in the area where the winds blow steadily and strongly from the northeast, and all sailors know that the pretty little trade clouds are sure signs of the trade winds, which hold steady and strong during most of the year and that a ship sailing "in the trades" may be reasonably sure of good, strong, sailing breezes.

These Northeast Trades blow north of the 


\section{CURRENTS AND STREAMS 25}

equator, but south of the equator, or "across the line" as sailors say, there are other trade winds known as the Southeast Trades.

Between these two trade winds is an area where the winds are usually light, variable and irregular and where long periods of calm prevail. This is the Doldrums and in the days when all commerce was carried on by sailing ships, vessels were often delayed there for days or weeks.

If the Gulf Stream is followed south it will lead at last to the Straits of Florida, where it issues from the Gulf of Mexico between the western end of Cuba and the Florida Keys. It is from this spot that the stream starts forth on its long journey and by studying a map of the Gulf of Mexico it is easy to discover why the great current flows out through the Florida Straits and into the north. As the trade winds blow steadily and almost continuously from the east they blow or push the surface of the water ahead of them and this water, carried ever westward by their force, finds its way between the various West Indian islands into the Gulf of Mexico. As the gulf is en- 
closed by solid land on all but the eastern side the water cannot move further west and as the pressure from the east continues it finds its outlet in the only available opening, which is the Florida Straits.

But a very large quantity of water flows out between the various West Indian and Bahama islands before it is forced into the Gulf of Mexico. Through the Windward Passage, between Haiti and Cuba; the Crooked Island Passage; the Mariguana Passage; the Santaren Channel and other openings among the Bahamas, strong currents of water flow north and west to add their quota to the mighty bulk of the Gulf Stream.

Although it cannot be seen that the water in the Gulf of Mexico is higher than that on the outside, yet it can be proved by visiting the little islands which form the eastern boundary of the Caribbean Sea and which are . known as the Lesser Antilles. These islands are but a few miles apart and while on their western or leeward sides the sea is calm and smooth, on the eastern or windward side the surf beats on the beaches in great white-crested 


\section{CURRENTS AND STREAMS}

rollers and the palm trees thrash and bend to the stiff trade wind. Between the islands, in the narrow channels, the water is rough and choppy and runs like a mill-race towards the west as it is forced past the islands by the strong northeast wind. On the Atlantic or windward side the tide rises and falls regularly for five or six feet, but on the leeward or gulf side of the same islands there is scarcely any difference between high and low water,only a few inches or a foot or two at the most. This seems very odd and remarkable at first and if we stop to think about it we must realise that when the tide is low on the windward side of the islands it must be several feet below that on the leeward side where it does not fall, and this proves that the water in the Caribbean Sea and the Gulf of Mexico is actually higher than that in the Atlantic Ocean outside. Although at first it may appear as if the water on one side of the islands must be five or six feet higher than on the other side, yet this is not actually the case, for a portion of the water does run out against the trade wind, but before much of it can escape through the 
narrow openings between the islands and against the wind, the tide turns and forces it back. In fact the amount of water that runs back is so inconsiderable, that the level of the Gulf of Mexico remains only about three feet above that of the ocean, as has been proved by careful surveys and observations.

The trade winds, however, are not the only cause of the Gulf Stream and similar currents, for the water of the ocean is itself constantly in motion, owing to the revolution of the earth upon its axis and the variation in temperature between the cold water of the arctic regions and the warm water near the equator. As heated water expands and rises and cold water contracts and sinks there is constantly an interchange of water between the polar and the equatorial regions which causes the warm water in the tropics to flow north and south to replace the colder and heavier water from the arctic and antarctic regions. As the earth revolves upon its axis from west to east and as the water is free to move it slips backward as the earth turns, or in other words moves slowly westward, just as part of the 


\section{CURRENTS AND STREAMS}

water on the surface of a revolving grindstone slips backward on the surface of the stone instead of travelling along with it.

If there were no land masses in its path the water of the oceans would all move round and round over the surface of the earth, while at the same time flowing slowly north and south from the equator, but as the earth moves faster near the equator than at the poles the motion from east to west would vary according to the distance from the equator. Thus, at the equator, the earth moves practically one hundred and seventy-five miles a minute while in temperate latitudes it moves only about one hundred and thirty-five miles a minute and at the poles it moves far slower. As the currents of water moving north or south' reach portions of the earth's surface which are moving slowly and as this water, when it left the equator, was moving rapidly towards the east, it has a tendency to travel faster than the earth itself, thus forming a current from west to east. The cold water from the north and south, coming from portions of the earth which are revolving slowly and reaching re- 


\section{THE OCEAN}

gions where the earth revolves rapidly, have a tendency to lag behind and flow towards the west. This cold water being confined by the continent in its westward flow and by the Gulf Stream to the east, follows along the coast towards the south, and is known as the Arctic Current. Although a vast amount of this cold water reaches the tropics and gradually mingles with the warmer waters, yet even a larger amount comes from the Antarctic seas, for the contour of the bottom of the ocean's bed prevents a large part of the north polar water from flowing south. In the case of the air these same things occur and it is these phenomena which produce the strong easterly trade winds near the equator and the stormy westerly winds in the north and south polar regions, so in reality the trade winds themselves and the ocean currents which they produce are both due to the revolution of the earth upon its axis and to the fact that cold water or air contracts and sinks while warm water or air expands and rises.

As the air is not prevented from moving freely by obstacles in its path the wind cur- 


\section{CURRENTS AND STREAMS 3I}

rents are regular, but the water, moving in much the same manner and being still further pushed along by the winds, cannot continue to flow in the direction in which it starts because of the various continents and islands in its pathway and hence it flows in the direction of the least resistance and follows, more or less, the shores of the lands towards north and south.

Although it is only within comparatively recent years that scientists have studied the Gulf Stream and have made systematic surveys and explorations of this great ocean river, yet it has been known for many centuries. Even Columbus noticed the current and later navigators were familiar with it. The first chart of the Gulf Stream was published by Benjamin Franklin, however. When the great statesman was Postmaster General of the Colonies he noted that the Royal Mail packets took a longer time to cross the ocean than did the ships sailing to and from Massachusetts and Rhode Island. A conference with various captains resulted and the American skippers stated that they sailed in the 
stream or current when travelling eastward and took care to avoid it when travelling westward. Franklin considered this of great importance and with the aid and information furnished by whaling captains he prepared and published a chart of the Gulf Stream. This chart, although crude and incorrect, in view of our present knowledge, was excellent for its day and gave a fairly good idea of the general speed, direction and size of the warm ocean current that flows into the North Atlantic from the Caribbean and the Gulf of Mexico.

We have already seen how the Gulf Stream follows up the coast of our continent, and in the Pacific another similar current, known as the Japan Stream, flows north along the coast of Asia just as the Gulf Stream follows along our own coast. South of the equator, and flowing in the same direction as the southeast trades, are other currents. One of these flows south along the coast of South America and is known as the Brazilian Current while another moves southward around Australia and is called the East Australian Current. 


\section{CURRENTS AND STREAMS}

In the south-seas there are still other great ocean streams which flow easterly, for in the broad sweep of the South Pacific and South Indian oceans there is open water completely around the earth and no land interferes to check the flow of water from the south polar regions which flows north to take the place of the warm water of the Brazilian and East Australian currents. A large portion of this great mass of cold water travels northeast, strikes the western coast of South America and is deflected to the west, where it mingles with the warm water of the equatorial current and forms the Australian Current. Another vast amount of cold water travels up along the western coast of Africa and forms the Benguela Current, while still another of the south-polar streams flows west of Australia around the Indian Ocean and between Africa and Madagascar and forms the Mozambique Current. These three currents, in combination with the East Australian and Brazilian currents, form immense, almostcircular ocean rivers far more regular than either the Gulf Stream or the Japan Stream, 
and they have a tremendously important bearing upon the climates of the countries whose shores they wash. Indeed a great many of the most productive and fertile portions of the earth would be barren and uninhabitable were it not for these ocean streams to which most people give so little thought. Thus, if it were not for the arctic current which flows along our eastern coast, New York would have a semi-tropical climate, for it is in the same latitude as southern Italy and Spain. On the other hand, if the course of the Arctic current or the Gulf Stream should be altered and the cold water from the north should be diverted towards Europe, Dublin and London would have the cold, dreary climate of Labrador and Newfoundland. So also, on our Pacific coast the warm water of the Japan Stream gives to British Columbia and Oregon a mild, pleasant climate, although these places are as far north as Newfoundland. Could man manage to alter the courses of any of these great ocean currents he could change the climate of continents and produce perpetual summer where now the 


\section{CURRENTS AND STREAMS 35}

land is locked in snow and ice throughout the long winter months. It is fortunate that this cannot be accomplished however, for no one could foresee what terrible catastrophe might result from even the slightest interference with the established course of these ocean streams. 


\section{Chapter III}

\section{DERELICTS AND ICEBERGS}

I HAVE already mentioned the Doldrums, that portion of the ocean where the airs are light and baffling, and where sailing ships sometimes drifted for a long time without finding a breeze to carry them on their course. As this is the hottest portion of the ocean the sailors often suffered terribly, as their vessels rose and fell with flapping, empty sails for day after day and no breath of wind ruffled the surface of the smooth and brassy sea. Even the awnings gave little relief; the water in the casks became hot, foul and rotten; the pitch in the deck-seams boiled and bubbled and the captains and crews almost went mad while they drifted helplessly along and waited for a breeze to carry them out of the Doldrums and into the trade winds.

At such times the mariners tried to pass away the weary hours by swapping stories of 


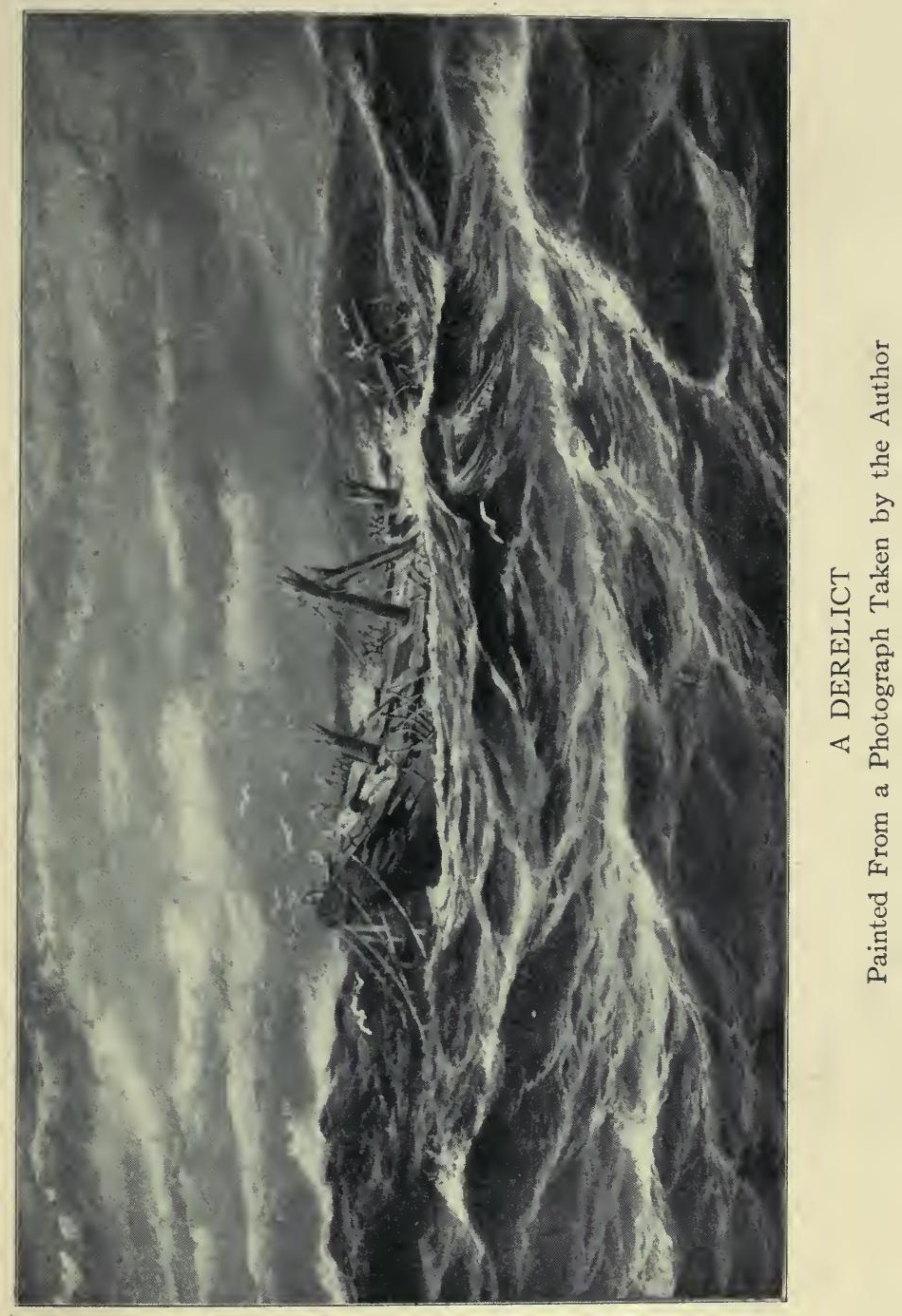



the sea. They told of the "Flying Dutchman," of ships that floated about forever,their sails and cordage bleached and rotten, their sides overgrown with weeds and moss and their decks manned by crews of ghosts and skeletons. They told of sea-serpents, of wonderful sea-monsters and of "Corposants," "St. Elmo's Fire," and of many other weird and uncanny things.

Sailing ship mariners were an imaginative lot and many of their tales were made out of whole cloth, but on their long voyages the men actually saw many strange and mysterious things. Most of these are now well known and have been explained and reasoned out by modern science, but a great many happenings at sea are as mysterious and inexplicable as ever. Science tells us that the strange, pale lights and balls of fire which dance about on the rigging of ships in the tropical nights are "electrical phenomena," but that doesn't explain them, and it is a very hard-headed and matter-of-fact scientist indeed who doesn't feel "creepy" and whose spine doesn't tingle when he sees a great, round fire-ball rolling along 
the rail of a ship or poising on the end of a yard-arm, or when tongues of green and blue flame dance from masts and rigging or even from the heads and bodies of the men.

Disabled ships often float for long periods, and the sailors, seeing these sodden, weedgrown, ocean waifs, easily peopled them with ghosts and spirits. From such sights and fancies grew the yarns of ghost-ships, Flying Dutchmen, the Ancient Mariner and other tales. While we know that these stories were not true the fact remains that abandoned ships known as Derelicts always are floating about in the ocean and $d o$ wander hither and thither. as if manned and steered by invisible hands.

Perhaps, sometime, you may see one of these derelicts as you speed across the broad ocean in a great passenger ship and if you do you will find it a sad and pitiful sight indeed. A lonely, black, weather-beaten hulk rolling slowly to the ocean swells, its sides green and weed-grown, its torn and tangled rigging hanging in tatters over the sides and its decks and broken rails peopled by screaming sea-birds. 


\section{DERELICTS AND ICEBERGS}

Looking upon this sodden, desolate mass, this drifting corpse of a once-stately and beautiful ship, we wonder what tragedy of the sea lies hidden in her storm-wracked skeleton. Perhaps her men were saved by some passing vessel, perhaps they took to the boats and died a slow and miserable death of thirst and starvation upon the vast expanse of ocean; but like as not their fate will never be known; the derelict will never be identified and some trim revenue cutter will send her to the bottom, a mystery of the sea; one of those "missing ships" which sail forth yearly never to be seen or heard from again.

Perhaps this forsaken wreck was caused by another derelict, for these water-logged ships are a great menace to navigation and our revenue cutters are constantly cruising about, searching for derelicts which they sink with shells or dynamite. Probably a large proportion of the ships which never reach port, and which are posted as "missing," are sunk by running into derelicts, for the low-lying hulks are hard to see on a dark or stormy night and a vessel striking one may sink so 
quickly that the crew has no time to take to the boats.

Whenever a steamer or a sailing vessel sights a derelict its size, location and appearance are reported to the Government and regular charts or maps are published at frequent intervals giving the location and description of all known derelicts. Many of these floating wrecks are easily identified by their appearance or the names which are still visible, and if you will study one of the Pilot Charts of the North Atlantic Ocean you will be greatly surprised to find how these deserted ships travel about. For months or even years the wrecks are reported, sometimes far down near the equator and again among the icefloes and bergs of the far north. Although the derelicts are dangerous obstacles in the way of ships yet they have been of great value in mapping ocean currents, for by comparing the various charts and the drift of the wrecks, oceanographers have been able to trace the course of many ocean currents and streams with great accuracy.

In recording the derelicts our Government 


\section{DERELICTS AND ICEBERGS}

carries out a very elaborate system which is most interesting. Each wreck and derelict reported is at once given a serial number and its position is plotted on a blackboard and if it cannot be identified by name the description is compared with other reports and frequently in this manner the unknown wreck is recognised. In order to trace the complete track of a derelict, whose name is unknown, and to facilitate finding it on the register, each report is registered with an "identification number" in addition to its serial number; while each derelict, whose name is known, has a separate place or page in the register devoted to that vessel alone. When a wreck or derelict is reported within striking distance of an available naval vessel a memorandum of the report is sent by the Hydrographic Office to the Chief of the Bureau of Navigation and proper orders for a search and destruction of the wreck are issued. Quite frequently, however, the wreck is reported in some remote part of the ocean and before a naval vessel can reach it the derelict drifts far away and is lost for some time. The work 
done in destroying these dangerous floating hulks is most important and few people realise how many are annually destroyed and removed. In the space of a few years as many as seventy-five derelicts have been sent to the bottom by torpedoes, ramming and fire, while twenty or more are yearly towed into port.

Sometimes even a war-ship finds it a difficult matter to destroy a derelict which, months before, had been abandoned by her crew as in a sinking condition. On October 22, 1893, the abandoned American threemasted schooner Drisko of two hundred and forty-eight tons, lumber-laden and waterlogged, was sighted by the U.S.S. San Francisco. The officers found it was impossible to tow the derelict and three thirty-four-pound guncotton torpedoes were attached to the wreck's keel and exploded, and while these inflicted a great deal of damage the derelict continued to float. Five more torpedoes were then exploded under the keel and the back and frames of the hulk were broken. Still she floated and the San Francisco rammed the Drisko amidships. This broke her in two and 


\section{DERELICTS AND ICEBERGS}

released the cargo, and to make sure that the stubborn wreck would sink, the San Francisco fired several shells into her stern, scattering the fragments of the once-staunch schooner far and wide.

Only by such methods can the ocean lanes be kept free from floating wrecks, and even with all our efforts a great many vessels strike derelicts and are injured every year. There are so many wrecks floating about,-as many as one thousand having been reported in one year from the North Atlantic alone,-that it is almost impossible to hunt down and destroy them all, but fortunately they do not all stay afloat or drift about for very long. It is estimated that the average length of time which a derelict remains afloat is one month, and as an average of about nineteen wrecks are reported monthly, there must be about nineteen wrecks constantly afloat in the North Atlantic. The majority of the derelicts are seen in the Gulf Stream off our Atlantic coast, north of $30^{\circ}$ north latitude and west of $60^{\circ}$ west longitude, and thus in the track of a great deal of navigation. That they are a serious 
menace is proved by the fact that during a period of six years sixty-one collisions with derelicts were reported in the North Atlantic, of which ten resulted in a total loss of the vessel, twenty-three in serious damage, eleven vessels were damaged slightly, and the damage to the rest was unknown.

All mariners dread derelicts, for they can never tell where they may run against one, even with the frequently published pilotcharts and reports. Derelicts cannot be depended upon to remain in any one place, but have most remarkable ways of drifting hither and thither, sometimes disappearing for months at a time and suddenly reappearing hundreds of miles from the spot where they were last seen.

It is interesting to study the drift of these ocean waifs, many of which sail rudderless and unguided for such great distances. In fact the Government charts show that in six years twenty-five derelicts were reported which drifted one thousand miles or more, eleven drifted over two thousand miles, and three travelled over five thousand miles. The 
record for all was held by the three-masted schooner Fannie E. Wolston, which was abandoned on October I $5^{\text {th, }}$ I89I, and was last seen on February 20th, I894, or eight hundred and fifty-eight days from the time she was left to the mercy of winds and waves. During that time this ocean waif drifted the enormous total of seven thousand and twentyfive miles and, as at last accounts she was still supposed to be afloat, no one can tell how far she eventually travelled. During the time that this derelict was reported she traversed a large portion of the North Atlantic in her wanderings. Abandoned off Hatteras she travelled northward in the Gulf Stream until off Norfolk, Virginia, when she started eastward and drifted far towards the coast of Africa, being reported more than halfway. across the broad Atlantic on June I 3 th, I892. Here her course altered and for three hundred-odd miles she moved directly south, until July I 4 th, when, as if guided by unseen hands, she headed northwest, drifted for two hundred miles, turned on her tracks, retraced her course for a hundred miles or so, again 
doubled, and on September 6th was only a few miles from the spot where she had been reported a month previously. From there she travelled westerly for nearly four hundred miles, turned towards the north and covered another three hundred miles, swung to the east for nearly seven hundred miles and on January, I893, was only a short distance from the locality in which she was seen in June of the preceding year. Here again this remarkable wreck shifted her course towards the south, crossed her former track twice, and by May was on the border of the tropics, midway between Florida and Africa, and a thousand miles from where she had been seen in January of the same year. Once more she turned her nose towards the distant shores of America, travelled for six hundred miles in an almost direct course, turned east for one hundred miles, again headed for our coast, and on November 10th, I893, was but five hundred miles from where she was originally abandoned and within the same distance from the Florida coast. Here again commenced that erratic, zigzag behaviour for which the 


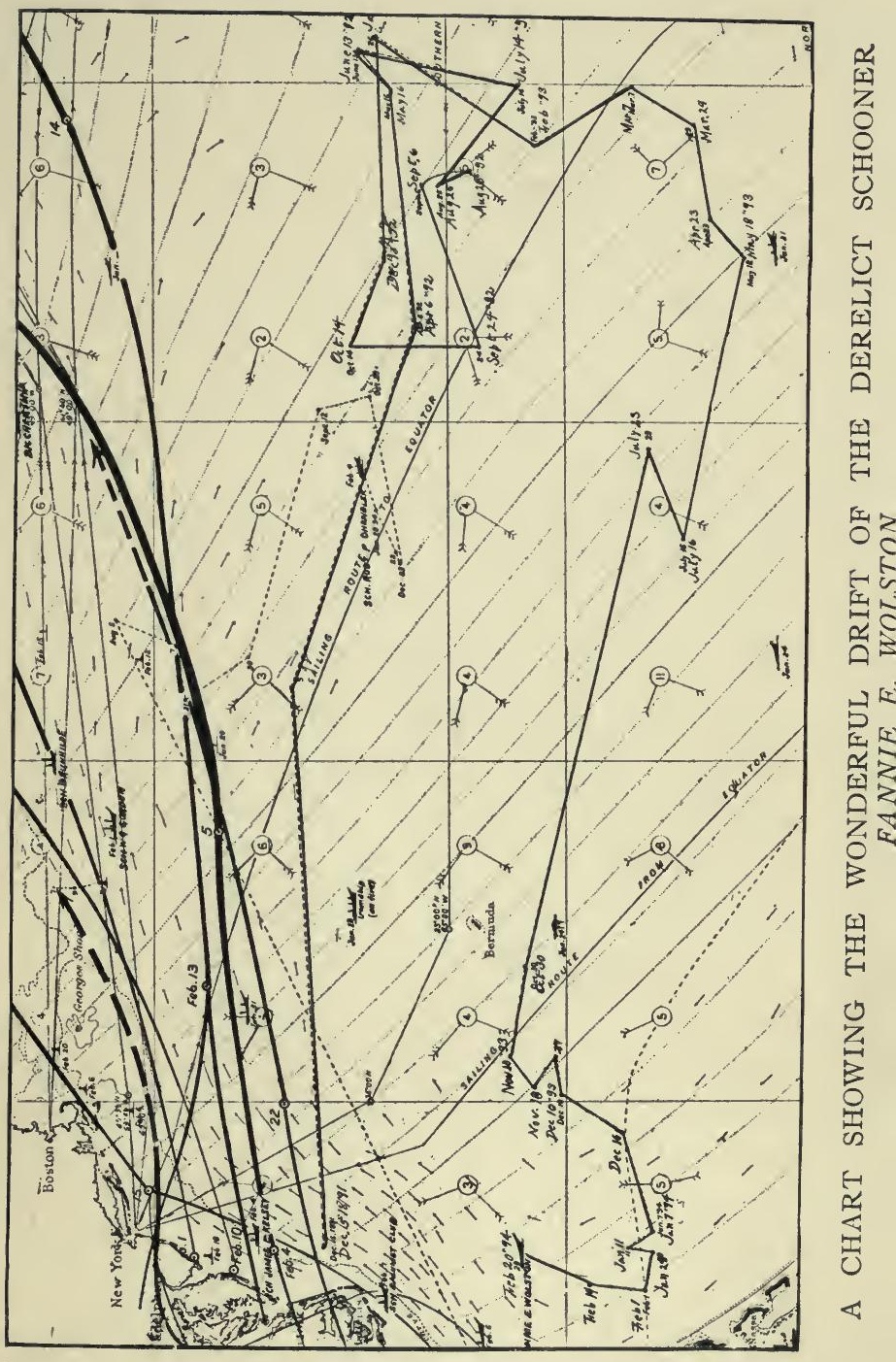





\section{DERELICTS AND ICEBERGS}

schooner had become famous, and for three months she travelled by short, irregular tacks back and forth, north of the Bahamas, until on February 2oth she was last reported about two hundred and fifty miles east of Savannah, Georgia, having endured the stress of storm, winds and seas for nearly two years and a half after being abandoned by her crew as in a sinking condition. Sometimes derelicts divulge most curious things when boarded, for they are often abandoned by their crews in a great hurry or in a panic, and not infrequently the men are lost and there is nothing to show why they deserted their apparently seaworthy ship. On at least two occasions ships have been found sailing aimlessly about under full sail, in perfect condition and without a soul on board. When boarded everything was found undisturbed and in order. Pots of partly-cooked food were on the galley stove, charts and papers were spread on the cabin table, clothing and personal effects were in lockers and chests and everything about the ship appeared as if she were still occupied by her missing crew. Various explanations have 
been offered for such strange conditions, but no acceptable theory, as to why such vessels were suddenly deserted, has been forthcoming, and they still remain among the most baffling mysteries of the sea.

Many derelicts float bottom-up and not a few stories have been written in which men were represented as living for days or weeks within these capsized hulks. As these derelicts contain a large amount of air a man undoubtedly could live for some time within one of them, but there is no authentic instance of the kind. One such derelict proved a great surprise to the officers of the naval vessel which destroyed it, however, for as the first shell struck the hull and tore a great hole in the planking, scores of living creatures swarmed through the aperture. They were cats; countless numbers of them; descendants of the ship's cats which had been left on board when the wreck was abandoned and which had fed upon the rats in the hold and had increased and multiplied in their floating prison.

Almost as dangerous to navigation as the derelicts are the floating masses of ice known 


\section{DERELICTS AND ICEBERGS}

as icebergs. Fortunately for mariners bergs are confined to the far north and far south and the adjacent seas. In the southern oceans there are so few vessels that bergs and floating ice are no serious menace, but in the North Atlantic the masses of ice drift across the lanes of travel of transatlantic steamers and are exceedingly dangerous. Nearly every season some ship runs into a berg, while others have very narrow escapes and oftentimes such collisions result in a tremendous loss of life, as in the case of the Titanic disaster. Although so dangerous, yet, like derelicts, icebergs have enabled our Government to determine many valuable facts and to obtain much interesting data in regard to ocean currents. Ever since the Titanic catastrophe a strict icepatrol has been established and two United States cruisers, or revenue cutters, as well as British ships, are detailed solely for this duty, so that the danger of ships striking bergs has been greatly decreased.

In clear weather icebergs are not particularly dangerous, even at night, for they may be seen for a long distance-on ordinary days 
for twelve to fifteen miles-and instances are recorded of ice being sighted for eighteen or twenty miles in clear, sunny weather. Even at night, in clear weather, bergs may be seen two or three miles away when the moon is shining; for a mile or more when there is no moon and on cloudy nights for fully half a mile.

Unfortunately the portions of the ocean where bergs are most numerous are also the most stormy, hazy and foggy. Even a very light fog will greatly reduce the distance at which a berg may be seen and it is seldom that one can be sighted over two miles distant if there is any fog whatever, while in a really heavy fog a very large berg may not be visible until within two hundred yards. Mariners travelling through the seas where they are likely to meet bergs are greatly in dread of fogs for this reason and invariably keep a sharp lookout, but quite often the man on watch fails to sight a berg because of too much precaution. This may seem strange at first thought, but it is easily explained. Whereas ordinarily a lookout can see a berg 
much further away from aloft than from the decks, in a dense fog the man on deck can often sight a berg farther away than the lookout can, owing to the fact that the water lapping about the base of the berg is more readily distinguished than the ice itself. Moreover, on large ships, the lookout is frequently so far above the water that he may have an unobstructed view of the horizon even though a good-sized mass of ice may be within the distance of a mile, and hence at night he may fail to see it at all, whereas if he was lower down, the ice would loom above the edge of the horizon. So too in using searchlights the lookout is often hindered instead of helped, for if he stands behind or beneath the beam of light he can see nothing. If, however, he stands fifteen feet away on either side he can see readily and he can distinguish bergs even when he stands a hundred feet or more back of the light.

Besides seeing bergs mariners are often warned of their proximity by other means. Among these are sound, for a large berg will frequently give off an echo which may be 
heard for some distance. This is not, however, a very reliable means of locating ice, for a berg may or may not give an echo according to whether or not its sides are steep and perpendicular or the face of the ice is turned towards the sound or is slanting or oblique. Experiments by the ice-patrol boats prove that fully ninety per cent. of the attempts to locate bergs by sound are without result and that it is practically impossible to get an echo from a berg more than half a mile distant and, moreover, the echo when it does occur may be misleading. In one case, recorded by the ice patrol, an echo was obtained when the ship was between two masses of ice, one a so-called "growler," or piece broken from a berg, and the other a large berg; and as events proved the growler gave forth an echo, whereas the berg gave none. Many sailors depend for a warning against bergs largely upon the temperature of the air or water and the "feel of ice" in the air, but from the experiments and experiences of the Government boats such methods are very unreliable. In fact the officers of the ice-patrol 
claim that sudden changes of temperature mean nothing so far as ice is concerned. In many cases they found no change in the temperature of the water up to within a ship's length of bergs, whereas the coldest water they found was one hundred miles from the nearest ice. Even close to a berg the temperature of the water falls only from two to four degrees. Flocks of birds sometimes indicate the nearness of ice, but, unless one is familiar with the species of birds, their absence or abundance can not be depended upon to prove bergs near at hand, for on the fishing banks one often sees, far from ice, large flocks of various seabirds which have been attracted by the fishing vessels. The only sure way of navigating in safety in those seas where bergs are liable to be met is to proceed very slowly and cautiously and to use all the known means of locating ice without depending too much on any one method, especially in thick weather. All icebergs are formed in the far Arctic or Antarctic, where glaciers fill the deep valleys and fjords that lead inland from the sea. As these glaciers move slowly-like great frozen rivers 


\section{THE OCEAN}

-into the sea the outer ends break off and float away as icebergs.

Nearly all the bergs which drift into the steamship lanes of the North Atlantic come from western Greenland, while a few drift south from the Spitzbergen Sea and Hudson Bay, for bergs may travel enormous distances and may endure for two years or more if they do not reach water warm enough to melt them rapidly. Only a small portion of the icebergs ever drift south to the vicinity of the Grand Banks and the ocean steamship routes, for on their journey down from the shores of Greenland they meet with many stoppages and mishaps. Of the thousands of bergs which start on their southward trip many ground in the Arctic basin and break up. Others reach the shores of Labrador and ground among the numerous islands, bays, headlands, shoals and reefs of that coast. Still others break up and disappear at sea and only a few pass safely to the regions off the Grand Banks of Newfoundland.

The greatest factor in the drift of the bergs is the Labrador Current, which passes south 


\section{DERELICTS AND ICEBERGS}

along the coasts of Baffin Land and Labrador and flows at an average rate of from ten to thirty-six miles a day; but even in this current bergs at times drift northward without any apparent reason, thus presenting another mystery of the sea which is yet to be solved.

As the bergs are formed from ice frozen at a very low temperature their surfaces melt very rapidly, when exposed to a thawing temperature, and the difference in tension between their exterior and interior often results in their bursting apart with deafening sound.

We are all familiar with the pictures of icebergs in geographies and other school books, but these lofty, overhanging, craggy, pinnacled forms are the most unusual of all and no two bergs are really anything alike in shape. Some are low, or squareish, others are crowned with spires, domes, minarets and peaks, and still others are pierced by great caves and fissures. There are bergs with round tops, flat tops, sloping tops and peaked tops, and with sloping sides, sheer sides, and craggy sides, and in size they vary as greatly as in form. 
Vessels often report bergs half a mile or more in length and over three hundred feet in height, but bergs of such dimensions are extremely rare and it is seldom that they are seen with a greater altitude than two hundred feet or a greater length than five hundred feet. The portion above water is, however, but a small portion of the entire mass of ice, usually but one-eighth or one-ninth of the whole berg. This does not mean that the berg must be eight or nine times as deep beneath the sea as the height of the visible portion above it, but that the submerged weight or mass must be eight or nine times as great as the visible portion.

For example a large, solid mass of ice may have but a single, lofty pinnacle above the sea and this may reach several times the height of the submerged portion. In fact there is an authentic record of an iceberg which grounded in sixteen fathoms of water and which bore a thin spire over one hundred feet in height.

This immense sunken part of a berg is sometimes more dangerous to vessels than the 


\section{DERELICTS 'AND ICEBERGS}

visible berg, for the concealed portions often extend a long distance on every side of the central peaks and these hidden masses of ice are as bad as sunken reefs. Several instances are on record of ships having struck such an outlying spur of ice when the captain had seen the berg and had-as he thought-given it a wide berth.

With all their bulk and size icebergs are very brittle and a very slight impact will often accomplish their destruction. Sometimes a single blow of an axe will split a huge berg, or the sudden concussion of a gunshot may shatter it. Moreover the bergs are often very nicely balanced and the least melting of their surfaces or other changes may shift their centres of gravity and cause them to capsize. Several ships have been injured by bergs suddenly breaking up or capsizing when close to them.

When such changes take place a berg may alter its appearance entirely and a lofty, pinnacled mass of ice may suddenly be transformed into a flat or rounded, low-lying berg. Many bergs, however, drift all the way from 
the far polar regions to the waters off the Newfoundland coasts without change and not infrequently polar bears are seen on floating bergs far out at sea. Even men at times have travelled long distances on bergs and been rescued by passing ships. On October 14, 1871, Captain Tyson of the U.S.S. Polaris, in company with nineteen persons, became separated from the rest of the ship's company by the ice breaking apart just south of Littleton Island. The party had no boat, and being unable to regain the solid ice they were compelled to remain on the drifting mass, which, once in a current, commenced to travel southward and out to sea. Here the little party remained; ever travelling slowly southward and constantly in dread of the ice breaking up; on the brink of starvation and exposed to the fury of the Arctic storms and icy gales. At one time a polar bear climbed aboard the drifting ice and an Eskimo hunter in the party added him to the larder. Now and then a seal would clamber upon the ice and would form a welcome addition to the bill of fare, while gulls, auks, murres and other sea birds were often 


\section{DERELICTS AND ICEBERGS}

captured. For six long months the little party lived upon the drifting ice and on April 30,1872 , were picked up by the Newfoundland sealing steamer Tigress off the Straits of Belle Isle, over fifteen hundred miles from where they had first become separated from their companions. Strangest of all not a life was lost and, moreover, while but twenty persons started on this remarkable voyage twentyone were taken from the ice by the men of the Tigress, for during the trip a son had been born to the wife of Eskimo Joe. Some of the members of this little party of castaways lived at Noank, Connecticut, and there Eskimo Joe settled down, and his son, born upon a drifting ice-floe in the Arctic, was a playmate of the author of this book in his youth. 


\section{ChAPTER IV \\ TIDES AND WAVES}

SOME of the greatest mysteries of the sea are of such everyday occurrence and so familiar to us that we seldom give them more than passing thought or stop to realise how really remarkable they are. Among them are the tides, and while we all know that tides occur and we look upon them as a matter of course, yet they are really very strange and mysterious things and are difficult to explain satisfactorily. We attribute the rise and fall of the tides to the moon, but after all we really have no proof that the moon causes them, and our reason for believing that they are produced by that planet's influence is mainly due to theory and our knowledge of certain natural laws.

For a very long time man has noticed that the intervals of the tides correspond with the time of the moon's passage, and as we know 
that bodies of matter, such as the earth and the moon, possess a force called "gravitation" we have come to the conclusion that the force of gravitation of the moon causes our tides. But if we stop to consider the matter we will realise that this very gravitation is itself a mystery and hence the tides, even when explained in this manner, still remain mysteries of the sea.

The moon of course exerts her attractive force upon all portions of the earth's surface, but the water, being free to move, is drawn towards the side of the earth nearest to the moon. The broader the surface of the water the greater will be the amount which follows the moon from east to west. On small bodies of water the tides no doubt occur, though the amount of the water attracted by the moon is so small that it is not noticeable, but on every ocean, and even on the larger lakes, tides are known to occur. No doubt there is a distinct "tidal wave" on every ocean as the moon passes over it, but the largest and principal tide is formed in the Pacific and follows after the moon from east to west, and 
62

\section{THE OCEAN}

does not reach the coast of North America until it is thirty-six hours old. Strangely enough a second tidal wave is formed on the
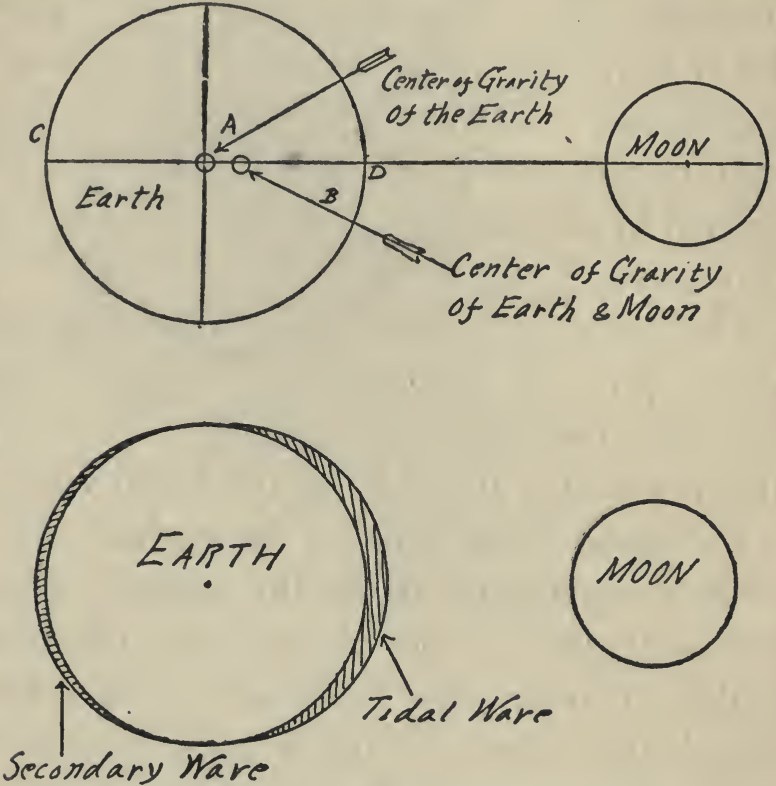

HOW THE MOON CAUSES TIDES

side of the earth opposite the moon and at first thought this would seem to refute the theory that the moon really causes the tides. To explain this second tide is far more difficult than to account for the first and several well- 
known laws and facts must be taken into consideration. In the first place, although we speak of the earth "revolving on its axis," in reality it does not revolve about its absolute centre-like a wheel about its axle-but instead it rotates about the centre of gravity of both the earth and moon combined, for the two planets really form a single unit in the solar system. This is perhaps more readily understood by studying the diagram on page 62 in which $A$ represents the true centre of gravity of the earth, while $B$ represents the centre of gravity of both the planets together. It is easy to see that if the earth is revolving around the axis at $B$ the side $C$ must travel faster than $D$ and therefore the mobile water on that side will have a tendency to be thrown from the surface, just as mud is thrown from a swiftly-travelling wheel, and it is this tendency that is supposed to cause the tidal wave opposite the moon.

Tides do not always rise and fall the same amount, but vary at different seasons and at first this may seem peculiar if we assume that they are caused by the moon. If every large 
64

\section{THE OCEAN}

body exerts a force of gravitation upon the water the sun must also attract the sea, although, owing to its greater distance from the earth, it exerts only a very little force as compared with the moon. When, however, the sun and moon both act together the highest tides are formed, which are known as "Spring Tides" or "Perigee Tides," and when the two planets are opposed and exert their forces in different directions "Neap Tides" or very low tides result.

If you visit various points on the seacoast you may be surprised to find that the amount of rise and fall of the tide varies a great deal. In one spot the tide may rise and fall for six or eight feet while in another locality, only a few miles away, there may be a rise and fall of but two or three feet. In reality the tide itself rises and falls the same amount in both places but the water rises and falls more or less according to the surrounding shores, the bottom of the ocean and the wind. I have already told how the tides on some of the West Indian islands rise and fall but a few inches on one side of an island and five or six 
feet on the other and how this is caused by the tide being unable to flow out against the wind and currents. In a lesser degree the same thing occurs wherever a strong current or wind prevails on our own coasts or where a large bay or harbour is connected with the sea by a narrow opening or channel. In such places the water from the large bay cannot flow out through the narrow entrance during the six hours between high and low tides, and hence the water inside does not rise and fall the same amount as the tides themselves. On the other hand, where there is a long, narrow harbour or inlet connected with the ocean by a broad estuary or strait the very reverse happens. In such places the incoming tide piles up as it proceeds between the narrowing shores and produces an enormous difference between the depth of water at high and low tide.

In the Bay of Fundy, Nova Scotia, the difference between tides is from fifty to sixty feet and in the Bristol Channel about forty feet, although on the shores outside of these bays the real tide rises and falls only five or six 
feet. In situations such as these the bottom of the incoming tide "drags" and the tide, instead of rising gradually as on most coasts, approaches in the form of an immense wave and often travels with great speed, its crest curling and foam-capped like a huge roller breaking on a beach.

These great "tidal waves" are called "bores" and frequently boats are destroyed and lives lost by being caught in the irresistible, oncoming tidal "bore."

We speak of the mass of water, supposedly attracted by the moon and which produces our tides, as a "tidal wave," but in reality this is not a true wave at all and is very different indeed from another kind of "tidal wave."

While the so-called tidal wave is a mass of water which actually moves along, the water in true waves does not move forward but merely up and down, although the waves themselves move forward. The fact that the water of waves moves only up and down is easily proved by tossing a bit of wood upon the water and, if no tide is flowing and no wind 


\section{TIDES AND WAVES}

blowing, the floating timber will merely rise and fall without moving along.

A still better idea of the motion of waves may be obtained by moving some object along the under side of a piece of paper or cloth. The "wave" of paper or cloth thus produced will appear to move forward just as the water of real waves looks as if it was moving, but in reality the cloth or paper remains stationary just as the water remains practically stationary, while the wrinkles of the material, which represent the waves, actually move along. When waves are caused by the force of the wind upon the surface of the water they form in fairly regular lines at right angles to the course of the wind, but as they reach shallow water they alter their course and break upon the shore in a line nearly parallel with the coastline. This is due to the fact that the portions of the waves nearest to the shore are retarded by the shallow water while the portions still over deep water, proceed more rapidly and thus the waves gradually swing around in line with the coast. This same retarding effect of shoal water upon waves 
causes the great rollers and breakers which we see upon our coasts after heavy storms. The larger the waves the greater the depth of water affected by them and, when this depth is sufficient, the lower portions of the waves are held back by the bottom of the sea near the shore and the upper parts travel more rapidly and break or curl over the lower portions. This breaking of waves upon a shore gives a still greater appearance of the water itself travelling forward, but between the waves the water flows back to its normal height, which would not be the case if the water itself were really moving forward, as in the case of the tide.

Out at sea, in deep water, even the very largest waves do not break and curl, save where they come into contact with some other object or other waves or when their tops are blown off by the wind. When the wind travels faster than the waves the tops are forced ahead of the lower portions and the waves break in much the same manner as when the lower parts drag on the shore, for in each case the upper parts of the waves travel faster 


\section{TIDES AND WAVES}

than the lower parts and curl over in advance. Waves, in mid-ocean, may reach an enormous size and some have been measured which were thirty or forty feet in height. Such waves, should they reach the shore, would pile up to still greater heights and would possess enormous destructive force, but as a rule the size of waves is greatly overestimated and waves ten or twelve feet in height are unusually large. It often happens that one wave overtakes another and combines with it to form a wave much larger than its fellows and this great wave may overtake and combine with still others until a gigantic wave is formed which towers far above all the surrounding seas. Such waves are called "cumulative waves" and when such a cumulative wave meets a ship it frequently causes a vast amount of damage. A short time ago the Clyde West Indian liner Seminole was struck by such a wave, thrown upon her beam ends and seemed about to capsize, when a second cumulative wave struck the ship on the opposite side, righted her and saved her from capsizing, although 
in doing so it carried away nearly all her deck-houses, cabins and upper works.

As a rule, however, the largest ocean waves are not particularly dangerous to a well-built, sea-worthy ship unless they curl or break, for by heading into the waves and either steaming slowly or "lying to" the ship will rise and fall, but will safely ride out the seas. It is the breaking seas that sailors fear and mariners often hang bags of oil over the ships' bows and then the oil, spreading upon the surface of the sea, prevents the waves from breaking.

Although wind is the commonest cause of waves yet there are certain waves which are produced by other causes. An earthquake at sea, or even on land; a subterranean volcanic eruption,-or even the sudden eruption of a volcano on shore,-may start a wave, or a series of waves, on its travels. Such waves are known as "tidal waves" for like the tides they travel across immense areas of the ocean. Although, at sea, such a wave may be only a few feet in height and would hardly be noticeable, yet it may be of enormous area and may affect the water for a great depth. When 
such a wave reaches shallow water the bottom commences to drag, the oncoming wave in the rear overtakes it and the whole stupendous mass culminates in a vast, onrushing comber which sweeps all before it. Such a tidal wave partly destroyed Lisbon, another spread devastation along the western coast of South America, and in various portions of the world immense damage has been caused by them. Sometimes, when such a wave approaches a harbour, it tears anchored ships from their moorings, carries them along on its crest and drops them far inland where they rest high and dry as the water recedes. On the island of St. Croix, in the West Indies, there was formerly a large schooner resting beside the roadway, among a grove of palm trees a long distance from the sea, and with her hull transformed into dwelling places and shops by the natives. This vessel was carried to her strange resting place on the crest of an immense wave a number of years ago and the size and height of the wave may be imagined from the fact that it carried the vessel clear over the tops of the intervening palm trees. 
During severe hurricanes in the tropics, immense waves are often formed which cause enormous losses to shipping, as well as to the coastwise towns and lands, and in many places the destruction wrought by the waves is far greater than that caused by the wind itself. At such times the open sea is far safer than an anchorage near shore and many a captain has saved his ship and the lives of his crew by putting to sea in the very teeth of a hurricane. This was the case at the time of the great hurricane in Samoa, when British, German and American warships were cast upon the shore and smashed into kindling wood by the wind and waves, while the British ship Calliope steamed out into the screeching, howling gale and sought safety in the open ocean.

Even the heaviest seas in mid-ocean are safer than much smaller seas near shore and while hurricanes, severe gales, immense waves and waterspouts are all dangerous, yet the actual losses of ships from such causes are comparatively small, when the vessels have plenty of sea-room. Moreover storms seldom ex- 


\section{TIDES AND WAVES}

tend over a very wide area of the ocean and one may sail from smooth, pleasant weather into a heavy sea and gale and out again into calm water in a comparatively short time. To the landsman unfamiliar with the sea, a storm or a heavy sea may appear to cover the entire ocean, but in reality it may extend only for a few miles. When a ship is tossing about and rolling madly among mountainous waves, with a gale howling and screeching through the rigging and sleet and rain pelting down like shot from a gun, it is hard indeed to realise that, within a few miles, some other vessel may be sailing under a sunny sky with a gentle wind and over an almost smooth sea.

Some parts of the ocean are far more stormy than others and in such places sailors look for gales, rough seas, fogs and bad weather. In the North Atlantic, around Cape Horn and in many other places mariners are far more apt to encounter foul weather than fair, while in other localities good weather is the rule and severe storms are seldom met. Between the eastern coast of the United States and the West Indies and Africa one may often travel 


\section{THE OCEAN}

for days over a sea as smooth as glass and with just a gentle breeze which scarcely ruffles the surface of the ocean and the traveller may make the trip back and forth over this route for years without encountering a severe storm. On the other hand every trip may be rough and boisterous for, after all, the question of good or bad weather is largely a matter of chance or "luck." The region off Cape Hatteras is usually considered stormy and rough and yet the author has made sixteen ocean trips past Hatteras and on every occasion but one, has enjoyed the pleasantest of weather and the smoothest of seas.

Nevertheless Hatteras well deserves its reputation for rough weather and during many months of the year one may expect unsettled, boisterous and heavy weather off this cape. It is in this region that sudden; severe squalls, showers, electrical phenomena, and even snow in June, are often encountered and not infrequently one or more waterspouts are sighted near the edge of the Gulf Stream even in smooth weather. On one occasion the author saw three of these strange funnel-shaped col- 


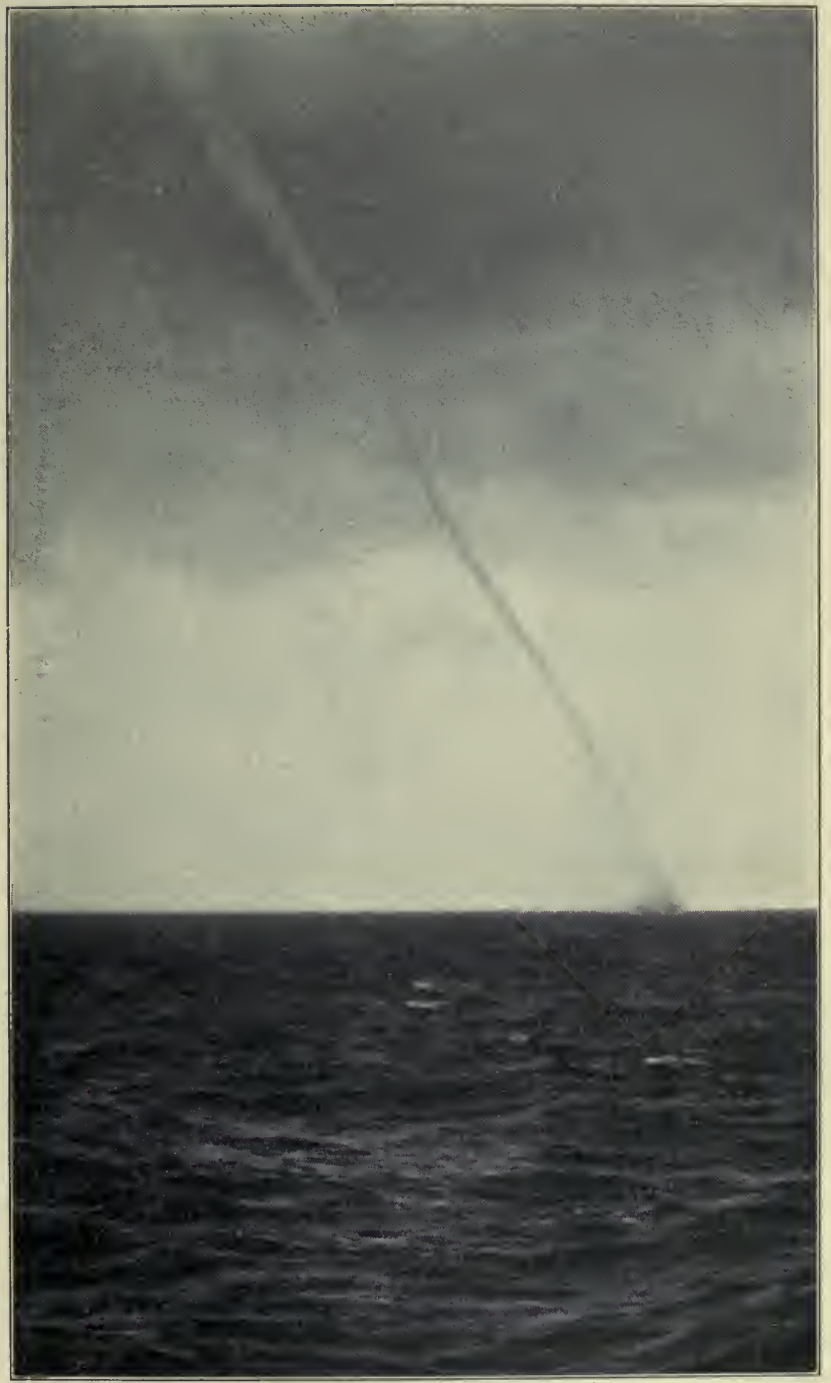

(From a photograph by Dr. Edgar Johnson, S. S. Brazos)

A WATERSPOUT AT SEA 



\section{TIDES AND WAVES}

umns of water at one time, two of which passed within a few hundred feet of the ship. The common belief that waterspouts are very dangerous to vessels has little foundation in fact, for as a rule they can readily be avoided by steamers and even if they do hit a ship comparatively little damage results. The deluge of water may smash boats and light upper works and the tornado-like wind, which accompanies the waterspouts, may tear away awnings, sails or similar objects, but serious injuries from waterspouts are very rare. Sometimes a waterspout may actually be watched as it forms and it is a strange sight to see a dark, angry-looking cloud descend towards the water, where, almost instantly, a little, white-crested wave rises from the sea, increases rapidly in size,-churning and boiling as if agitated by some great force below, and then with a sudden rush springs upward in a slender, tapering column and joins the lowhung cloud above. Sometimes the waterspout is very slender, curved and twisted; at other times it is stout, funnel-shaped and almost vertical, while occasionally the conical, whirl- 


\section{6}

\section{THE OCEAN}

ing column of water may not extend to the cloud above, but may be separated by a wide space so that no visible reason appears for the mass of disturbed water which stands up, like an inverted cone, above the surface of the sea.

Oftentimes waterspouts will form and remain almost stationary in one spot for a long time and then gradually subside. At other times they may form and break and reform repeatedly within a short distance, or sometimes the spouts may go racing off across the sea with tremendous speed. In every instance, however, their cause is the same and they are formed by whirling winds, like miniature tornadoes, which create a suction or partial vacuum in the air above the sea and thus draw up the water from below. If the whirling wind ceases or encounters a wind blowing from another direction, or if the column of water meets some obstacle, the suction ceases and the spout bursts and falls like a cloudburst. If the rotary force gradually decreases, or the suction is insufficient to continue to draw up the water; the spout may 


\section{TIDES AND WAVES}

slowly disappear or it may break in the centre, the lower portion dropping back to the sea while the upper part,-in the form of a heavy, black, funnel-shaped cloud,-may continue for a long time and may travel for a considerable distance before it releases the water it has drawn up and allows it to fall in a shower of brine. Waterspouts are more often seen at sea than on lakes or other bodies of water but many instances are recorded of waterspouts drawing all the water from a pond or lake and leaving the bottom bare, while fishes, frogs and other creatures were carried off by the whirling cloud to be dropped at some distant point. The "showers of fish" and the stories of "rains of frozs" are readily accounted for in this way as a good-sized waterspout might easily draw large fish and other marine creatures into the clouds and transport them for a number of miles.

In a great many places a choppy, rough sea is almost always to be found but usually the rough water in these localities is not due to wind or storm but to ocean currents or tides which remain constant at all times. 
The English Channel is a case of this sort, while the trip across the Gulf Stream to Bermuda is another. Where the warm water of the "Stream" flows north and meets the cold water of the Arctic current flowing south, there is almost always a choppy, short sea such as sailors term "nasty" and which on a large scale is much like the queer, choppy, conical, little waves which one may often see in narrow channels at the turn of the tide. These latter are known as "Tide Rips" and are caused by the tide flowing against the wind, or by a tide flowing in one direction meeting a current or a tide flowing the opposite way. Such tide-rips are usually small and amount to but very little, but at times; when the tide flows swiftly and a strong wind is blowing, the waves may become very dangerous and unpleasant. In some parts of the oceans such tide-rips are of enormous size and the various irregular and erratic currents and counter-currents produce a tumbling, foaming, swirling mass of water of immense power and force. Of this character is the famous "Maelstrom" and the "Scylla and Charybdis," and 


\section{TIDES AND WAVES}

while modern steam vessels may navigate such places in comparative safety the old-fashioned sailing ships were often imperilled by the dangerous currents and whirlpools and gave them a wide berth. 


\section{Chapter V \\ SAFEGUARDS OF THE SEA}

WHEN once we study the sea and realise the innumerable dangers which threaten ships on every hand we wonder, not that so many ships are lost, but that so few of them meet with disaster. Reefs, rocks and shoals, icebergs and ice-floes, floating derelicts, strong currents, wind and waves, fog and haze, hurricanes, tornadoes and waterspouts, as well as other ships and fire, all add to the dangers of navigation, and the captains and officers must be constantly on the alert and must exercise unceasing vigilance every moment they are at sea. Even the greatest care would be of little avail were it not for the safeguards of the sea such as lighthouses, buoys, charts, etc., the meaning and operation of which are, to most people, as mysterious as Old Ocean itself.

Of all safeguards of the sea the lighthouses and lightships are the most in evidence and 


\section{SAFEGUARDS OF THE SEA 8I}

the most familiar, for their lofty towers or bobbing hulls in the day and their twinkling beams of light at night are easily seen and recognised. All around the world lighthouses are established, but they are most numerous along those coasts where there is the greatest amount of shipping and where the shores are most dangerous.

Many of the lighthouses are built upon the land, often at some distance from the sea, while others are built upon the very edge of the water and still others are reared directly from the breaking waves on isolated reefs or rocks, sometimes a long distance from the land. If all lighthouses were alike in form and colour, or all cast the same kind of light, mariners would be confused and the lighthouses would prove a menace rather than a help. For this reason the various houses and towers are painted different colours and their lights are distinct so that one cannot be readily mistaken for another. Some lights are steady and white, others are red, others flash alternately red and white, while still others flash white at varying intervals, but in each and 
every case the colour and duration of the lights are recorded on charts and by this means a mariner may always know where he is, if he can see a lighthouse. Lightships are also identified by their lights at night and in the daytime they are recognised by their name and number which are painted in huge letters and figures upon their sides. The lightships serve much the same purpose as the lighthouses and in fact they are really floating lighthouses and are placed on or near shoals, reefs, or bars where it would be impractical or difficult to build and maintain a lighthouse. Of course every lighthouse and lightship must have some one constantly in charge, for if the lights should fail for even a few moments ships and many lives might be lost and day and night, through summer and winter, through storm and calm, some one is constantly on watch in every lighthouse and lightship along the coasts. Where the lighthouses are on land the life of the keeper, as he is called, is not so hard or unpleasant for the lighthouses are quite large and comfortable and are often surrounded with flower and vegetable gardens, 


\section{SAFEGUARDS OF THE SEA 83}

while friends and neighbours are within easy reach. It is quite different in the case of the houses far from shore on isolated reefs and rocks where the keeper and his assistants are cooped up in tiny buildings perched directly over the sea and far from all friends and companions. Here they must remain absolutely alone and cut off from the rest of the world for weeks at a time, while all about the seas break and roar, the storms howl and the solid steel and stone work of their lighthouse homes shake and reverberate to the tremendous buffeting of the elements. Once in a while a lighthouse-tender visits them, bringing supplies, newspapers and magazines, but in many places the whole long winter is passed without a single visitor or a word from the outside world, owing to the great ice-floes which stretch on every hand and prevent any vessel from approaching. In these outlying lighthouses life is terribly lonesome and monotonous but on the floating lightships it is even worse. The lighthouse keeper may be isolated, cut off from his fellows and surrounded by the tumbling waves and howling gales, but at 
84

\section{THE OCEAN}

least he has a strong, fairly-comfortable house in which to live. The men on the lightships are not only isolated and far from their friends and surrounded by stormy winds and waves, but are robbed of the secure and comfortable quarters of the lighthouse as well. The lightships are staunch and seaworthy, yet in the relentless storms of their exposed anchorages they bob and toss like corks and not infrequently their cables part or their anchors drag and the ships go drifting out to sea. When the lightships are not equipped with power,-which was often the case a few years ago,- the vessels may drift for many miles out to sea and, if not sighted or picked up by passing vessels, the keepers may find themselves on the coast of another far-distant land before they are rescued. They have one great consolation, however, and that is that their ships are built so strongly and are so well adapted to riding out the heaviest seas and fiercest gales that, barring collision with another ship or a derelict, or unless they strike a rock or reef, they have little to fear, for seldom indeed does a lightship founder through stress of 
SAFEGUARDS OF THE SEA 85

weather alone. Nowadays, moreover, most lightships are provided with propellers and power and if their anchors drag or their cables part they can work back to port or to their station without much difficulty.

The discovery of the wireless telegraph also did much to mitigate the hard lives of the keepers of lightships and lighthouses, for, equipped with wireless, the men on these isolated safeguards of the sea may communicate with the rest of the world and talk with ships at sea and in case of accident or trouble they can call for assistance.

In many instances the safety of vessels demands lights where it would not be worth while or practical to build a lighthouse or anchor a lightship. Sometimes these spots are inaccessible to lighthouse-tenders or are surrounded with so many shoals, reefs, or rocks, or so long locked fast in ice that it would be impossible to maintain a regular lighthouse service. At other points the shoals or reefs are only dangerous to comparatively small vessels and it would not pay to establish a real lighthouse. Under such conditions the 
usual method is to install a beacon or a lightbuoy. These are towers of stone or iron, or floating iron buoys, securely anchored and bearing bright lights which operate automatically. Such beacons and gas-buoys may have either steady or flashing lights and as they require attention only at long intervals a great many of them are in use along our coasts. While lighthouses, beacons, etc., are all of the utmost importance for warning mariners of dangerous spots and for enabling them to learn their ship's location and bearings, yet sailors would find it a most difficult matter, by such helps alone, to pick their way into harbours and other localities with which they are unfamiliar. Buoys are used to enable sailors to find their way among reefs, shoals and other obstructions, and to those familiar with the meanings of buoys, they serve to guide the course of a ship just as plainly as sign-posts at cross-roads guide travellers by land. The landsman finds it truly marvellous to watch a sailor steam or sail up some winding, tortuous channel; turning first to right and then to left; doubling and swinging about, with noth- 


\section{SAFEGUARDS OF THE SEA 87}

ing to guide him but black and red sticks or huge, coloured, iron cans bobbing about in the water.

But to the sailor each of these signs or buoys and many other marks, which the landsman

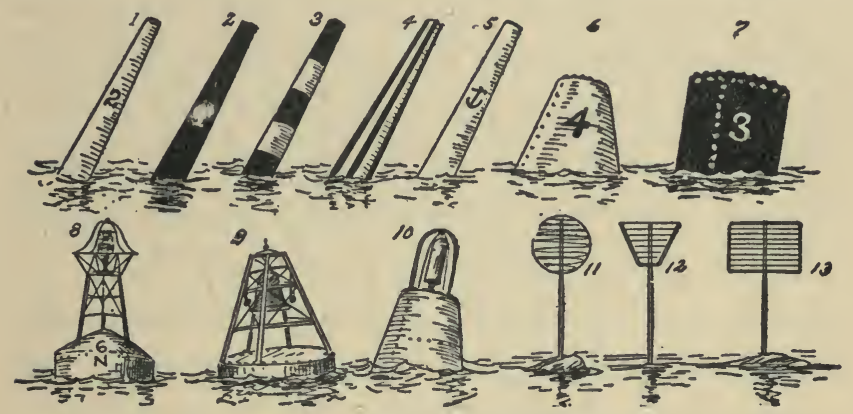

SAFEGUARDS OF THE SEA

1. Red spar buoy 2. Black spar buoy 3. Red and black danger buoy

4. White and black channel buoy 5. Anchorage buoy

6. Red nun buoy 7. Black can buoy 8. Gas buoy 9. Bell buoy I0. Whistling buoy II, 12, 13. Perch and ball beacons

fails to note, mean a certain thing and the mariner knows that if he follows the course indicated by the buoys he will be perfectly safe.

For example, he knows that when leaving a harbour he must pass all the red buoys on the left or port side of his ship 
and all black buoys on the right or starboard and when entering a harbour he must do just the reverse and must pass the red ones on his right and the black ones on his left. So too he knows that other parti-coloured buoys mean various things; that a buoy with horizontal stripes of red and black means danger and must be given a wide berth, while a buoy marked with perpendicular black and white stripes means mid-channel and may be passed on either side. In addition each buoy is numbered, the red buoys being given even numbers and the black ones odd numbers, so the passing sailor may know at a glance just where he is, for on the charts every buoy is plainly indicated with its colour and number. Now and then one sees a buoy very different from the others; either bearing some queer, easilyidentified object above it, such as a keg, cage, or disk, or painted in sharply contrasting colours in huge squares or other designs. Each of these has its own meaning and is designated on the charts and the officers of the passing ships have only to compare the buoys and beacons with their charts in order to know exactly 


\section{SAFEGUARDS OF THE SEA 89}

how to steer, even though they have never been in the locality before.

From all this you may see how really simple it is for a good mariner to find his way into harbours and along coasts where there are lights, beacons and buoys, but in a great many places there are none of these safeguards of the sea and the sailors must depend upon other methods of safely navigating their vessels along the dangerous shoals and reefs. It is in this work that charts are of the greatest value and a sailor without charts would be greatly handicapped and would have to proceed very slowly and cautiously in any strange locality. There are a great many kinds of charts including pilot charts of the great oceans, sailing charts from one distant point to another, charts of individual countries and islands and harbour charts. The pilot charts of the ocean are very elaborate and complete and to the landsman they appear a hopeless, unmeaning jumble of red and blue lines, figures and symbols, letters and arrows, queer, wavy lines, areas of shaded lines and many other mysterious and incomprehensible signs. In reality each of 
these things has a definite meaning and the mariner or pilot can read and understand them as readily as you can read and understand an ordinary printed page. Upon these ocean charts are plotted the. various courses for sailing vessels and steamers from port to port, the tracks of storms and the ocean currents. In addition there are symbols and numbers indicating the areas of winds and calms and the direction of prevailing winds; the regions of fogs, storms and rains; the magnetic variation of the compass; the location of icebergs and ice-fields; the location and drift of derelicts; the location of drifting buoys, logs, spars and other objects; the weather and storm signals of the various countries bordering the seas covered by the charts, as well as much other information of value to sailors.

On these charts, as well as on those charts which show the principal sailing routes from one port to another, the land and the various harbours are on a very small scale and by these charts alone sailors could never find their way into the various ports. In order to do this they must have coastwise and harbour charts, 
each of which covers only a small portion of the sea and land. On these charts the various channels are marked with innumerable figures showing the depths; letters designate the character of the bottom at various points, and all rocks, reefs and other obstacles, as well as all the various buoys, beacons and lights are shown. Moreover these charts illustrate prominent landmarks, such as hills, mountains, tall trees and buildings, etc., which serve as bearings and minute detailed sailing directions are also included.

With such a chart a mariner may readily find his way into a strange harbour or may navigate his ship through strange waters, even though there are no buoys, lights or similar guides. By frequent soundings with the lead, and by comparing the depths and the samples of bottom with the chart, the captain or pilot of the ship may locate the position of his vessel with great accuracy and by proceeding slowly, and sounding as he proceeds, and watching landmarks and bearings he may wend his way into most difficult and dangerous spots in safety. This may seem very mys- 
terious to a landsman, for it is very difficult to understand how mere depths of water and the tiny samples of bottom, brought up on the grease at the end of the sounding-lead, can tell a sailor where he is. As a matter of fact there are seldom two spots in any locality where the depths and bottom are alike or where the water shoals in exactly the same manner. Thus if the lead indicates ten fathoms and muddy bottom and at the next sounding shows eight fathoms and muddy bottom, the sailor, by referring to the chart, may be sure he is on or near the spot where the soundings and bottom agree with those designated on the chart. If, by a study of the chart, the officer finds that the proper course lies to the north and has a depth of nine fathoms and a sandy bottom he has but to steer in that direction and sound and if the stated depth and sandy bottom is found he knows he is right, whereas if a different depth or bottom is encountered he can still locate his position by the chart. Many times bearings on shore are almost as useful as buoys or lights and by keeping certain prominent 


\section{SAFEGUARDS OF THE SEA 93}

landmarks in line, or in proper relation to one another, very tortuous and difficult channels may be followed.

Of course in thick or foggy weather it is impossible to see landmarks or lighthouses, or even beacons and buoys, and the danger of vessels running on rocks or shoals would be very great, unless some means were provided for warning ships and letting their officers know of the whereabouts of danger spots. This is accomplished by means of bells, sirens and horns which are sounded during thick weather. Each lighthouse or lightship is provided with a fog signal of some sort and, in order that a mariner may know which signal he hears, each is arranged to sound at definite, stated intervals or in a distinct manner. Many of the most dangerous spots are not, however, provided with either lightships or lighthouses, and in such cases it is usual to establish a whistling-buoy or a bell-buoy. The former is a buoy which is provided with a horn or whistle operated by the rise and fall of the waves, while the bell-buoy is provided with a large bell. Beneath the bell is a smooth disk upon 
94

\section{THE OCEAN}

which a round, iron ball rolls back and forth, thus clanging the bell with the least motion of the buoy.

Of course all these buoys, lightships, beacons and lighthouses require care and attention, for if even one buoy goes adrift, one light goes out or one of these safeguards of the sea should fail to operate properly there might be great losses in ships and human lives. In order to give all these things proper attention the Government maintains a large fleet of lighthouse-tenders whose duty it is to visit the various ships and lighthouses, carry provisions and supplies to the keepers, look after the beacons and buoys and watch over the thousand and one details of the service. Buoys cannot be left continually in the sea, for after a comparatively short time the iron buoys become rusty, the wooden buoys worm-eaten, and both iron and wooden ones are soon covered with such a thick growth of seaweeds, barnacles, etc., that they sink deep in the water and are not easily seen.

Moreover, during the cold, stormy, winter months, the expensive iron buoys are liable 


\section{SAFEGUARDS OF THE SEA 95}

to be injured or carried away by the ice and spar-buoys of wood must take their place. For these reasons a number of vessels must be kept constantly employed in taking up buoys and putting down new ones and to simplify this work various stations are established at different parts of the coast where the old buoys are repainted and cleaned, the new ones stored and vast quantities of supplies and apparatus are kept constantly on hand. These depots are most interesting spots for here one may see the great buoys and lights at close quarters, may examine the mechanism by which the various appliances are operated, and may obtain a good insight into the systems and methods by which the mariners are protected by these safeguards of the sea.

Even with all these ingenious and elaborate efforts to guard and protect mariners it often becomes impossible for a ship to seek safety in a harbour, for there are often long stretches of exposed coast with no harbours or sheltered spots. When a vessel is caught in a severe storm in such a spot she is in great danger of being blown onto the shore and wrecked 


\section{6}

\section{THE OCEAN}

and to prevent such disasters the Government has provided great walls of rocks called breakwaters, in the shelter of which ships may lie in safety during bad weather. At nearly every dangerous spot on the coast there are life-saving stations where hardy, fearless men are constantly on watch for disabled or helpless vessels and where every possible device for life-saving is kept ready for instant use. Here are powerful, staunch, non-capsizable and non-sinkable life-boats, life-lines, breechesbuoys, guns for throwing lines across stranded ships, life-belts and life-preservers, and countless other appliances and apparatus for saving the sailors and passengers on any vessels that may be wrecked in the vicinity. Nearly every one of these stations, lighthouses, lightships and similar places is provided with wireless apparatus, signal-flags and weather and storm signals, and by means of these they can communicate with passing ships, warn them of approaching storms and in many other ways aid in safeguarding both vessels and lives.

Aboard the ships there are still other safeguards and life-boats and rafts, life-preservers, 
life-belts, fire-hose and pumps are ever on hand to prevent loss of life, ship or cargo by any of the numerous dangers of the sea. All of these things are very important and were they always kept ready and in good order comparatively few lives would be lost. But unfortunately familiarity with the sea often breeds contempt and men who have sailed for years and years without loss or accident frequently become careless and allow their lifesaving appliances to become useless through rust, decay or lack of care and inspection. On well-regulated ships the boat and fire drills are a regular part of the routine. As in many cases the men never know when the gongs and whistle will sound the call to boats and pumps and never can tell whether it is a real alarm or merely a practice drill, they become very expert in quickly manning and launching the boats and getting the hose at work and there is little excitement or disorder.

Still in spite of all these safeguards on shore and sea, and even aboard the ships themselves, there are numbers of vessels wrecked 
98

\section{THE OCEAN}

and destroyed and many lives sacrificed, for it is impossible to guard against every danger or to foresee all that may occur, but if we study the statistics we shall find, that compared with the immense number of human beings who yearly sail forth in ships, an insignificant number are lost and that a sea voyage is one of the safest means of travel known. 


\section{ChAPTER VI}

\section{LIFE IN THE GREAT DEPTHS}

I HAVE said that the majority of the inhabitants of the deep sea have never been seen by man, but nevertheless we have seen thousands of the denizens of the ocean bed and know that in this strange world dwell some of the weirdest and most remarkable creatures that can be imagined.

Only within very recent times has anything been known of the mysteries of the deep sea and a few years ago any one who described or figured such marvellous creatures as are now known to exist would have been dubbed a "nature faker" of the most outrageous sort.

t We owe our knowledge of the deep sea and its inhabitants principally to the United States Fish Commission in this country and to various European expeditions abroad, although numerous wealthy individuals, - notably the late Alexander Agassiz and the Prince of 
Monaco,-have spent fortunes in fitting out scientific expeditions to add to our knowledge of this strange submarine world.

For many years the United States Fish Commission carried on a systematic work, exploring the bottom of the North Atlantic, under the direction of the late Prof. Spencer F. Baird and Prof. Addison E. Verrill and the various reports of these and other naturalists are as wonderful as any fairy tale, although told in the dry and matter-of-fact way of practical scientists.

$x$ The earliest work of the Fish Commission was carried on under the greatest difficulties and small, obsolete, naval vessels or tugs and makeshift apparatus were employed. Even under such conditions the results of the deepsea work were so remarkable that very soon special vessels were designed and built for the purpose, apparatus was invented and made for the work and laboratories were constructed with every facility and convenience for carrying on investigations of the ocean and its life.

The principal apparatus used in exploring the deep seas are trawls and dredges. The 


\section{LIFE IN THE GREAT DEPTHS IOI}

former are merely large, strong nets attached to a stout, iron frame formed like runners (Fig. I) and which are dragged slowly along at the bottom of the sea. The dredges used
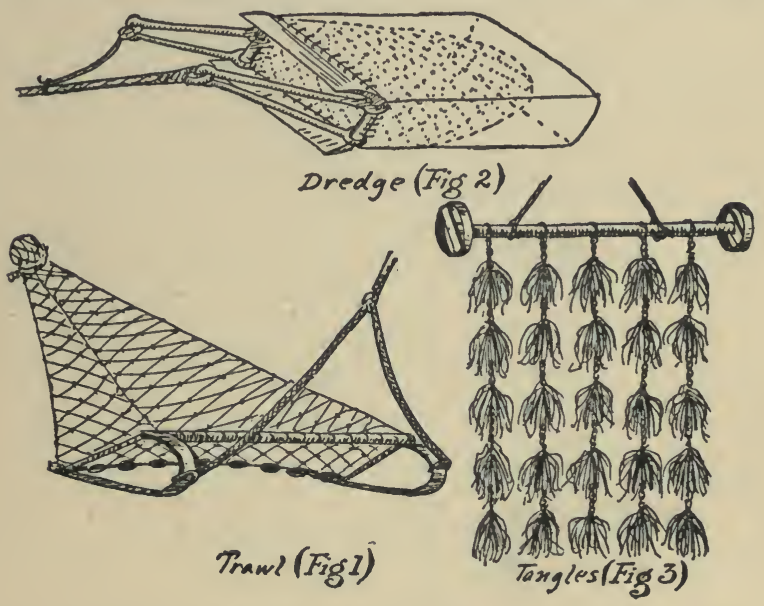

INSTRUMENTS FOR COLLECTING DEEP SEA IIFE

are fine-meshed nets, or bags, of stout twine attached to a steel or iron frame with flaring scrapers and protected by a bottomless bag of stout canvas (Fig. 2). Although both the dredge and the trawl are used by dragging them along the bottom of the sea, yet each has its special purpose and is employed under 
different conditions. While the dredge may be used on almost any kind of bottom and scoops up the mud, sand and any slow-moving creatures which are in its track, the trawl is used only on comparatively smooth bottoms and does not scrape up the mud, but merely catches living creatures, plants and other forms of life with which it comes in contact.

In addition to the trawl and dredge another very useful piece of apparatus is used which is known as the "Tangles" (Fig. 3). This is simply an iron bar with rollers or runners on the ends, and to it are attached a number of chains covered with masses of unravelled rope. When the tangles are drawn over the bottom the strands of rope become entangled in the spines, branches or legs of various creatures and hold them fast and by this simple method vast numbers of strange forms of life are obtained which would escape both the trawl and dredge.

While these three instruments bring up incredible numbers of deep-sea denizens, yet the spots which they actually touch and the locali- 


\section{LIFE IN THE GREAT DEPTHS IO3}

ties over which they are dragged, are infinitesimal as compared to the whole vast bed of the sea, and the very fact that they do catch such numbers of creatures proves how thickly populated the depths of the ocean must be and how the bed of the sea must fairly swarm with animal life.

Moreover, a great many of the more active creatures are able to escape the slowly-moving dredge or trawl, while still others are far too large and bulky either to be enmeshed in a trawl or captured in a dredge. It is therefore highly probable that the animals we obtain by these methods are no more representative of all the denizens of the deep than land animals captured in a similar way would be typical of all the living creatures which inhabit the earth.

The great bulk of animals obtained from the deep sea are small, sluggish and belong to the lowest forms of animal life. Among them are starfishes, sea urchins, sponges, corals, gorgonias, shells and molluscs, crustaceans, worms, hydroids, bryozoans, sea-anemones and similar creatures, but many of them so unlike 


\section{IO4}

\section{THE OCEAN}

their representatives in shoal water, so marvellously coloured, so gigantic in size or so remarkable in form that they are scarcely recognisable. In addition to these lower animals are a great many squids, and octopi, and numbers of fish, and among these occur the strangest and weirdest of forms.

I I have already mentioned the enormous pressures which obtain at great depths as well as the stygian darkness and intense cold and nearly every living creature drawn from its natural home on the ocean's bed is specially formed and peculiarly adapted to life under such conditions. Many of them are so flabby, pulpy and jelly-like that they almost drop to pieces when they reach the surface, although in their natural homes the very flabbiness of their tissues enables them to withstand the great pressure of the water which is equal in all directions,- - both outside and within their bodies.

At first thought it seems strange to think of any creature existing under the enormous pressure of several thousand fathoms of water, but we must remember that water is practic- 


\section{LIFE IN THE GREAT DEPTHS IO5}

ally non-compressible and that animals whose tissues are filled with water do not suffer owing to the pressure being equal on all sides, whereas, if their tissues contained air, they would be squeezed to a fraction of their original size. A rise of an inch in the barometer piles half a ton or so upon our own bodies and yet we suffer no inconvenience as the pressure is equal on all sides. So the deep-sea creatures can exist through large variations in water pressure and many species are found at depths of from six to two thousand fathoms.

When drawn to the surface, however, these deep-sea creatures fairly burst with the release of the pressure under which they have lived. The eyes are forced from their sockets, the scales and skin fall off, the swimming bladders of fishes are forced from their mouths and oftentimes the specimens are scarcely more than detached fragments by the time they can be preserved.

- The sole occupation of these deep-sea creatures is to eat, breed and escape their natural enemies and with many species eating appears to be of more importance than anything else. 
Some of the deep-sea fishes have such huge mouths that they are really nothing more than living funnels, while the enormous teeth of others give the owners a horribly ferocious and savage appearance. Some of these fishes are shown in the drawing on the page opposite (Figs. I-5).

Others have great membranous stomachs which are as flexible as rubber and specimens have often been captured which had swallowed other fishes far larger than themselves, the unfortunate victims still being enclosed in the elastic stomachs of their captors when the latter were dumped out of the trawl upon the steamer's deck. One of these fishes is popularly known as the "Black Swallower" (Fig. 4).

- Many of the deep-sea fishes are blind, but provided sometimes with slender feelers or filaments which enable them to locate their prey and other objects without the aid of sight. Others have enormous eyes which at first seem out of place and useless in their environment of perpetual darkness. But when we study them closely we find that these huge eyes no 


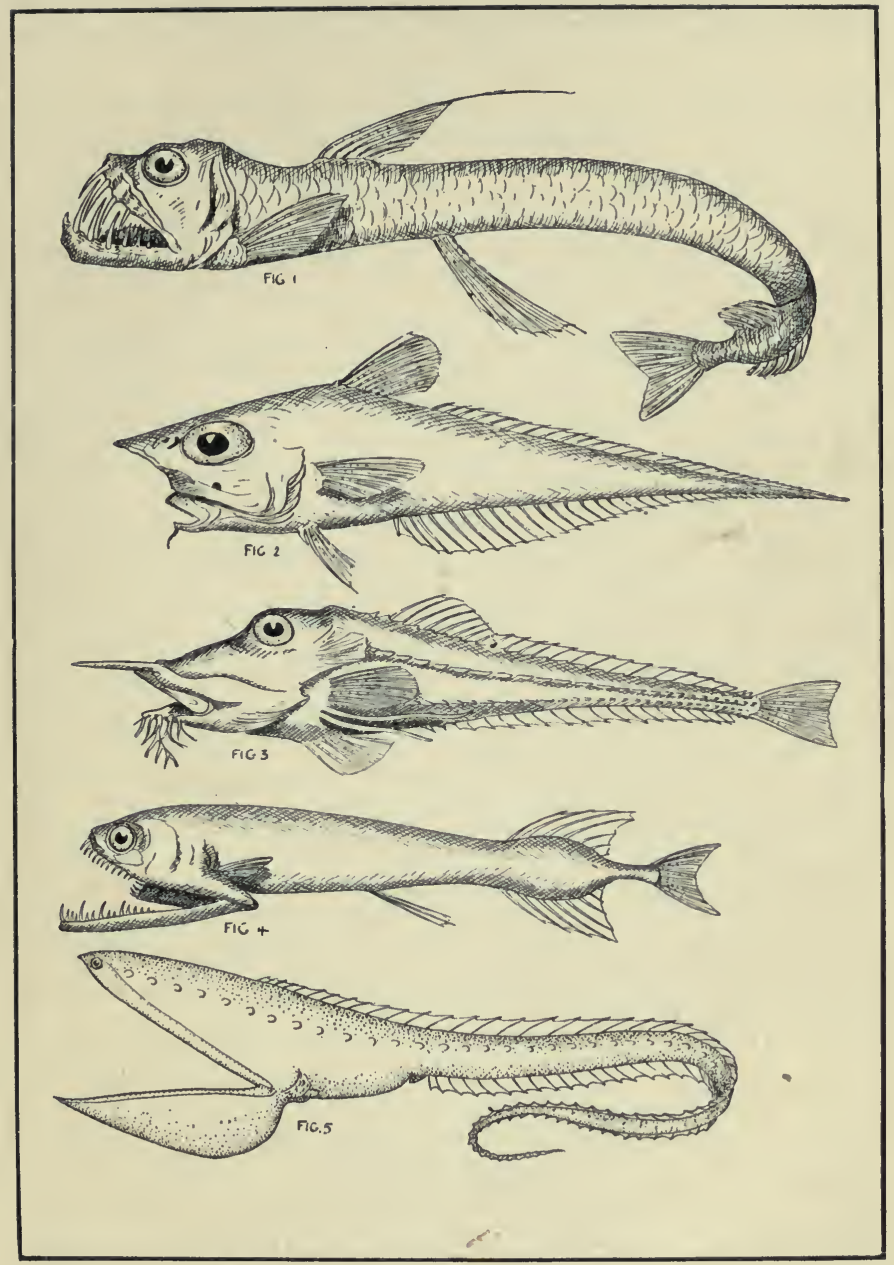

WEIRD FISH FROM THE OCEAN DEPTHS 

doubt prove very useful, for while the sea itself is never penetrated by the light of day yet innumerable species of the creatures which inhabit it carry their own light about with them.

$\Varangle$ Nearly all the lower forms of life, and many of the fishes, which inhabit the deep-sea are furnished with phosphorescent, light-producing organs. Some are provided with regular search lights, others have rows of small lights along their sides, others have luminous fins or light-giving organs on the head, while some have long, movable appendages bearing brilliant lights at their extremities. These strange creatures not only illuminate their own way with these natural lamps as they swim about, but no doubt locate and dazzle their prey as well, or attract other creatures within their reach, just as a lamp or candle attracts moths.

For all we know the natural impenetrable blackness of the depths of the sea may be brilliantly lit up by its countless myriads of phosphorescent inhabitants. Even the tiniest microscopic creatures are phosphorescent and 
we all know how brilliant are the lambent, phosphorescent waves which we sometimes see at the surface on dark, warm, summer nights. Knowing what wonderfully grotesque and "impossible" creatures actually inhabit the deep-sea and realising how little chance we have of capturing the larger and more active forms of life at great depths, it is impossible to say what may and what may not exist in that vast, unknown world.

There, far out of sight and safe from molestation or capture, there may be gigantic and terrible creatures which have survived since far-distant prehistoric times. For all we know, great marine reptiles may still dwell in the caverns and crevices of submarine mountains thousands of fathoms beneath the surface of the sea. Of course such creatures, if they do exist, must be very different from any living or fossil creatures with which we are familiar. Through the countless ages since animal life first appeared upon the earth there has been plenty of time for nature to adapt almost any form of life to an existence at the bottom of the sea, and at almost every haul 
LIFE IN THE GREAT DEPTHS IO9 of a dredge or trawl from the depths of the ocean strange creatures are obtained whose anatomy, forms and characteristics upset all our preconceived ideas of nature's laws in respect to animal life.

Moreover, we know very little about the real life of prehistoric creatures. We find their skeletons preserved in rocks, sand and clay in the form of fossils, but in all probability only a very small proportion of the creatures of those far-off times have been preserved in this way and every year new and more remarkable fossils are discovered.

At one time we know the sea covered nearly the entire globe and countless thousands of strange animals swarmed in the vast waste of waters. Here and there, as the sea receded, these creatures were left stranded or were trapped within lagoons, bays and inlets and their bones were left to be found by us as fossils.

The great majority of the marine creatures of those past times no doubt escaped the fate of their fellows and continued to dwell safely in the sea as the oceans became smaller 
and smaller and the land took form and increased in area.

We know, for instance, that in prehistoric times gigantic sharks swarmed in the sea, sharks which were many times larger than the largest of modern man-eaters, for in Florida, Carolina and many other places, as well as upon the bottom of the sea, their teeth are found by bushels, - teeth acute as needles, with sharp, saw-like edges and six inches or more in length and breadth. In other places we find thousands of vertebræ of huge porpoise-like animals, which bore no resemblance to our graceful, playful "sea-pigs" of to-day, for the ancient creatures were long, slender, snake-like and of gigantic size. In still other places we find the remains of wonderful swimming-reptiles; some long and slender and fish-like in form with jaws like crocodiles; others with great clumsy bodies and elongated snake-like necks and heads, while still others were eel-like in form and were veritable seaserpents.

+ Many people, among them prominent scientists, believe that a few survivors of some of 


\section{LIFE IN THE GREAT DEPTHS III}

these strange prehistoric creatures still exist in the depths of the sea and that an occasional individual, disabled, sick or injured comes to the surface and is seen by man and reported as a "sea-serpent."

$\checkmark$ To most people the idea of the "sea-serpent" really existing may seem preposterous and foolish, for the sea-serpent is so often reported and so many people have claimed to have seen it that we have come to consider it as a myth and think the stories about it pure "yarns." The very fact that so many people claim to have seen the sea-serpent and that a great many of these individuals are men of little or no imagination and of unquestionable veracity, goes far towards convincing scientists that there must be some foundation for the stories. Moreover, the most trustworthy of alleged observers of sea-serpents do not agree in their descriptions of the monsters and this leads many well-informed naturalists to the firm conviction that not one, but many, sea-serpents really live in the ocean. In fact we actually know that sea-serpents $d o$ exist and while none of those known to science would answer the de- 


\section{THE OCEAN}

scriptions of those which mariners and others claim to have seen, yet unusually large specimens of their kind might easily be called veritable sea-serpents.

The strange "Ribbon-Fish" is one such species. It is supposed to be an inhabitant of great depths and only to appear on the surface when sick, or injured, but in reality nothing definite is known of its habits or natural home, as all the specimens hitherto taken have been found floating upon the sea or washed ashore. One individual, nearly twenty feet in length, dashed itself upon a beach in Bermuda and was seen swimming through the water by several people who stated that it propelled itself by loops or convolutions, exactly as the sea-serpent is described as swimming by those who have said they saw this sea-monster. Other ribbon-fish have been taken which were over twenty feet in length, and there is no real reason why this fish should not occasionally grow to a size of seventy-five or one hundred feet. If the ribbon-fish does reach such a size there is little doubt that it is the real, or one of the real, sea-serpents. The long filaments near the 


\section{LIFE IN THE GREAT DEPTHS Ir3}

head, the high, serrated dorsal-fin and the snake-like body are perfectly in accord with the majority of descriptions of sea-serpents as given by the most trustworthy observers. The so-called "mane" is well represented in the fleshy, ornamental appendages about the head of the fish and the "saw-like crest" of the seaserpent has its counterpart in the stiff spines and web of the fin along the back of the fish.

In the Indian Ocean and other parts of the world long, eel-like sharks occur, while in other portions of the sea true snakes, which are very venomous, are found in immense numbers. These snakes are small, it is true, but if we can imagine that related creatures reach large size we can readily believe that they might well be called sea-serpents.

The belief in sea-serpents is very ancient and it may be within the bounds of possibility that early man was familiar with huge seareptiles which have since become extinct or nearly so. Virgil's story of Laocoön and his sons being strangled by sea-snakes is a familiar example of the world-wide belief in such creatures, but it was not until 1755 that any ex- 
tended scientific account of such sea-monsters was printed. This account was written by Pontoppidan in his "Natural History of Norway," an English edition of which was printed in London. The author was a clergyman and bishop and evidently took great care to investigate the authenticity of the accounts he had heard. In fact he himself doubted the existence of a sea-serpent until so much affirmative evidence was produced that he was convinced that such creatures existed, and he called sceptics "enemies of credulity," and in his book he quotes many sworn statements of persons who had seen the monster.

Pontoppidan claimed that the sea-serpent sheds its skin like true snakes and stated that a cast-off skin was found at Kopperwiig and used as a table cover. He also mentions the fact that the sea-snake laid a week in a creek in the vicinity and left the old skin behind. In 1742 Hans Egede published a "Natural History of Greenland" in which he tells of a marvellous sea-monster which was observed in Davis Strait. He states that "it was such an exceedingly large animal that when it raised 


\section{LIFE IN THE GREAT DEPTHS II5}

itself out of water its head reached as high as a mast and the body was throughout as thick as a ship, compared with which it was three or four times as long." It had a long, pointed muzzle and spouted like a whale. On the front part of its body were two great, broad feet or fins and the uneven skin appeared armed with scales. Otherwise it had the form of a snake, especially in regard to its posterior part, and when it went under the water it threw itself backwards and stuck its tail out of the water at a height equal to a ship's length.

This same creature, or one like it, was the serpent figured by Pontoppidan and it is probable that the worthy bishop merely copied the picture in Egede's book. Owing to the various accounts he investigated, Pontoppidan decided, as have modern investigators, that there were various species of sea-serpents. In fact if we believe in the existence of such monsters at all we must be convinced that there are a number of strange creatures which are popularly called sea-serpents. 'Aside from the variation in size, which is of practically 
no importance, sea-serpents of various colours have been reported; some had shaggy manes, others long, bare necks, some had back fins, some were smooth and slimy, others rough and scaly, and one at least resembled a huge turtle with an enormously-attenuated snake-like neck. In nearly every case, however, the observers state that the monsters move with their heads projecting from the sea, but while some declare that the serpents "glide," others say that they progress by "loops," or "convolutions," by which "they draw themselves through the water."

Of course a great many of the accounts may have been based on inanimate objects and a vivid imagination, and in two instances at least, this is known to have been the case.

The captains of the ships Brazil and Pekin both reported that they met what they supposed was a terrible sea-monster and in each case they launched boats to attack the creature with harpoons and guns, only to discover that the supposed sea-serpent was merely a huge mass of seaweed, torn from its ocean bed 
and floating with its huge roots projecting from the water, thus giving the appearance of a snake-like head and a neck covered with a huge, saw-like crest.

To scoff at any tale of things with which we are unfamiliar or to set down as lies or imagination stories of sea-serpents, merely because we have not actually proved their existence, is very foolish.

For centuries the old Norse stories of the "Kraken" were considered as fabulous as the tales of the Phœnix, Centaur or other similar beings, but we now know that the "Kraken" stories were founded on facts and that the old Norsemen had good reason to tell their tales of the strange sea-monsters. It was accident that first proved the existence of the "Kraken" when, after a heavy storm, a gigantic sea-monster was washed upon the shores of Newfoundland. Descriptions of this creature and portions of its anatomy were sent to Prof. A'. E. Verrill at Yale, who at once realised that the strange monster was a gigantic squid or cuttlefish. Later, others were cast upon the shores or captured in a disabled or sick con- 
dition at sea, and within a few years several species of these hitherto unknown monsters were described. Although in form and appearance much like the common little squid of our sea coasts, these huge fellows were equipped with arms and tentacles thirty feet or more in length and had great bodies nine or ten feet long and seven to ten feet in circumference.

Once known to science the giant squids were studied and to-day we know that they inhabit portions of the deep sea and seldom come to the surface save by accident, and, moreover, we have discovered that these remarkable creatures, which for many centuries were considered as fabulous, form the great bulk of the food of sperm whales. If such enormous animals could exist unknown for many years and if species so closely related to the little puny squids of our coasts could so greatly exceed them in size, there is no valid reason for not believing that almost any other form of marine life may have unknown relatives of gigantic size.

Only a few years ago a strange object was 


\section{LIFE IN THE GREAT DEPTHS II9}

washed upon our Florida coast and, as in the case of the wonderful giant squids, photographs of this new "sea monster" and pieces of its substance were sent to Prof. Verrill. At first it seemed as if this would prove another unknown and gigantic cuttlefish, but upon examination it turned out to be a portion of some very different creature. Although some twenty feet in length and forty feet in circumference and weighing many tons, yet this great mass of tough, fibrous flesh was a mere fragment of some titanic marine monster and in its structure and shape so different from any known form of animal that no scientist could even guess at its origin and it has gone down to posterity as one of the mysteries of the sea. At any time, however, the world may be surprised and naturalists may be made happy by the discovery of the real sea-serpent, for the ways of the sea are strange and its mysteries are past our understanding. A subterranean convulsion, such as an earthquake or a submarine volcanic eruption, may injure or kill vast numbers of the inhabitants of the ocean's depths and floating upwards these 


\section{THE OCEAN}

creatures may throw a great deal of new light upon the hitherto unsolved mysteries of deepsea life.

Such things have happened in the past and may happen again at any time. Many years ago the naturalists of the Fish Commission discovered a new species of fish which was called the "Tile Fish." This fish was excellent eating and in a short time the deep-sea fishermen caught quantities of them and sold them in the markets. Suddenly the surface of the ocean was found strewn with dead and dying tile-fish which had been injured or killed by some unknown agency, and the once abundant fishes disappeared entirely from their former haunts.

No doubt some tremendous submarine earthquake or other cataclysm produced this sudden strange annihilation of the tile-fish and it may have been something of the same sort which destroyed the giant squids and thus gave them to our scientists.* Should a similar disaster occur at the right time and in the

* The tile fishes have again appeared in their old haunts (I915) and are now being brought to the New York markets for sale. 


\section{LIFE IN THE GREAT DEPTHS I2I}

right place still more wonderful creatures may rise from the depths of the ocean to the surface, and the sea "giving up its dead" may yet prove to all that the sea-serpent is not a myth but an actuality as real as the Kraken. 


\section{Chapter VII}

\section{LIFE AT AND NEAR THE SURFACE}

STRANGE and interesting as is the life in the great depths of the sea the creatures which dwell in the water itself, and on the bottom at moderate depths, are fully as interesting. Within the ocean there is not one, but many worlds of life and while the denizens of one of these submarine worlds may sometimes travel to another, or may be common to several, yet, on the whole, each individual species lives and dies under certain conditions and in a certain depth of water. Near the shores and between high and low water mark is one world of marine life; in shallow water, but never left bare by the tides, is a second world; at a greater depth is still another and so in deeper and deeper water other worlds occur until the very deepest waters of the seas are reached.

In addition to these various zones of life, 
LIFE AT AND NEAR SURFACE I23

containing the creatures that live upon the bottom of the sea, there are similar zones in the water itself and each is inhabited by certain forms of life that wander but little above or below the depth to which nature has adapted them. At the very surface of the sea there live and thrive vast numbers of animals which never descend to the bottom, even in shallow water. Many of the creatures which are found at some certain depth live in other stages of their existence in entirely different parts of the sea. The young of many shells, crustaceans and other marine animals swim freely about at the surface and only descend to the bottom when they attain a definite stage in their growth, while others live, during their youth, upon the bottom and in afterlife rise to the surface of the sea and never again descend to their birthplace.

For this reason scientists are often greatly puzzled and many years have been devoted to studying what was considered a new form of marine life, only to discover eventually that it was but one stage of some well-known creature whose life-history had been hitherto un- 
known. A number of these early forms of marine animals are shown in the illustration on the opposite page.

'A person unacquainted with these mysteries of ocean life would never connect a tiny, lively, rapidly-swimming creature, such as shown in Fig. 3, with the prosaic, immovable oyster, and yet this odd being is merely an oyster in its childhood, so to speak. So also the baby starfishes swim gaily about in their youth and appear as in Fig. 4, and the youngsters of many other shellfish travel hither and thither upon the surface of the sea in early life. Perhaps the strangest of all such creatures are the barnacles, for the shell-clad barnacles, which we find attached to rocks and other submerged objects, are in reality true crustaceans like crabs and lobsters, and in their young stages swim about readily and appear as in Fig. 9. Even young corals swim about and in many cases baby crabs and the young of other free-moving or swimming animals bear no resemblance to their parents.

'Although science has established the identity of many of these odd creatures and has 


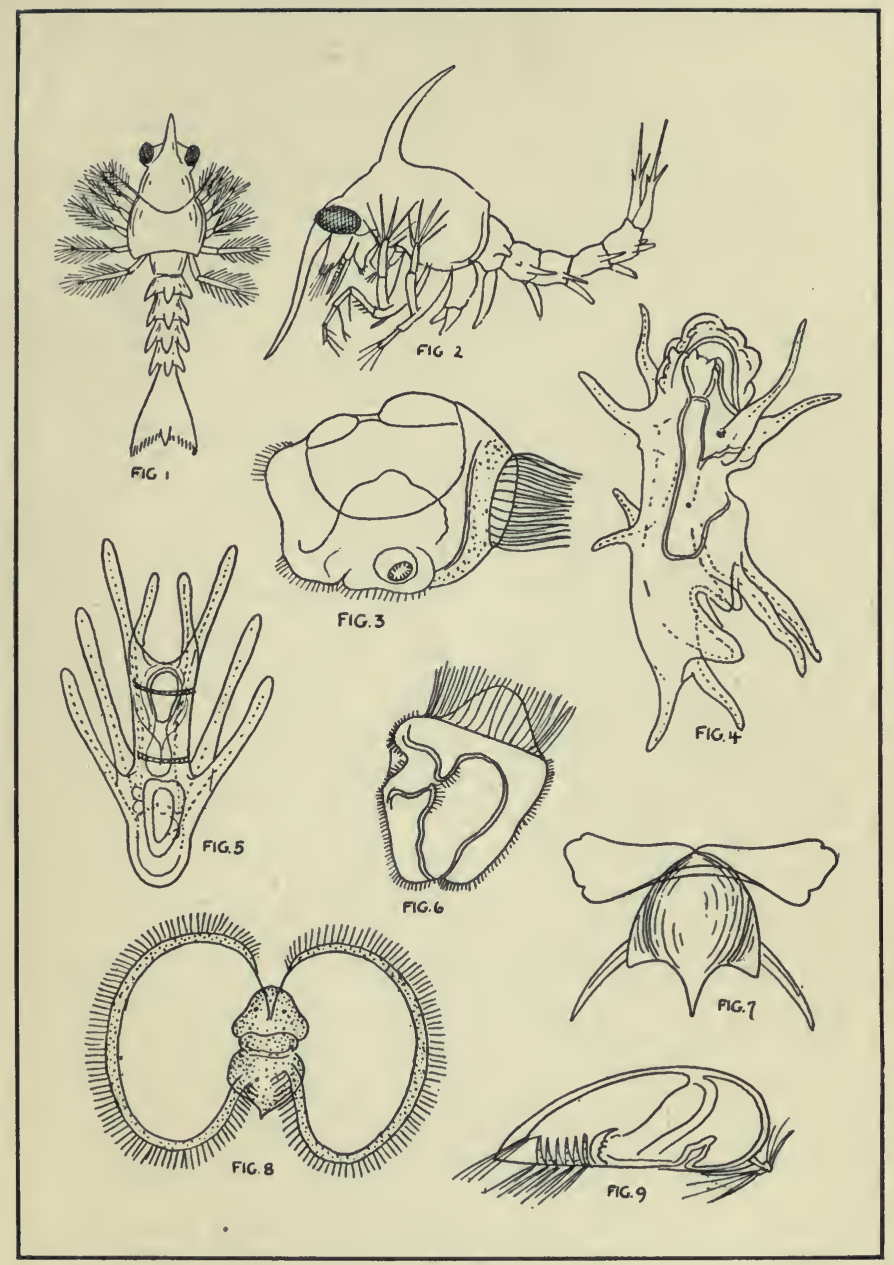

FORMS OF SURFACE LIFE

I. Young Lobster 2. Young crab

4. Young starfish

7. A Pteropod or swimming shell

9. Young barnacle
3. Young oyster

6. Young worm

8. Young sea snail 



\section{LIFE AT 'AND NEAR SURFACE I25}

carefully traced their life-histories, yet countless other creatures are known only from a few specimens, or in one stage of their existence, and their lives and habits still remain mysteries of the sea.

If you look upon the surface of the ocean, as you travel over it in a boat, it may appear barren of life and the only objects you see may be bits of floating sea-weed, odds and ends of trash and rubbish. But drag a finemeshed net behind the boat and empty it into a basin of clear sea water and you will be amazed at the myriads of strange animals that have been obtained from the apparently lifeless surface.

Most of these creatures are very small and thousands of them will escape your observation entirely, as they are perfectly transparent and of almost microscopic size, but if you wait until dark and agitate the water they will make their presence known by bright flashes of phosphorescence. A large proportion of these very minute creatures are the young or larval forms of larger marine animals, but in addition there are inconceivable numbers of 
tiny animals known as diatoms and foraminifera.

Although extremely small these creatures are marvellously beautiful in form and their fragile, calcareous shells or skeletons are far prettier and more regular than any sea-shell. The variety of shapes is almost endless and yet every species has a form peculiar to itself and may be easily recognised. These little animals may seem of little account and beneath your notice, but in reality they are of immense importance and without them the great, teeming oceans would be barren, lifeless wastes. All over the ocean and at nearly all depths these minute creatures swarm and as in a few gallons of water there may be millions of them, you can realise what inconceivably tremendous hordes must be scattered through the seas.

These tiny things are constantly being devoured by larger marine animals and upon the larger creatures still larger animals feed, so you see that really a great deal of marine life depends upon these almost microscopic creatures. 


\section{LIFE AT AND NEAR SURFACE}

127

Moreover, they are constantly dying and their skeletons are ever sinking slowly to the bottom of the sea and for some $50^{\circ}$ north and south of the equator and at depths up to two thousand four hundred fathoms, the bed of the ocean is largely composed of their shells. This formation is known as "Globigerina Ooze" or "Foraminiferous Ooze," and in many places it forms a large part of the so-called "sand-banks" which block harbours and channels.

This ooze would be just as thick throughout the entire bed of the ocean were it not for the fact that at great depths the tiny calcareous shells are dissolved. All the dead and decaying animal matter also sinks slowly down in the sea, but in the dark, cold water it decomposes very gradually and in many places it forms a thin, slimy layer of a gelatinous substance which for many years puzzled scientists. At first it was thought to be a special organism, created for the sole purpose of providing food for deep-sea life, but it is now known to be nothing more nor less than de- 
caying material from countless millions of dead inhabitants of the sea.

Of course the skeletons and shells of all the marine creatures which die sink to the bottom of the ocean, but the tiny diatoms and foraminifera so greatly outnumber all other forms of ocean life that their remains are the most in evidence in most places. So marvellously abundant are these minute creatures that a single ounce of sand sometimes contains over three millions of their shells. In prehistoric times the ancestors of these foraminifera were even more numerous and their fossilised skeletons have formed the bulk of the chalk cliffs of England, the building stone of Paris and even the mighty blocks from which the Egyptian pyramids were constructed.

All this is very interesting when we give it a thought, and it all goes to prove what a wonderful thing the ocean and its life really is, but to study ocean life at its best we must look to the fairly shallow water on the great submerged plateaus, the submarine mountaintops and reefs and near the coasts of continents and islands. In such places the sea sustains 
a wonderful amount of life which forms a world, marvellous in the variety of its denizens and as fascinating as fairy-land.

In shallow water the sunlight penetrates for considerable depths, the water is not under enormous pressure and the temperature varies with the distance north or south of the equator. Hence, in moderately shallow water many forms of life thrive which would find existence impossible in the great depths, and in various parts of the world different animals occur which are peculiar to their particular localities and cannot exist in waters of other depths or temperatures.

Beneath the water is a fierce, never-ceasing struggle for existence between the various animals and nearly every marine animal feeds upon some others, so that in the shallow waters, where life is most varied and abundant, we find the greatest opportunity to learn of the lives and habits of marine creatures. Here, too, fish find the most food and in places, such as George's Banks, the Grand Banks and the coral reefs of tropical seas, fishermen find the best ground for their labours. 
Oftentimes the strong lines and sharp hooks of these fishermen become entangled in the strange animal growths at the bottom of the sea or odd and remarkable creatures are captured accidentally. Such unusual specimens, brought home by the fishermen, and many of them have never been obtained in any other way, have been of incalculable value in learning what we know of ocean life.

Not only have the inhabitants of the ocean taught us a great deal about the sea and its life, but in addition they have been of the utmost importance in helping us to solve many mysteries of life and of the laws of nature which have a great bearing on the whole animal kingdom. Here, in the teeming sea, the weak invariably succumbs to the strong, unless provided with some means of protection which enables it to escape destruction by its enemies. As a result of this, many of the inhabitants of the sea exhibit marvellous and peculiar forms, colours, or habits which at first sight appear without significance or reason, but which are really of the most vital importance to the creatures themselves and 
have aided naturalists in discovering some of the greatest truths in regard to nature.

If you have examined the surface animals you cannot have helped noticing that the largest proportion of them are nearly or quite transparent and that only the eyes, some of the internal organs, etc., can be distinguished as they swim rapidly about in clear water. Even fairly good-sized fish may sometimes be found which are perfectly transparent and only their eyes and the contents of their stomachs are visible. Some of these are slender and eel-like and others are flat and look like queer little flatfish or flounders. The eel-like creatures are the young of the big Conger eels and for many years were considered a different creature. You will have to laugh if you catch some of these funny, transparent surface fishes, for they can see straight through their own heads and, as they swim about, they seem to wink at you with the eye on the opposite side.

While you may be greatly interested and amused at these ghostlike fishes the fact that they are so transparent may not appear of any 
great importance, but in reality it is a most wise provision of nature and prevents the wholesale destruction of these little creatures, many of which are the young forms of animals that in later life are very valuable to man. If these surface creatures were opaque, or brightly-coloured, they would easily be seen by fishes and other hungry animals swimming below the surface and would be plainly visible to sea-birds hovering above the waves. Their transparency, however, protects them from these numerous enemies until, in later life, they assume other forms, colours and habits and are better able to look after their own safety.

Even as it is vast numbers are devoured and only a very small percentage ever reach full size. In the same way, if we study the creatures in shallow water, or even at great depths, we will find, when once we know their habits, that their strange forms and peculiar colours serve equally useful purposes. The brilliantly-tinted and conspicuous things are usually poisonous or possess stings and thus warn other creatures of the danger of attacking 
them. Some of the forms so closely resemble bits of rock, seaweed or other objects that we cannot distinguish them until they move about, and other creatures, which are not provided with natural means of protection, have learned to conceal themselves by planting various bits of seaweed and other growths upon their own shells or skins. More wonderful than all we will find that many soft, helpless animals have become lifelong companions of dangerous, poisonous creatures for the sake of the protection their strange friends afford, thus forming veritable submarine partnerships.

I have said that many marine animals cannot live away from their normal homes on account of the difference in temperature of the water, but there are times when certain creatures may wander far from their ordinary haunts and may live and thrive for a long time thousands of miles from where they usually occur. For example, the water of the Gulf Stream is much warmer than the surrounding ocean, even as far north as New England, and during the summer months many strange tropical marine creatures are carried north by 


\section{THE OCEAN}

this great ocean river and are washed upon our shores or captured by fishermen. No doubt it was in some such manner that many marine animals have been scattered far and wide and are found in various parts of the ocean, and one of the greatest problems that oceanographers and scientists have had to solve is how and why some marine creatures are found in widely separated parts of the sea while closely related species are confined to a single locality.

In shallow water the appearance of the ocean's bed must be very different from that at great depths, for in the warmer waters and where more or less sunlight filters through from the surface, the bottom of the sea is covered with a perfect forest of strange growths; a veritable jungle of remarkable animal and vegetable life.

Just as the greatest abundance of terrestrial animal-life is found in the tropical lands, so in tropical seas we find the greatest number and forms of marine life, and just as the vegetation of tropical countries is ranker, more luxuriant and more brilliant than the forest 
LIFE AT AND NEAR SURFACE 135 growths of the north, so the marine growth of the warm, equatorial seas is more luxuriant, more varied and ranker than submarine growth in northern seas. This only applies to the shallower waters, however, for at great depths the water is always cold and many of the same animals occur in both tropical and northern seas.

We naturally always associate corals with the tropical seas, for the greater number of corals are natives of warm waters and, moreover, the majority of tropical corals can live only within a hundred feet or so of the surface; but even in the far north corals occur abundantly in deep water. Some are found as far north as Greenland, and one species, which is common in northern seas, is found at low-water mark on the New England coast. So, too, sponges, which we always associate with the tropics, are not confined to tropical seas but great numbers occur in the waters of the polar regions and in all seas between the tropics and the arctic and antarctic circles. Many of the more noteworthy and largest forms of these northern sponges are found 
only in deep water, as in the case of corals, but like the corals other sponges occur along our shores at low-water mark.

Many other very interesting forms of marine life which in the tropics are found only in deep water, may be discovered along the shore in shallow water in the north, for the limits of the various zones of under-sea life are greatly influenced by the temperature of the water. No doubt, if we could descend to the moderate depths of the ocean in the north we should find the bottom covered with a dense forest of seaweeds, sponges, gorgonias, corals and other marine life, for we know, from the great numbers of specimens that are sometimes drawn up in a single haul of a trawl or dredge, that in places the bottom must be covered by such a living jungle. The only trouble is that in northern waters such places are in rather deep water and are far beyond the reach of human eyes. In the tropics, on the other hand, the ocean bed teems with multitudes of forms of animal and vegetable life within a few feet of the surface, or even between high and low-water mark, and more- 
over the water is so clear and transparent that man can look upon this marvellous marine world beneath the surface of the sea.

Even more remarkable still, the bottom of the sea in the tropics has been actually photographed and one may sit in a northern theatre and see moving pictures of the bed of the tropical sea th. Jwn upon the screen. These wonderful pictures, taken by the Williamson Brothers with apparatus which they invented and made for the purpose, show the marvellous abundance and variety of submarine life to the very greatest advantage. But even these pictures fall far short of giving us an adequate idea of the jungles of growths and the forests of corals which cover the bed of tropical seas in many places. Divers who have descended in certain localities report corals as large as forest trees; great, massive growths with trunks several feet in diameter and with broad spreading limbs interlacing on every side and forming a roof of tangled, impenetrable branches very similar to a forest on land.

In addition to these lofty, branching, treelike forms there are great, rounded, dome- 
shaped masses of brain-corals, of ten many feet in diameter and height, while innumerable other forms grow upon ledges, rocks and from the bottom on every hand. As corals, when living, are of every imaginable tint and shade of colour we can imagine what a strange, wonderful, brightly-coloured world such a place would be. Think of great living trees of fawn, purple, pink and red; of huge, brilliant-orange domes scattered on every side; of growths of lavender, scarlet, emerald and blue clinging to rocks and cliffs; of waving seafans of golden-yellow; of immense masses of inky-black sea-rods springing like bunches of grass or reeds from among the more brightlycoloured surroundings, and you will have some idea of the appearance of these marvellous jungles of marine life. In place of birds and butterflies, gaudy red, blue, purple, green and gold fishes dart hither and thither among the branches of coral; great octopi lurk in crevices of the rocks and caves and giant scarlet crabs scuttle over the bottom of the sea to hide themselves from sight among clumps of purple and lavender weeds. 
In many places these coral trees and the more massive rocky corals grow upwards until they reach the surface of the sea, and in numerous parts of the West Indies and in other warm latitudes one may actually walk about among these wonderful growths at low water.

When the corals thus reach the surface, or to within a short distance of it, they form the so-called coral-reefs and in many places they are a.great menace to ships. The largest of all coral-reefs is the Great Barrier Reef off the western coast of Australia where, for hundreds of miles, the corals grow by countless millions and are exposed at low water, forming a veritable wonderland for any one interested in marine life.

Although such reefs are dangerous to mariners, yet they are very useful as well, for they break the force of the sea and waves and protect the shores and in many places ships find safe anchorages from storms in the shelter of coral-reefs. In this way one of the greatest dangers of the sea may be utilised for man's advantage and protection.

Where these coral reefs are exposed to the 
force of the waves they are constantly being broken off at the surface and the bits of coral, lodging among the living growths and piling up on the bottom, gradually form a solid mass. About the sides of this the living corals continue to grow and spread and in time a little islet appears above the breaking waves. Slowly but surely the little spot of coral increases in size, bits of floating weed and wood are added to it, seeds and nuts find lodgment in the crevices, vegetable life appears and eventually the once-submerged reef becomes a true coral-island with nodding palms and rich green vegetation covering its surface. Sometimes the corals may grow in more or less circular form with deep water in the centre and the islets formed retain this circular shape and are known as "atolls."

But the circular form of most atolls is due to the corals growing about the rims of submerged volcanic craters. Other atolls, known as "Serpuline Atolls," are produced in quite a different manner. These seldom are of large size and are composed mainly of the hard, calcareous tubes of a group of marine 


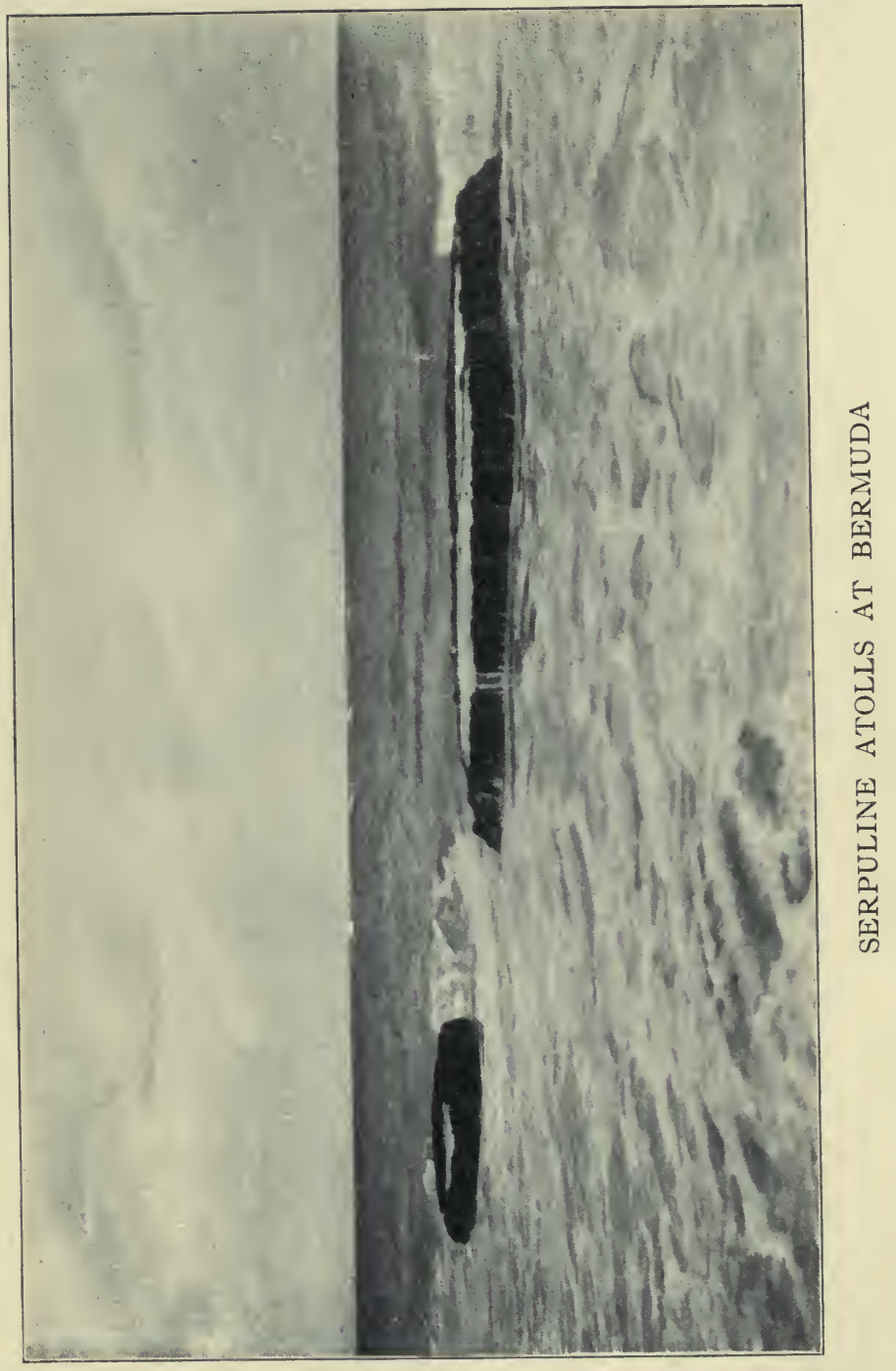





\section{LIFE AT AND NEAR SURFACE I4I}

worms known as "Serpulæ," although corals are usually found in large numbers among them. The animals grow thickly upon the wave-washed rocks between high and lowwater mark and their hard shells and constant growth protect the outer surface of the rocks from the action of the seas which constantly dash against them. The falling spray and water soon wear away the unprotected top of the rock, however, and in time leave only a narrow rim, covered with the growth of serpula and coral, which then appears exactly like a true atoll in miniature. These little atolls are very common in Bermuda and are known locally as "Boilers," from the fact that the surf constantly breaks or boils upon them.

Reef-building corals can live only in warm waters and so coral islands are never seen in the north, the most northern of all living coral-reefs being those of Bermuda.

Although these wonderful forms of marine life are confined to warm seas, yet we must not think that the arctic and antarctic waters are devoid of animal life in shallow water. The polar seas fairly swarm with marine crea- 
tures, and in those cold and dreary oceans are found some of the most remarkable and interesting forms of all sea animals and among them are the largest animals that we know of in the world.

Giants are always interesting, whether they are human, animal or vegetable, and while in past ages nearly all divisions of the animal kingdom boasted of giants of far greater size than those of the present day, yet even now gigantic creatures exist in numbers in the sea. On land the giant animals of prehistoric times were mostly stupid, slothful creatures incapable of self-defence and without brains enough to protect their own eggs or young, and they rapidly succumbed to more active and intelligent creatures until all but a few representatives, such as the elephant, rhinoceros, etc., were exterminated. In the seas, however, the great creatures were less liable to destruction, and while many of these were exterminated, others, such as the sharks and whales, survived, and to-day some of these reach almost as gigantic dimensions as their ancestors of prehistoric times. 


\section{LIFE AT AND NEAR SURFACE I43}

The whales are the largest and the best known of all marine giants, and oddly enough these enormous creatures have descended from land giants. At first sight one sees little or no resemblance between whales and any form of terrestrial animal, and indeed their form is so fish-like and they are so strictly maritime in their habits that many people consider them fish. In their life-history, anatomy and many other important points they are far more like land animals than fish, however, and even a few moments' study will prove how erroneous and foolish it is to confuse these great creatures with true fish. While fish breathe water, from which the air is separated by means of organs called gills, whales breathe air and separate the life-giving oxygen from the other gases by internal lungs like land animals. Moreover, fishes are cold-blooded creatures, whereas whales are warm, red-blooded animals, and in addition whales suckle their own young like other mammals. Merely because they live in the sea and propel themselves about by their tails and flippers is no reason for confusing them with fish, for seals, wal- 


\section{THE OCEAN}

ruses and similar animals do the same and yet no one would think of calling a seal a fish.

Whales, porpoises, narwhals and several other species of large marine animals are very nearly related and if the skeletons of some of these are examined we will find that beneath the flesh and skin the bones of diminutive hind legs may still be seen. Once upon a time all such creatures had well-developed legs and lived, at least part of the time, on land, but owing to various circumstances they spent more and more time in the water until at last they abandoned the land entirely and took up their life in the sea, and their legs, for want of use, gradually disappeared, while their fore feet developed into flippers. Because they forsook the land and dwelt in the sea they were free from the attacks of other creatures, and no doubt this very fact was a most important cause of their having survived through all the countless ages to the present time.

Although whales are found in all oceans the largest species dwell in the Arctic and Antarctic seas, and strangely enough these 
LIFE AT AND NEAR SURFACE I45

largest of all living animals feed entirely upon the smallest and most insignificant forms of marine life. Indeed, so small are the animals upon which the arctic whales feed that it would be impossible for a whale to capture enough of these tiny creatures to keep him alive if he had ordinary teeth. To enable them to subsist upon the tiny atoms of life in the ocean, nature has provided the Right Whales with specially-developed mouth organs and growths which are entirely different from those possessed by any other creature. This remarkable structure is called "whalebone" or "baleen," and is a horny growth like the close-set teeth of a gigantic comb. When the whale is hungry he swims with open mouth through the sea and then, closing his jaws, expels the water between the strips of whalebone. The water passes out, but the baleen, acting like a huge sieve or strainer, prevents the tiny animals in the water from escaping and the whale gulps these down greedily. In this remarkable manner the various species of Right Whales or Baleen Whales gather their supply of food and you can therefore see how 
important the abundance of small surface-life proves to these great creatures. There is, however, another group of whales which have absolutely different habits and to whom the absence or presence of swarming tiny creatures in the water makes no difference. These are the Sperm Whales and they inhabit the warm and temperate seas. While nature provided their cousins, the Right Whales, with the remarkable whalebone and left them without teeth, she gave the Sperm Whales a set of splendid sharp-pointed, ivory teeth, with no whalebone. The reason for this great difference between the Right and the Sperm Whales is readily understood when we know their habits, for the active, sharp-toothed Sperm Whales feed upon large marine creatures and dive to great depths in search of their prey. The favourite food of Sperm Whales is the giant squids I have mentioned in another chapter, and many species of these deep-sea devil-fishes have been described from fragments of their anatomy found in the stomachs of Sperm Whales.

While whales are the largest of all ani- 


\section{LIFE AT AND NEAR SURFACE I47}

mals, yet many true fish grow almost as large, and several species of the seal family may also be considered as giants of the sea.

Our common seals and even the Sea Bears or fur-seals, and the Sea Lions are far from gigantic, but the great Walrus is a true giant and in the Antarctic the huge Sea Elephants grow to still more enormous size. All of the seal family, however, are really land animals which spend a large part of their life in the water, and unlike the whales, they can remain out of water for long periods and can travel readily for considerable distances on land. Still more remarkable than the seals, and in some ways forming a sort of connecting link between them and the whales, are the strange creatures known as Manatees and Dugongs. These are inhabitants of tropical waters and while they can drag themselves upon the shores to sun themselves, yet they spend nearly all of their lives beneath the surface of the sea. Unlike the whales and seals, which feed upon animals and therefore belong to the carnivorous group of mammals, the manatees and dugongs are vegetarians and subsist upon sea- 


\section{8}

\section{THE OCEAN}

weeds, marine-grass and other forms of vegetation.

Beyond a doubt the ancestors of these "sea cows" were slow-moving, browsing beasts which dwelt upon the land, just as the prehistoric ancestors of the seals and whales were savage, meat-eating creatures which roamed among the swamps and rushes of the coasts in those far-off times. While so very different in habits these several forms of ancient animal life saved their descendants from total destruction by taking refuge in the sea.

All this we know, just as we know that every form of marine life, from the smallest microscopic diatom to the giant whales, has its place and its importance in the ocean world, but just how such things came about and just what took place in those dim ages of the past is another unsolved mystery of the sea. 


\section{Chapter VIII}

\section{THE STORY THE SEA HAS TOLD}

You may wonder how we know these things, how scientists can be sure that the ancestors of whales, seals and manatees lived on land, how naturalists can prove that certain occurrences took place or that certain things existed in the immeasurably distant prehistoric times.

Really there is nothing puzzling, nothing mysterious about it, for the sea has left its story plainly written for those who know how to read it and it is just as foolish to refuse to believe this story as it would be to refuse to believe a real book merely because it was printed in a foreign language which some of us cannot read.

The story that the sea has left for scientists to read and interpret is far more enduring than any book ever written by man, for the story of the sea is engraved in solid rock and is as lasting as the world itself, and while its 
first chapters were written countless millions of years ago, yet Old Ocean has not yet finished its book, but day in and day out is adding new pages to its history.

The greatest portion of the ocean's story is written upon its shores and at any time, if you walk along the seashore, you may see the wind and waves, the bits of flotsam and jetsam and the countless tiny marine animals busily writing and illustrating the story of the sea.

We speak of the shores of the sea as if they were hard and fast boundaries, but in reality the shores are not constant and everywinere they are ceaselessly changing, so that what is the shore to-day may not be the shore at all in a short time, and in the sea's story each of these changes is carefully and indelibly recorded and forms a paragraph, a page or a chapter.

Wherever the sea meets the land there are shores of some sort. In one spot they may be smooth, almost level sand-beaches, at another they may be rough, rugged and rocky, at another the cliffs may rise abruptly from the waves, while at still another place broad, 


\section{THE STORY THE SEA TOLD I5I}

slimy, mud-flats may be exposed between the tides.

In each and every case, however, the effect of the sea is plainly seen. The bases and faces of the rocky cliffs are worn, broken and carved by the beating of the waves; the sand is pounded firm and compact by the sea and its shoreward limit is marked by low ridges or hills of loose, drifting sand and coarse sedge and grass. Everywhere upon the surface of the sand-beaches and mud-flats are the irregular, wavy lines that mark the lapping edges of receding waves, while, zigzagging over them, are the trails left by crawling snails, scurrying crabs and other creatures. If we should dig into the sand and mud we would find countless creatures living in holes, while dead shells, crabs and other hard-shelled creatures lie about in profusion. Even if the sea itself was nowhere in sight you would know you were on the seashore by these infallible signs and even under the cliffs, or upon the rockstrewn parts of the shore, you would recognise the presence of the sea by the wave-worn rocks, the rounded stones and pebbles and the 


\section{THE OCEAN}

dead shells. Perchance you may see some prominent landmark, such as a bent or twisted tree, an old stone dock or some queerlyformed cliff near the sea. The old, gnarled tree may be close to the water's edge, with its roots washed bare of earth by the high-flung waves of winter's storms. The broken-down dock may be high and dry and many yards from the water, or the cliff which attracted your attention may be several feet above the tide and yet appear as if carved by the action of the waves. You may wonder why the tree should grow so close to the salt water; why the dock should have been built so far from the edge of the shore or how the rocks could have been smoothed and cut far higher than the heaviest seas can reach.

If you meet some old, gray-haired and wrinkled native and listen to his yarns and gossip he may tell you that he can remember when the old tree grew far back on the grassy meadow; he may talk of the days when the nearby hamlet was a thriving little port, and may point to the tumble-down dock and tell of the craft that formerly moored beside it. 


\section{THE STORY THE SEA TOLD 153}

He may even relate how his grandfather or great-grandfather was wrecked upon the coast and was washed upon the strange-shaped pinnacle of rock and clung there all night long, while the angry waves dashed about him and almost tore him from his precarious foothold.

If you meet such an old man who can remember events and the location of objects for sixty or seventy years back, you will be in luck, for the book of the sea has been written under his very eyes and although he may not know it, he has seen many a page of the ocean's story completed during his long life. The old tree which formerly stood in the meadow and now topples at the brink of the waves proves that the sea has gradually eaten into the land and that what was once the shore is now far beneath the waves. The dilapidated dock, high and dry above the tide, shows that the sea has receded and is forming a new shore from what was once the bed of the ocean, while the carved, rocky point, once worn and cut by wind and waves, marks a former coast-line and its height above the present sea proves how far the waters have receded from their 


\section{THE OCEAN}

former limits. You marvel how this can be, how the sea can grow smaller in one spot and can grow larger and deeper in another, but in reality this is not what has taken place. When we say the sea recedes it does not mean that the water actually becomes less in the ocean, and when we say the sea encroaches on the land we do not mean that the ocean really grows larger, for when it is extending shoreward in one spot it may be backing away from the land in another and whether it does one or the other depends a great deal upon the character and situation of the land, and the wind.

If the shore is flat, low and sandy a heavy storm may cut far into it in a single day or a night and the breaking waves and undertow may carry enormous masses of material into deep water. In this way the coast line, where sandy, may be wonderfully altered in a few hours and a cape may disappear or a peninsula be cut in two in a short time. The sand, washed away from the shore, may be carried far out to sea and scattered over the bottom in deep water or it may travel but a short dis- 


\section{THE STORY THE SEA TOLD I55}

tance and then pile into bars or shoals which are exposed at low tide. Gradually more sand may wash into the spaces between these bars and in time the sandy beach may stretch unbroken for a far greater distance than before the sea cut away the shores. Such alternate cutting and filling may continue for years on a sandy coast, or the wind, whipping the loose sand into hills, may form dunes which become bound together with growing plants and the once-flat beach may be transformed into a coast of bluffs and hills with only a narrow strip of wave-washed beach along their bases.

If the shore is rocky and bold the storms may undermine the cliffs and cause great masses to fall to the sea where, in time, they will be worn and ground into pebbles and shingle which will form a barrier to protect the cliffs above from further damage. If the shores are muddy, deep channels may be cut into the yielding material by heavy waves and the water, filling these, may leave the mud-flat exposed to dry and harden and in time become solid land. 


\section{56}

\section{THE OCEAN}

All these changes of the shore are caused by the action of wind and waves alone, but strange as it may seem the land itself is gradually rising or falling in many places and this also greatly affects the shores of the sea. If the coast is high and precipitous the rise or fall of a few inches in centuries may make no appreciable difference, but if the shore is low and sandy or muddy even an inch or two in the rise or fall of the coast land may result in vast changes, for in many places the wide mud-flats and extensive sand-bars are only an inch or two beneath the surface of the water.

As you walked along the smooth beach or across the mud-flats at low water, you noted the wrinkly lines left by the waves, and the irregular trails of shells and small animals, and, if you glanced behind you, no doubt you saw the deep imprints of your own feet, while if a sudden shower passed over, the large drops of rain made queer little bowl-shaped impressions on the sand and mud. Afterwards the tide slowly rose and covered the flat or beach with water and when the tide again fell,-if 


\section{THE STORY THE SEA TOLD I 57}

you had looked for your footprints and the marks of the rain-drops you would have found they had disappeared. Perhaps they were actually destroyed by the action of the waves, if the sea was rough or the wind strong, but more likely they were merely filled up with fine mud or sand and could not be seen, although still remaining in the material beneath the new covering. Again and again the tide will rise and fall, each time depositing more and more silt and sand over your footprints and the raindrops and the myriad other marks until, at some distant time, many feet of hard, compact sand and mud may cover the smooth surface whereon your footsteps were deeply imprinted. Each of these succeeding layers of material bears other marks and each is a page of the sea's story covering the one beneath. If, in years to come, you could carefully turn back each of these mud or sand pages until you exposed the one upon which you walked, you would doubtless see your footprints surrounded by the impressions of the rain-drops and, even if by that time the sea had receded and the flats were high and dry, you would 
know that the marks had once been made between tides.

'Although you cannot actually accomplish this in the soft sand and mud yet you can imagine how the successive layers would appear if they were so hard that you could pull them apart to reveal the marks upon them.

This is exactly what the scientists have done, for through the countless ages since the world began the mud and sand that once formed beaches and flats has been hardened into stone, and upon these rock pages of the sea's story many wonderful things are inscribed.

Each layer of sand, each stratum of mud, has formed a distinct layer of rock, and of tentimes these are easily separated and come apart in broad sheets or slabs covered with marvellous records of what took place upon the seashores in the dim ages when the earth was young.

Of course not every piece of sandstone shows such marks, for vast areas of the ancient shores were no doubt deserted and unmarred by passing creatures. In other places storms and waves washed the imprints from the flats for days, months and years before a layer of 


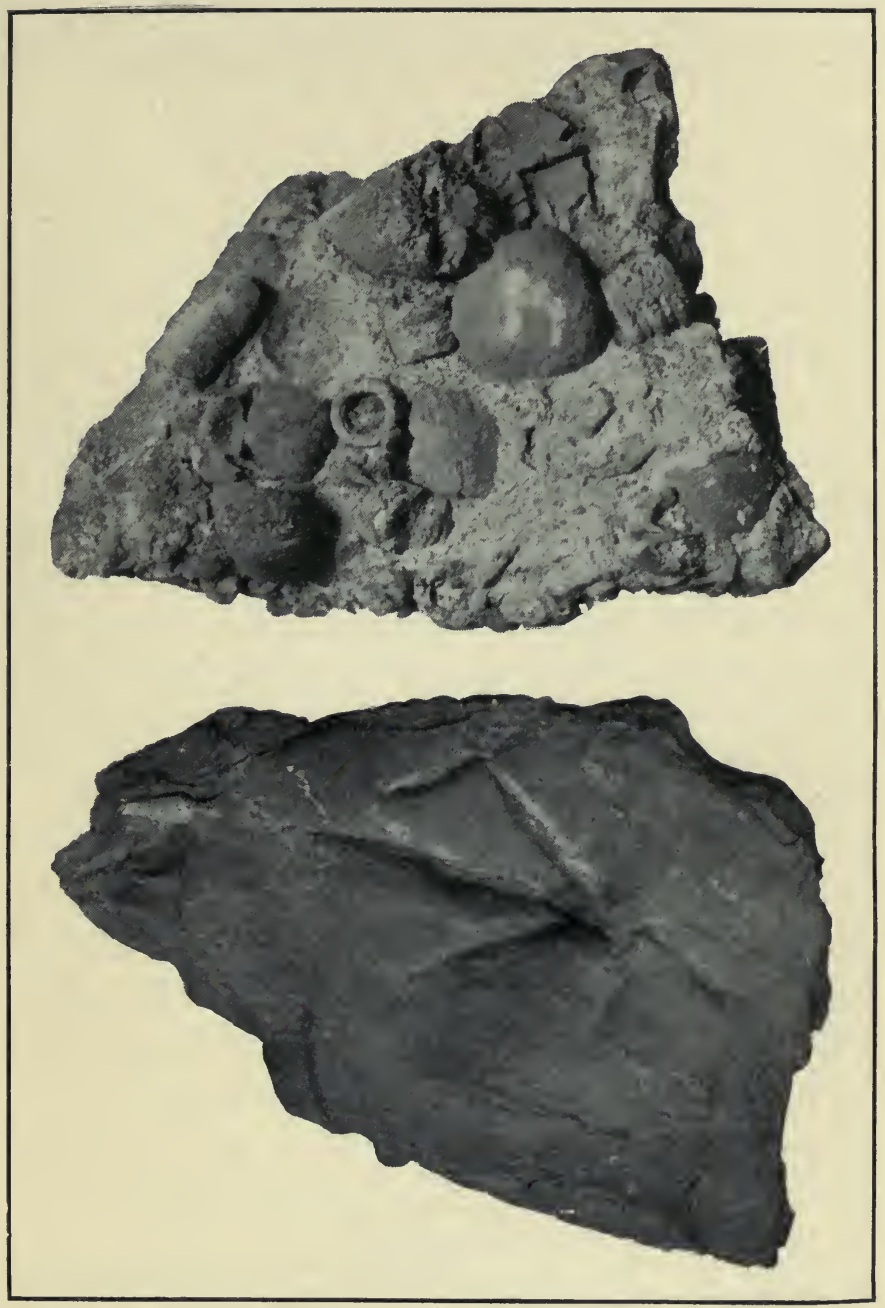

PAGES FROM THE SEA'S STORY

Above: Fossil shells and corals once at the bottom of the sea Below: A fossil footprint in sandstone 



\section{THE STORY THE SEA TOLD I59}

mud or sand was allowed to settle and form above any mark which had been made. But in the deposits of sandstone and other rocks, which were once the shores of the sea, we find innumerable numbers of the little, wavy lines which mark the lapping wave-edges while the little half-round holes made by falling raindrops are very common. Here and there we may trace the irregular track of a tiny snail or mollusc, while in some places the rocks, when split apart, reveal hundreds of the perfectly preserved skeletons of fish. Sometimes the slabs of stone show still more wonderful and remarkable records and when the layers are separated they disclose great three-toed footprints; the tracks of huge cumbersome creatures which lumbered across the sand-beaches and mud-flats in the prehistoric days and left their sharply-marked trails upon the smooth surface. At times these tracks are single and apparently made by one animal, while at other times they cross and recross and there are tracks of various sizes showing that not one but many animals wandered over the flats between tides. These things all prove that these 
160

\section{THE OCEAN}

creatures existed in the most ancient times and by innumerable collections and careful study, scientists and geologists have classified the various beasts, fishes, insects and other creatures which lived in those days and can trace their ancestors and descendants, and even know fairly well how the strange creatures really appeared in life. It is an easy matter to tell which forms lived first, for, of course, each layer of rock covers layers that were made before it and thus the deeper the layer of rock the older the record and the more ancient the creatures which made the tracks.

These are only one kind of pages from the story of the sea and beneath the waves the chapters are also being written. Here the dead and dying animals are constantly accumulating and are being covered with fine mud, ooze and sand, in places forming deposits many feet in depth. Just as, through the vast lapse of time which has passed since animal life first appeared in the sea, the mud and sand of the shores have been transformed to sandstone and shale, so the ooze and dead shells at the bottom of those ancient seas have been 
THE STORY THE SEA TOLD I6I

transformed into solid rock. While the shores formed sandstone or slate, because of the material of which they were composed, the material at the bottom of the sea formed limestone because it was composed mainly of lime from the myriads of tiny shells and skeletons of marine animals.

In addition to shells these petrified portions of the ocean's bed contain corals, worm-tubes, sea urchins and various other forms of marine life, many of which no longer exist. Sometimes these specimens are crowded together into a mass in which the various animals are scarcely distinguishable, while at other times they are separated and are beautifully preserved. As a rule the fossils are much harder than the surrounding rock, and very frequently the softer portions have been decomposed and worn away through exposure to the weather for countless ages and the shells and similar fossils have been left free in the earth, clay or sand. When this occurs one may often find specimens of shells or seaurchins so perfect in every detail that it is difficult to believe they are made of solid 
stone and have not crawled about on the seashores for millions of years.

Many such fossils are found in the sandy wastes of the Desert of Sahara, for the desert was once the bed of an immense sea. In many parts of the world vast deposits of this shellfilled limestone occur and often where they are far distant from the present level of the sea. This proves that once the sea covered these portions of the earth where the fossil bottom is found and in addition it is often possible to determine whether the land rose and caused the sea to recede gradually or rapidly.

Very often these beds of dead shells and other marine animals are hundreds of feet in thickness, showing that the sea remained above such places for ages and ages, while in other localities the deposits are thin and sparse, showing that they formed the bed of the sea for a comparatively short time. In some places they are smooth and in even layers, proving that the bed of the sea rose slowly and steadily without disturbing the accumulation at the bottom. But in other places the layers of fossil shells are twisted and bent, 


\section{THE STORY THE SEA TOLD ${ }_{1} 6_{3}$}

mixed and scattered, and show every evidence of having been violently thrown up and forced out of place by subterranean eruptions or tremendous earthquakes.

Sometimes these ancient sea-beds are found on the very edge of the present shore, at other times they are far inland on high land. Some of the most extensive and beautifully preserved are in the interior of Canada, others are in our central and western states, others are high up on lofty mountain sides and others are found scattered in dry and arid deserts.

Moreover, we know by these pages of the ocean's book that in former ages the sea was much warmer than to-day, for many tropical forms of animal life were found abundantly in what are now the polar regions. Immense deposits of rock composed entirely of fossil corals occur in many northern districts far from the present sea, and while these rocks may at first sight appear utterly unlike coral and may look like ordinary stone, yet when cut and polished every minute detail of the coral is shown to perfection. Of course the entire bottom of the sea was not covered with 


\section{4 \\ THE OCEAN}

dead shells and similar creatures in those days any more than it is all covered with the same sort of life to-day. There were vast areas of sandy bottom, immense stretches of mud, cliffs, rocks and coral reefs, and each and every one of these are found preserved in the form of solid rock to-day. Here and there in the ancient bed of the sea, which is now dry land, we find the fossil bones of great seamonsters; huge marine lizards, gigantic sharks, strange fish and species of whales and similar marine mammals. In every case certain kinds of fossils are found associated, and while some kinds occur through various deposits covering countless ages, and some are even found alive to-day, yet in most cases each existed for a time, to be succeeded by others slightly different.

By such means scientists may trace the gradual transition, the slow change and the inevitable evolution that took place among the denizens of the sea. It is in this way that we read the story of the sea, that we know what manner of creatures inhabited it in ancient times, that we know how inconceivably an- 


\section{THE STORY THE SEA TOLD ${ }_{16} 6$}

cient it is and that we can prove that while the ocean now covers three-fourths of the globe there was once a time when it swept unbroken from pole to pole around the entire circumference of the earth.

Gradually the ocean has shrunk; slowly the land has risen above the waves. What were once great seas are now arid deserts, former gulfs and bays are now fertile, cultivated valleys, peaks that once were ocean islets are now forest-covered mountains, and the sandy beaches and muddy flats which have been transformed to stone, with the tracks of strange creatures and imprints of rain-drops still intact, are quarried from our hills and used to build our houses, flag our walks and to serve as doorsteps. 


\section{ChAPTER IX}

\section{THE BATTLE BETWEEN SEA AND LAND}

WHEREVER the land and sea meet there is a constant battle for supremacy. This battle has been going on since the world began, and through the countless ages, first the one and then the other has won in the everlasting warfare.

In a way this battle between sea and land has resembled a battle between human armies. There have been advances and retreats; the earth has sometimes been upon the defensive, at other times it has turned and taken the offensive; there have been flank movements, counter-attacks, turning movements and time and again both the land and the sea have cut off the other's line of retreat and have captured vast amounts of the enemy's forces.

Moreover, both the sea and the land have their allies who fight and work with them. 


\section{BATTLE OF SEA AND LAND 167}

On the side of the sea is the wind, the ice and the tides, while earthquakes also lend a helping hand at times. But all these allies of the sea are fickle and are liable to turn about and help the land and sometimes they even fight among themselves.

This battle of the sea and land is the longest war of which we have any knowledge, for it has been continuous since land and water were first formed, and doubtless it will continue as long as sea and land exist upon our planet. Moreover, it is a hopeless sort of battle, for neither side will ever win. First one gains and then the other, and while the sea may be constantly gaining in one portion of the world it may be losing in another place. It is an interesting struggle, and one which we may watch in perfect safety at almost any point along the seacoast.

Where the shores are sandy the line of battle is constantly changing and within a few days, or even hours, either the sea or the land may gain or lose many yards. On rocky shores the battle rages just as furiously, but in such places the land forces are strongly en- 
trenched and fortified and there is less apparent loss or gain by either side.

Wherever the sea dashes upon a sandy beach it pushes the sand before it and forms piles or ridges of sand above high water mark. As this dries the wind catches it in its grasp, whirls it about and scatters it far and wide. If the wind blows off shore the sand may be carried out to sea where it sinks to the bottom and forms sand bars, flats, or banks. In time these bars or banks may form slender capes or peninsulas which cut off a portion of the sea, and this enclosed water may become gradually filled with sand until no water remains, and where the sea once held sway there will be a broad level or hilly stretch of sand-dunes. Even the sea itself may prove its own undoing when it attacks a sandy shore, for the undertow of the waves often carries out sand and mud which forms bars and flats and forces the sea itself farther back.

Wherever the wind whips up the sand and blows it about it forms hills and hollows, often building up dunes or hills many feet in height. If these dunes are left undisturbed by strong 


\section{BATTLE OF SEA AND LAND 169}

winds and grass and weeds take root, the sand may become bound and held together by the growing vegetation and in time will resist the action of the wind and will form solid valuable land. In many places vast areas of land have been thus formed and men build houses and cultivate their crops where, in former years, the sea held full sway and ships anchored and fishermen plied their calling.

In other spots the sea has cut deep into the sandy shores and to-day there are deep bays and broad harbours where in former times forests of pine and cedar grew and villages stood upon the sandy soil.

On rocky shores the wind has little effect, but the resistless waves wear away the cliffs, gradually undermining great masses which fall to the beach below and are broken into bits and worn smooth and round by the action of the waves. In such places the ice aids the sea, for great blocks of ice dashed against the cliffs act like titanic hammers, and the water, penetrating the crevices of the rocks and freezing, forces the solid cliffs apart like blasts of dynamite. 
In such situations the sea often encroaches slowly but surely for year after year, and the strong rock-bound coasts prove of little avail against the onslaughts of their enemy.

On the northern coasts of Europe the rocky cliffs are receding at an average of fifty feet or more each year, and every season portions of the farms upon the cliff tops drop in fragments to the waves far below. Houses upon the lands above the cliffs are gradually moved farther and farther back and now and then some building is left too near the edge and some violent storm carries away a portion of the cliff with the building upon its summit. On the coast of California, and in many other places, the same gradual inroads of the sea are taking place, and within the memory of man a mile or more of solid, rocky coast has been won by the sea. Sometimes the masses torn from the land by the waves prove a barrier to prevent further progress of the sea, while at other times the forces of nature have raised the land beyond the reach of tide and wave, and have won back in a short time more than the sea gained in centuries. 


\section{BATTLE OF SEA AND LAND I7I}

This may seem strange at first, for we commonly think of the seashore as at a constant level, but in reality the elevation of the coasts is ever changing. In one place it may rise slowly through many centuries and in another it may slowly sink. At other times a portion of the coast may rise in a short time for many feet, and on the other hand a single earthquake or volcanic eruption may cause a portion of the coast to sink far beneath the level of the sea.

Even large islands at times sink suddenly beneath the sea without warning and many people believe that the wonderful continent of Atlantis really existed in ancient times and was submerged by some great cataclysm of this sort. We have no proof of this, but we do know that islands and large portions of continents have disappeared in this way. Some of these catastrophes took place ages ago, before man inhabited the earth, while others have occurred within comparatively recent times and even within the memory of living men.

Off the coast of Yucatan is a little island 
called Cozumel, a beautiful tropical islet almost unknown to the outside world, but wonderfully interesting to scientists. Here are numerous ruins of ancient Indian temples and many great carved statues or monoliths exactly like those found upon the mainland of $\mathrm{Yu}$ catan and Central America. This has led many scientists to believe that Cozumel was once a portion of Yucatan itself, and this theory is borne out by the fact that on the shores of Yucatan an ancient pathway of stone disappears beneath the sea and a similar pathway is found upon Cozumel also leading up from beneath the waves. If, as supposed, the land once extended unbroken between the mainland and the island great populous cities may have been engulfed when the sea won its battle and swept victoriously above the forests and the land. Perchance, if we could explore these ruins far beneath the waves, we might find the long-lost secrets of the ancient people who once lived in Yucatan and built the marvellous buildings found deep within the jungle. No one has ever been able to explain why these buildings and cities were suddenly 


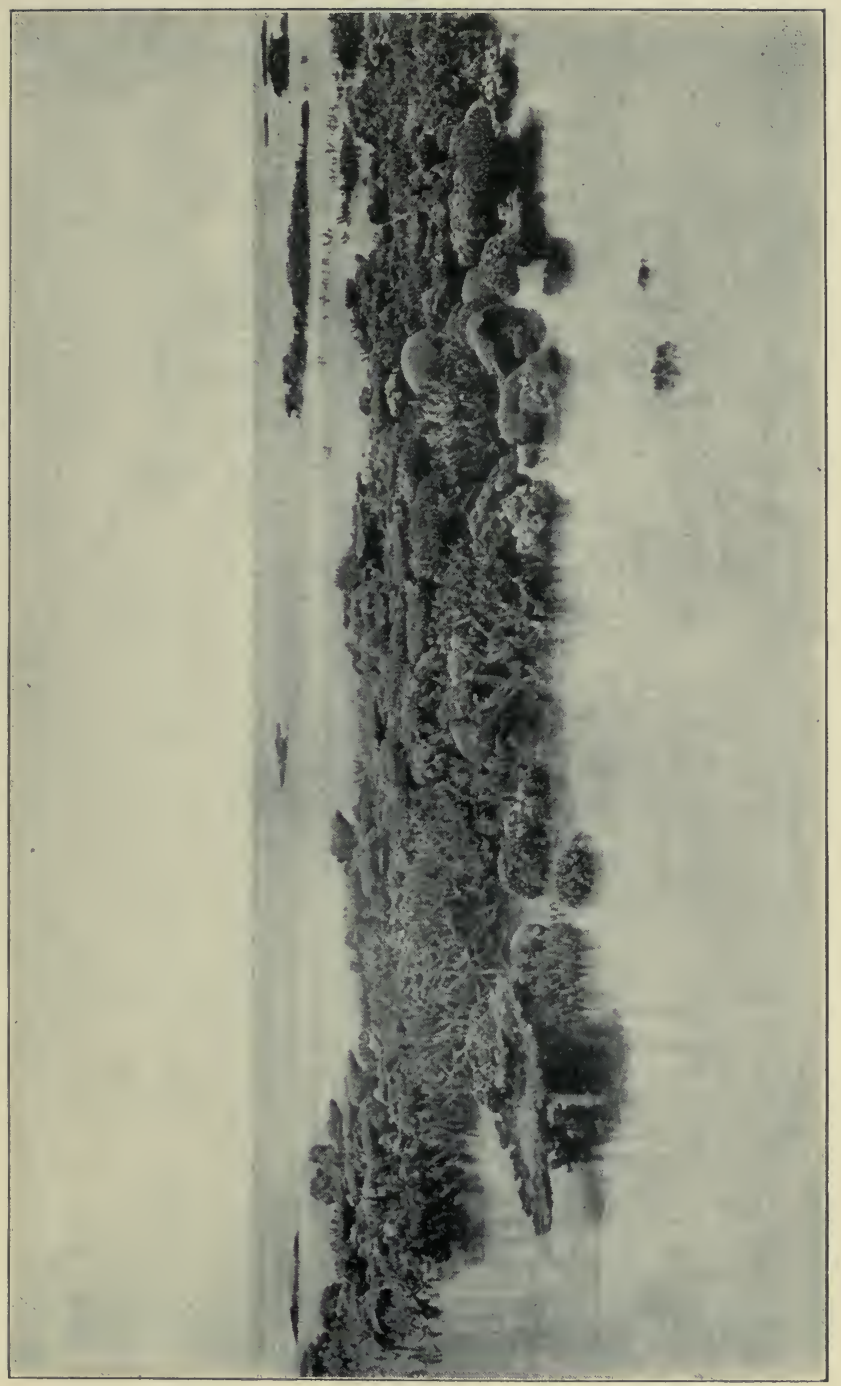

$\frac{5}{5}$

4

z

3
3
0
0
0
0

$\underset{2}{2}$

0

$\rightarrow 2$

근

30

焉

点

少。

논

学空

c

0

4

퐁

艺

담 



\section{BATTLE OF SEA AND LAND 173}

deserted, why great statues and enormous buildings were left half finished, why there is no key to the strange hieroglyphics that cover the buildings and monuments with inscriptions.

Perchance the same subterranean forces which submerged the coasts, and caused the sea to flow between the island and the mainland, destroyed thousands of the inhabitants and forced them to flee in terror from their half-completed labours.

Could we but visit that sunken land who knows but we might discover a key-a sort of Rosetta Stone-by which we could read the story of the marvellous civilisation that held sway in Central America countless ages before any white man trod the shores of our continent.

It would be interesting indeed to visit these submerged cities,-if they exist,-and while we cannot do this, yet in other places we may look down through the water upon cities which once stood, stately and populous, upon the solid earth.

At the island of Nevis is the sunken city of 
Jamestown, once the capital of the island and a wealthy and flourishing town. On April 30, I680, the island was visited by an earthquake and the busy town slipped without warning into the sea, carrying with it its populace and its riches.

To-day one may row above the ancient town and looking downward through the crystalline water, gaze upon old houses, stone walls, church towers and paved streets far beneath. The stonework is covered deep in coral growth, great masses of weeds and corals spring from the once-busy streets, fishes of gorgeous colours flit through ruined doors and windows, and great lobsters, crabs and octopi lurk in the halls and rooms that once echoed to laughter and music.

It is sad to think of such things, of the loss of life and property, the suffering and terror that occur when the sea wins and swallows the land and its inhabitants in this way, but sometimes such catastrophes seem guided by a divine justice and benefit the rest of the world. Such was the destruction of Port Royal in Jamaica. In the days of the Buc- 


\section{BATTLE OF SEA AND LAND 175}

caneers Port Royal was the favoured rendezvous of the pirates and freebooters that scoured the Spanish Main seeking booty and loot. To Port Royal they returned after their voyages and in the halls and taverns held high revels. Here they gathered vast stores of wealth and treasures won by bloodshed and destruction from far and near, until Port Royal became known as the richest place in the world. It was here that Sir Henry Morgan held forth. Here he had his home, and here he spent his ill-gotten gains from the sack of Panama, Cartagena, Porto Bello and countless captured ships.

It was a city of wealth, of unbridled passions, of vice and wild revelry, but suddenly it was ended without warning; the stronghold of the pirates was wiped out on June 7, I692, when Port Royal slipped into the bay and was buried beneath the waves, and the power of the freebooters was brought to a fitting end. Of the three thousand houses but two hundred remained above the sea, and of the wild, reckless inhabitants but a handful remained to tell the tale. Even these were cowed, frightened 


\section{THE OCEAN}

and so impressed with the swift and terrible punishment which had overtaken their fellows that they moved across the bay, laid the foundations of Kingston and settled down to lives of commerce, agriculture and honesty.

Perchance at some distant time, or perhaps within a month or a week, another convulsion of nature will raise these sunken cities above the sea. Once more men may walk through the long-silent and deserted streets and may again take possession of the gold and treasure so long buried beneath the waters of the victorious sea. 


\section{Chapter X}

\section{HUMAN LIFE UNDER THE SEA}

From earliest times man has longed to see the depths of the sea and to walk about upon its bottom. In every age and in nearly every land expert divers and swimmers may be found who can penetrate to wonderful depths and can remain below the surface for remarkable periods of time, but none has ever existed who could dive deep enough or remain long enough under water to walk about and note the marvellous sights below the waves.

Wonderful stories are told of men who dive to the depth of one hundred feet and remain under water for five minutes or more, but these are all exaggerations and no man has ever lived who could accomplish such feats.

In the Mediterranean, in the Orient, in the South Seas, in the West Indies and in many other places there are scores of men who make diving a business and depend for a livelihood 
upon their ability to dive to great depths and to remain under water for a long time. But none of these is able to remain below the surface for over three minutes or to reach a greater depth than forty or fifty feet. Time is a deceptive matter and while a man may appear to be below water for five or ten minutes, yet if we time him by a watch we find he is only there two minutes or so.

It is an interesting matter to watch one of these men at work, to look through the clear tropical sea and see the brown-skinned body shoot downward through the water, to see the dim, far-away form walk about, pick up objects from the floor of the sea and then rise like a cork to the surface. Sometimes the divers work head-down, prying, cutting or digging the sponges, corals, or pearl shells from their homes upon the bottom. At such times the watcher from above may see the diver's feet, soles-up and presenting a wonderfully curious sight as the owner works with his hands at the treasures of the sea below him.

Sometimes a diver will go below with a crowbar and a rope and far beneath the sur- 


\section{HUMAN LIFE UNDER SEA I79}

face will work away as unconcernedly as if on dry land.

In some countries the people seem to take naturally to the sea and are born divers. In the South Seas the natives are wonderfully expert and dive and swim like fish from earliest childhood, and in the West Indies the negro boys are as much at home in the water as upon the land.

Whenever a steamer arrives in a West Indian port it is immediately surrounded by hosts of black, brown, and yellow boys all clamouring for coins to be tossed overboard so they can dive for them.

Seldom indeed is a coin missed, and, as a rule, the diver clutches the coin long before it reaches the bottom. Sometimes the passengers toss coins over the opposite side of the ship and the boys, diving beneath the keel, catch them before they touch bottom. In West Indian and other tropical seas the water is marvellously transparent and the diving boys may be watched as they swim and dive after the coins, twisting, turning, somersaulting and even fighting among themselves under 
the water. Many of these men and boys are so expert that for a small sum they will dive into shark-infested spots and with knife in hand attack and kill these great man-eaters. Such duels between man and fish are extremely exciting, but it is seldom that the shark gets the best of the encounter, for the man's superior intelligence, his knowledge of the shark's habits and his skill in diving and swimming enable him to dive beneath the great fish where a thrust of the knife can be delivered in safety.

In order to reach greater depths and to remain longer under water man has for centuries attempted to devise means of diving in comfort beneath the sea. One of the earliest and most practical inventions was the Diving Bell. This consisted of a great metal, or wooden chamber of more or less bell-like form, which was lowered beneath the water and within which human beings could remain safely at considerable depths. If you place a glass, or a tumbler, upside down over a dish or a basin of water and push it to the bottom you will see that the water does not fill the 


\section{HUMAN LIFE UNDER SEA I8I}

glass but that a quantity of air remains within the tumbler above the water.

The diving bell operates in a similar manner, and the air contained in the bell enables the occupants to remain dry and comfortable after the bell is lowered to the bed of the sea. Unfortunately diving bells have limitations, for as the pressure of the water increases with the depth the air within the bell is compressed more and more until a point is reached where man cannot withstand the pressure.

In time better methods and the discovery of rubber led to the construction of diving-suits and to-day these are the commonest and most widely used of all devices to enable man to visit the bottom of the sea. The diver, clad in a diving-suit of rubber, with heavy leadsoled boots, great metal weights on his chest and at his belt and with fresh air forced by an air-pump through a hose from above, is able to walk about upon the bed of the sea and to remain under water for a long time. By means of the diving-suit wrecks are raised, treasure is recovered, pearls, sponges and other marine products are gathered, pipes and 


\section{2}

\section{THE OCEAN}

foundations are laid and other submarine work is carried on and much is done under water which could never be accomplished in any other manner. But even with a divingsuit man is still limited in his work beneath the sea, for the pressure of the water affects the man in the suit just as it affects the men in the diving bell or the naked diver of the tropics. In order to force the air down to the diver in his suit the pressure at the pump must be greater than the pressure of the water where the diver stands, and hence a point is soon reached where the pressure is so great that human flesh and lungs cannot stand it and death would result if it should be maintained.

Some men are able to withstand far greater pressures than others and are sufficiently accustomed to diving to remain under water for longer periods than their fellows, but the best and most experienced diver in the world can only remain below for a comparatively short time and can only penetrate to depths of twelve to twenty fathoms with safety.

With the construction of successful submarine boats man made a marvellous advance 


\section{HUMAN LIFE UNDER SEA 183}

in his conquest of the ocean's depths, and while no submarine has yet been built which can approach Jules Verne's "Nautilus," yet wonderful records have been made by these underwater craft.

Unfortunately submarines have proved of far greater value in destroying human life than in saving it, and so far have resulted in far more harm than good to mankind. Many attempts have been made to build submarine boats provided with lights, windows and other appliances for exploring the bed of the sea and wonderful claims have been made by the inventors of such craft. They have dwelt upon the vast numbers of rich wrecks lying upon the bottom of the ocean, the wonderful natural wealth of the sea which no diver can reach, and they have described how all such things could be found and gathered in by means of their inventions, but in each and every case insurmountable obstacles have been met which have not yet been overcome.

No one can say a submarine may not be built which will enable man to visit the ocean's bed, to search its recesses and discover its hidden 
I 84

\section{THE OCEAN}

riches and when such a craft is constructed man will indeed have conquered the depths of the sea. But even now submarines are really marvellous. They have navigated for hours beneath the surface, they have dived to over one hundred feet and have remained upon the bottom for an entire day and have risen again to the surface with their crews safe and uninjured. They have penetrated the ports of enemies and have destroyed huge warships and have escaped in safety and have swept swiftly beneath powerful explosive mines, torpedoed hostile ships and returned to their waiting friends after being under water for many hours.

Until the great European war no one realised the possibilities of submarines, but now that warfare has demonstrated their power, value and efficiency, much greater attention will be devoted to them. In the future submarines may prove as valuable in peace as in war, and sooner or later the "Nautilus" may become a thing of reality instead of fiction and the time may yet come when great passenger ships will cross and recross the oceans beneath 


\section{HUMAN LIFE UNDER SEA I85}

the surface of the sea and far below the reach of storms and waves. We may yet be able to take submarine tours to the pearl beds, coral groves and marine gardens of the tropics, and man may yet realise his ambition to explore the depths of the sea, to look upon its strange life and to solve its great mysteries. 



\section{INDEX}

\section{A}

Arctic Currents, 30, 34

Atolls, I40

Australian Current, 33

B

Bell-buoy, 93

Benguela Current, 33

Black-Swallower, I06

"Boilers," I4I

Bores, 66

Brazilian Current, 32, 33

Buoys, 80

\section{C}

Charts, 80, 89, 90

Collisions, 42, 43

Conger Eels, I3I

Continental Shelf, $6,7,8$

Coral Islands, II, I40

Coral-reefs, 9, II, I39

Corals, 9, IO, II, I36, I40, I63

Coral-trees, I39

Corposants, 37

Cumulative Waves, 69

D

Deep Sea Fishes, I03, I08

Derelicts, 38, 39, etc.
Diver, I78-I79, I8I-I82

Diving-bell, I80-18I

Doldrums, 24, 25, 36

Dredges, 100, 103

Dredging, 5

Drisko, 42

Dugongs, 147

\section{E}

East Australian Current, 32, 33

Eskimo Joe, 59

F

Flying Dutchman, 37,38

Fogs, 50, 5I

Fossils, 161, 163

\section{G}

Gas-buoy, 86

Gorgonias, 136

Growler, 52

Gulf Stream, 18 et seq., 3I,

32, 34, 42

Gulf Stream Slope, 8

$\mathrm{H}$

Hurricanes, 7I-73 
I 88

\section{INDEX}

\section{I}

Icebergs, 49 et seq.

Ice Patrol Boats, 52

Iron Buoys, 86

J

Japan Stream, 32, 34

\section{K}

Kraken, II7-120

L

Labrador Current, 54

Life Saving Station, 96-98

Lighthouses, 80-86, 93, 96

Lighthouse Tender, 83

Lightships, 8o-85, 93, 96

\section{M}

Maelstrom, 78

Manatees, I47

Mozambique Current, 33

N

Narwhals, I44

Neap Tides, 64

Northeast Trades, 24

\section{O}

Ocean Bed, 5, ro

Ocean Currents, I7 et seq.,

29,30
Octopus, 104

Ooze, I2, I4, I5, I26

Ooze, Foraminiferous, I26

Ooze, Globigerina, I26

$\mathrm{P}$

Perigee Tides, 64

Pilot Charts, 89

Polaris, U. S. S., 58

Porpoises, I44

$\mathbf{R}$

Rain of Frogs, 77

Ribbon Fish, II2

S

St. Elmo's Fire, 37

Sargassum, 22

Sargasso Sea, 23

Scylla and Charybdis, 78

Sea Bears, 147

Sea Cows, I48

Sea Elephants, I47.

Sea Lions, I47

Sea Serpent, II, I6, II9

Seaweeds, 136

Serpulæ, I4I

Serpuline Atolls, 140

Sharks, IIo, II3

Shore, I50 et seq., I66 et seq.

Seminole, 69

Showers of Fish, 77

Southeast Trades, 25

Spar-Buoy, 95

Sponges, I35, 136 


\section{INDEX}

Spring Tides, 64

Squids, 104, 118

Submarine, 182

$\mathrm{T}$

Tangles, ror-103

Tidal Waves, 6r, 66, 69, $7 \mathrm{I}$

Tide Rips, 78

Tides, 60 et seq.

Tigress, 59

Tile Fish, 120

Titanic, 49

Trade Clouds, 24

Trade Winds, 24, 28, 30, 36

Trawls, 100
U

U. S. Fish Commission, 100

W

Walrus, I47

Waterspouts, 74-75

Waves, 66, 69

Whales, I 43-147

Whales, Baleen, I45

Whales, Right, 145, 146

Whales, Sperm, I46

Whistling Buoy, 93

Wolston, Schooner Fannie

E., 45,47

Wrecks, 40 et seq. 



RETURN CIRCULATION DEPARTMENT

IO $\longrightarrow 202$ Main Library

\begin{tabular}{l|l|l}
\hline $\begin{array}{c}\text { LOAN PERIOD } \\
\text { HOME USE }\end{array}$ & 2 & 3 \\
\hline 4 & 5 & 6 \\
\hline
\end{tabular}

ALL BOOKS MAY BE RECALLED AFTER 7 DAYS

Renewals and Recharges may be made 4 days prior to the due date.

Books may be Renewed by calling $642-3405$

\section{DUE AS STAMPED BELOW}

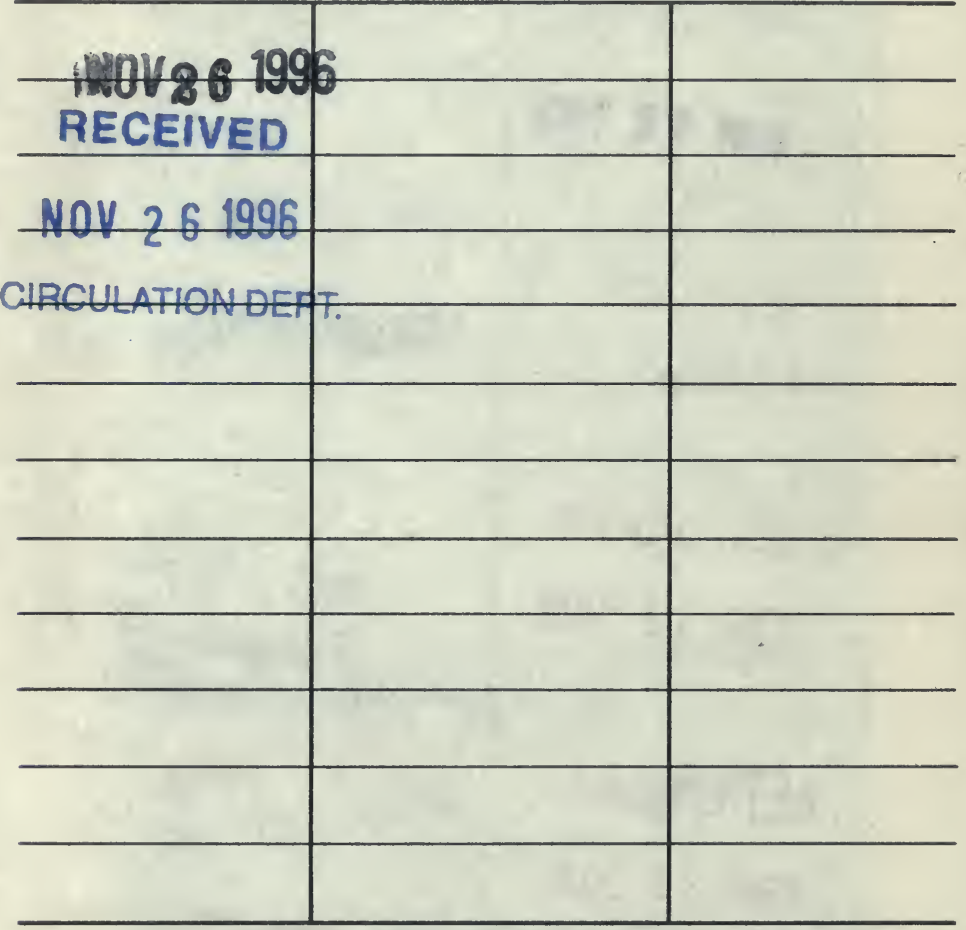

UNIVERSITY OF CALIFORNIA, BERKELEY

FORM NO. DD6 BERKELEY, CA 94720 


$$
\because \because \%
$$

\section{UNIVERSITY OF CALIFORNIA LIBRARY}




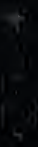

기

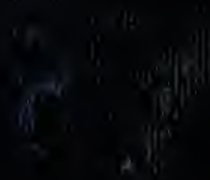

$x$ 